\title{
Desenvolvimento e aplicação de técnicas miniaturizadas de preparo de amostras para análises ambientais via GC-MS
}

\author{
Paula Grossi
}

Tese apresentada ao Instituto de Química de São Carlos, da Universidade de São Paulo para obtenção de título de Doutor em Ciências (Química Analítica).

Orientador: Prof. Dr. Fernando M. Lanças

São Carlos 
AUTORIZO A REPRODUÇÃO E DIVULGAÇÃO TOTAL OU PARCIAL DESTE TRABALHO, POR QUALQUER MEIO CONVENCIONAL OU ELETRÔNICO, PARA FINS DE ESTUDO E PESQUISA, DESDE QUE CITADA A FONTE. 
"Disciplina é a ponte que liga nossos sonhos às nossas realizações" 


\section{DEDICATÓRIA}

Aos meus pais Ana Lúcia e Sidnei e meu irmão Ricardo pelo apoio em todos os momentos da minha vida, pelo amor e formação. Ao meu esposo Daniel pelo amor, companheirismo e dedicação sempre presentes. 


\section{AGRADECIMENTOS}

Ao Prof. Dr. Fernando M. Lanças pela oportunidade de trabalho e pelo crescimento profissional e pessoal adquirido;

Ao Prof. Dr. Igor R. B. Olivares pelo auxílio e orientação para a realização deste trabalho;

A todo o pessoal do Grupo de Cromatografia;

À Odete pela ajuda e paciência;

Aos meus amigos, por todos os momentos compartilhados: Elke e Marcelo (pela amizade e ajuda), Raquel, Milena, Joel e todos que convivi durante esses oito anos em São Carlos;

À dedicação de Andreia e Silvia (Pós-Graduação);

Ao pessoal das oficinas mecânica (Alex e Ednelson) e vidraria, sempre auxiliando no trabalho;

À CAPES pelo apoio financeiro, ao IQSC e à USP pelo apoio institucional;

À todos que colaboraram, direta ou indiretamente, com este trabalho. 


\section{RESUMO}

Este trabalho apresenta o desenvolvimento e aplicação de técnicas miniaturizadas de preparo de amostras para análises ambientais via GC-MS. Dentre elas aplicou-se a técnica de Extração em Fase Sólida (SPE) na análise do regulador de crescimento de plantas, paclobutrazol (PBZ), em amostras de solo. Um método foi desenvolvido, otimizado e validado para o emprego da técnica acoplada à cromatografia gasosa e espectrometria de massas (GC-MS) na análise de PBZ em solo. Foram desenvolvidas também barras in-house, para Extração por Sorção em Barras de Agitação (SBSE), preparadas com PDMS, otimizadas, validadas e aplicadas na extração de pesticidas organoclorados no modo headspace acoplado a GC-MS. Adicionalmente, novos recobrimentos para SBSE a partir da modificação do PDMS comumente utilizado visando mudanças nas características de polaridade das fases sortivas foram desenvolvidos. Seguindo a tendência de miniaturização desenvolveu-se um novo sistema nomeado de Extração Sortiva Refrigerada (RSE), a qual considera a teoria de equilíbrio da HSSE e da SPME refrigerada. A técnica foi otimizada e aplicada em amostras de água do rio de Atibaia, coletadas na região de Paulínia-SP. 


\begin{abstract}
This study describes the development and application of different miniaturized sample preparation techniques for environmental analysis via gas chromatography and mass spectrometry (GC-MS). Among those techniques, the Solid Phase Extraction (SPE) was applied to the analysis of plant growth regulator, called paclobutrazol (PBZ), in soil samples. A method was developed, optimized and validated for the application of the technique coupled to GC-MS for the analysis of PBZ in soil. In-house Stir Bar Sorptive Extraction (SBSE) was also developed, optimized, validated and applied to organochlorine pesticides extraction in water samples in headspace mode followed by GC-MS. Additionally, new coatings for SBSE based on the PDMS modification commonly used to change the polarity characteristics of the sorptive phases were developed. Following the miniaturization trend, a new system called Refrigerated Sorptive Extraction (RSE) was successfully developed. This system was built with similar refrigerated SPME and HSSE equilibrium. Such technique was optimized and applied on water samples from Atibaia's river, collected in the region of Paulínia-SP.
\end{abstract}




\section{LISTA DE FIGURAS}

\section{Capítulo 1}

Figura 1.1. Etapas de um procedimento analítico. Extraído de [5]

Figura 1.2. Principais etapas em SPE, visando o isolamento de um analito [6].

Figura 1.3. Quadro das propriedades físico-químicas do paclobutrazol. Adaptado [15]

Figura 1.4. Fragmentos de massas do paclobutrazol, adaptado [19].

Figura 1.5. Processo de extração do Paclobutrazol: (1) pesagem das amostras; (2) extração em ultra-som; (3) centrifugação; (4) extração em SPE; (5) rotoevaporação à $40^{\circ} \mathrm{C}$; (6) análise por GC-MS Shimadzu QP5050.

Figura 1.6. Curva de calibração, faixa não linear entre 0,1 e 0,5 mg. $\mathrm{L}^{-1}$.

Figura 1.7. Curva de calibração, faixa linear entre 0,5 e 4 mg.L-1

Figura 1.8. Estudo da linearidade: concentração de PBZ (mg. $\mathrm{L}^{-1}$ ) versus área.

Figura 1.9. Comparação entre a linearidade através dos padrões e matriz fortificada. Concentração PBZ $\left(\mathrm{mg}^{\mathrm{L}} \mathrm{L}^{-1}\right)$ versus área cromatográfica obtida

Figura 1.10. Fragmentograma do paclobutrazol.

Figura 1.11. Cromatograma representativo da extração de paclobutrazol em solo na concentração de $2 \mathrm{mg}$. $\mathrm{L}^{-1}$ 


\section{Capítulo 2}

Figura 2.1. Esquema de barras magnéticas agitadoras recobertas com PDMS utilizadas em SBSE comercial.

Figura 2.2. Comparação da eficiência extrativa por SPME (PDMS: $0,5 \mu \mathrm{L}$ ) e SBSE (PDMS: $47 \mu \mathrm{L}$ ) em função do coeficiente de partição octanol/água, em idênticas condições experimentais. (Extraído de Almeida et al [11]).

Figura 2.3 Estatística de publicação dos trabalhos que aplicam SBSE.

Figura 2.4. Esquema do molde utilizado para o desenvolvimento das barras "in-house". (Extraído de [60])

Figura 2.5. a) Frasco de "headspace" e barra de SBSE utilizados na extração. b) Serpentina aquecida e agitador magnético onde o frasco de extração é colocado. Extraído de [13].

Figura 2.6. Efeito da temperatura do banho de aquecimento utilizado na extração

Figura 2.7. Curva cinética de extração para pesticidas organoclorados utilizando HS-SBSE (PDMS), $85^{\circ} \mathrm{C}$

Figura 2.8. Efeito do tempo na dessorção da barra de SBSE

Figura 2.9. Diagrama de Pareto para os efeitos estimados.

Figura 2.10. Gráficos de superfície de resposta para (a). temperatura de extração $\left({ }^{\circ} \mathrm{C}\right)$ versus tempo de extração ( $\left.\mathrm{min}\right)$, (b). tempo de extração (min) versus tempo de dessorção (min), (c). tempo de extração (min) versus força iônica $(\mathrm{NaCl} \%)$

Figura 2.11. Influência de diferentes solventes no processo de dessorção dos analitos

Figura 2.12. Cromatograma representativo obtido por HS-SBSE-GC-MS de uma amostra de água fortificada com 13 pesticidas organoclorados $(1 . \alpha \mathrm{HCH}$; 2. $\beta \mathrm{HCH} ; 3 . \gamma \mathrm{HCH} ; 4 . \Delta \mathrm{HCH} ; 5$. heptacloro; 6 . aldrin; 7. heptacloro epóxido; 8. $\alpha$ endosulfan; 9. DDE; 10. dieldrin; 11. endrin; 12. DDD; 13. DDT) a). Cromatograma mostra a dessorção com $200 \mu \mathrm{L}$ de solvente b). Cromatograma com dessorção em 1,5mL de solvente, evaporado até secura e reconstituído em $50 \mu \mathrm{L}$. Em ambos os casos, $2 \mu \mathrm{L}$ da solução final foram injetados no GC-MS para comparar as áreas obtidas. A linha pontilhada nos cromatogramas foi inserida para permitir uma comparação visual das áreas 


\section{Capítulo 3}

Figura 3.1. Comparação entre a barra de PU dopada com $5 \%$ de carvão ativado (---), PDMS convencional (---). Analitos: (a) anticonvulsivantes. 1. fenobarbitol, 2. epóxido, 3. carbamazepina, 4. metil-fenil-etil hidantoína. (b) ivermectina. Extraído de [26]

Figura 3.2. Comparação entre áreas dos picos obtidos por LC extraídos por uma fase pura de poliuretana e poliuretana dopada com material adsorvente. Analitos: (a) antidepressivos, (b) anticonvulsivantes, (c) benzoimidazóis. Extraído de [25].

Figura 3.3. Comparação obtida através dos cromatogramas da ivermectina: utilizando barra commercial e barras de PDMS modificadas com 5\% OV-17OH e 10\% DEGS (-). Extraído de [28].

Figura 3.4. Sistema RSE (a. Molde; b. Frasco headspace modificado; c. Sistema fechado; d. Conexão com anilhas de Teflon - aberto; e. Conexão com anilhas de Teflon - fechado; f. Sistema RSE montado)....

Figura 3.5. Esquema do sistema de RSE.

Figura 3.6. Frasco usado para o entrecruzamento do PDMS com as fases 118 empregadas na sua modificação, utilizando azo-t-butano. Extraído de [29]......

Figura 3.7. Cromatograma de extração de $\mathrm{OCP} 100 \mathrm{ppb}$ a $85^{\circ} \mathrm{C}$ em água, 120 minutos, através de RSE sem e com refrigeração à $0^{\circ} \mathrm{C}$. (1. a HCH, 2. $\beta \mathrm{HCH}$, 3. $\gamma \mathrm{HCH}, 4 . \Delta \mathrm{HCH}$, 5. Heptacloro, 6. Aldrin, 7. Heptacloro epóxido, 8. a Endosulfan, 9. DDE, 10. Dieldrin, 11. Endrin, 12. DDD, 13. DDT) .................

Figura 3.8. Gráfico de barras da comparação da extração OCP $100 p p b$ a $85^{\circ} \mathrm{C}$ em água, 120 minutos, através de RSE sem e com refrigeração à $0^{\circ} \mathrm{C}$. (Numeração na mesma sequência da Figura 3.6)....

Figura 3.9. Curva cinética de extração para os DDXs utilizando RSE (PDMS), $85^{\circ} \mathrm{C}$

Figura 3.10. UGRHI 05 - Piracicaba, Capivari e Jundiaí . Extraído de [29].

Figura 3.11. Ponto de amostragem 1: Final do contorno do Rio Atibaia na empresa Shell (região de curva).

Figura 3.12. Frasco de amostragem à margem do rio Atibaia..... 
Figura 3.13. Ponto de amostragem 2: Ponte sobre o Rio Atibaia na cidade de Paulínia, próximo à empresa Syngenta.

Figura 3.14. Placa indicando a interdição do bairro Recanto dos Pássaros, próximo ao local de coleta. Extraído de [29].

Figura 3.15. Extração de Benzeno utilizando barras desenvolvidas in-house com diferentes fases poliméricas. $(\mathrm{PDMS}=100 \%$ PDMS; RTX $=14: 86 \%$ de RTX/PDMS; OV-17= 50\% de OV-17/PDMS; OV-17Vinil= 5:95\% de OV17/PDMS)

Figura 3.16. Extração de Etilbenzeno utilizando barras desenvolvidas inhouse com diferentes fases poliméricas. (PDMS $=100 \%$ PDMS; RTX $=14: 86 \%$ de RTX/PDMS; OV-17= 50\% de OV-17/PDMS; OV-17Vinil= 5:95\% de OV17/PDMS)

Figura 3.17. Extração de Xilenos (soma o, $\mathrm{m}, \mathrm{p}$-xileno) utilizando barras desenvolvidas in-house com diferentes fases poliméricas. (PDMS $=100 \%$ PDMS; RTX= 14:86\% de RTX/PDMS; OV-17= 50\% de OV-17/PDMS; OV17Vinil= 5:95\% de OV-17/PDMS)

Figura 3.18. Comparação da extração de BTEX utilizando barras desenvolvidas in-house com diferentes fases poliméricas. (PDMS $=100 \%$ PDMS; RTX= 14:86\% de RTX/PDMS; OV-17= 50\% de OV-17/PDMS; OV17Vinil= 5:95\% de OV-17/PDMS)

Figura 3.19. a) Extração de OCPs em amostras de água utilizando diferentes fases poliméricas.

Figura 3.19. b) Redução da escala do gráfico da figura a. Os algarismos nos gráficos representam: 1) Alfa-BHC, 2) Beta-BHC, 3) Gama-BHC, 4) DeltaBHC, 5) Heptacloro, 6) Aldrin, 7) Heptacloro epóxido, 8) Alfa Endosulfan, 9) DDE, 10) Dieldrin, 11) Endrin, 12) DDD, 13) DDT. 


\section{LISTA DE TABELAS}

\section{Capítulo 1}

Tabela 1.1. Concentração de Paclobutrazol em dois intervalos para estudo de lineridade......

Tabela 1.2. Estudos de recuperação: níveis de fortifação, áreas obtidas, recuperação obtida e critérios EPA.

Tabela 1.3. Estudos de precisão: níveis de fortifação, áreas obtidas, recuperação obtida, precisão (coeficiente de variação) e critérios EPA

\section{Capítulo 2}

Tabela 2.1. Algumas aplicações biológicas recentes.

Tabela 2.2. Algumas aplicações ambientais recentes.

64

Tabela 2.3. Algumas aplicações em alimentos recentes.

Tabela 2.4. Planejamento Fatorial fracionado $\left(2^{4-1}\right)$ usado para otimizar as extrações por SBSE

Tabela 2.5 Coeficientes de partição octanol-água (log $\left.\mathrm{k}_{\mathrm{O} / \mathrm{w}}\right)$, íons selecionados $(\mathrm{m} / \mathrm{z})$ e respectivos tempos de retenção $\left(\mathrm{t}_{\mathrm{R}}\right)$ de cada analito. Os íons foram selecionados de acordo com a inspeção dos fragmentogramas.

Tabela 2.6. Resultados dos experimentos do Planejamento Fatorial fracionado $\left(2^{4-1}\right)$

Tabela 2.7. Diferentes solventes utilizados na dessorção dos analitos

Tabela 2.8. Resultados da precisão para os 13 pesticidas organoclorados estudados

Tabela 2.9. Resultados da linearidade expressos pelo coeficiente de determinação $\left(\mathrm{r}^{2}\right)$ para os 13 pesticidas organoclorados estudados....

Tabela 2.10. Dados obtidos de Limites de Detecção (LOD) e Quantificação (LOQ) e Recuperação. 


\section{Capítulo 3}

Tabela 3.1. Coeficiente de partição octanol-água (log ko/w), ions selecionados $(\mathrm{m} / \mathrm{z})$ e tempo de retenção $\left(\mathrm{t}_{\mathrm{R}}\right)$ para os analitos analisados sob as condições experimentais do estudo.

Tabela 3.2. Recuperação dos DDXs em água fortificada a 90, 120 e 180min de extração $\left(85^{\circ} \mathrm{C}\right)$............................................................................................ 122

Tabela 3.3. Resultados da precisão para os DDXs por RSE............................... 124

Tabela 3.4. Limites de detecção e quantificação encontrados............................ 124

Tabela 3.5. Resultados encontrados comparados com a legislação.................. 132 
SUMÁRIO

RESUMO

ABSTRACT

LISTA DE FIGURAS

LISTA DE TABELAS

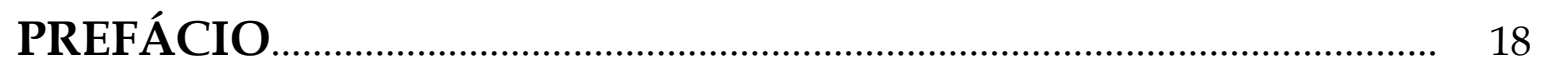

Capítulo 1

1. INTRODUÇÃ

1.1 PREPARO DE AMOSTRAS ...................................................................... 22

1.1.1 Extração em Fase Sólida (SPE)...................................................................... 25

1.2 PACLOBUTRAZOL

1.2.1 Análise de Paclobutrazol_......................................................................... 30

2. OBJETIVOS

3. PARTE EXPERIMENTAL ……............................................................ 33

3.1. PADRÕES E REAGENTES....................................................................... 33

3.2. EQUIPAMENTOS E MATERIAIS UTILIZADOS...................................... 33

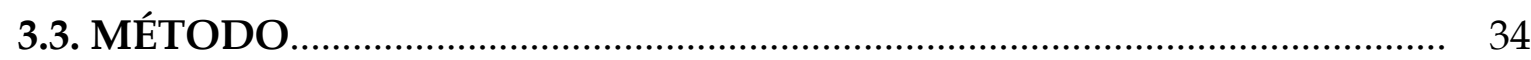

3.3.1. Preparo dos padrões analíticos................................................................. 34

3.3.2. Condições cromatográficas.........................................................................

3.3.3. Preparo das amostras...................................................................................

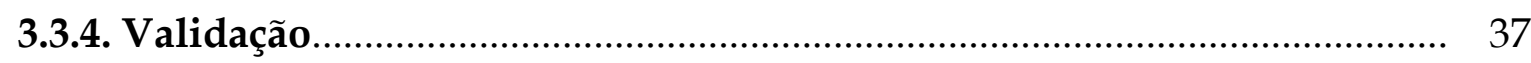

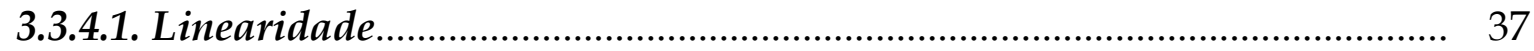


3.3.4.3. Precisão

3.3.4.4. Exatidão

4. RESULTADOS E DISCUSSÃO.

4.1. PREPARO DE AMOSTRAS

4.2. VALIDAÇÃO 41

4.2.1. Linearidade 41

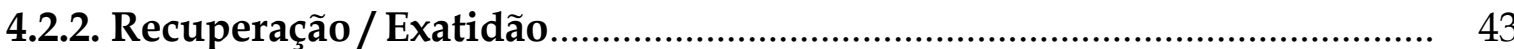

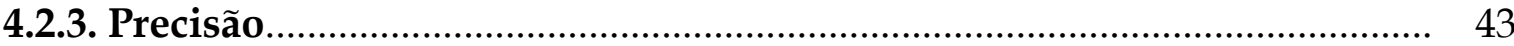

4.2.4. Limites de Quantificação e Detecção........................................................... 44

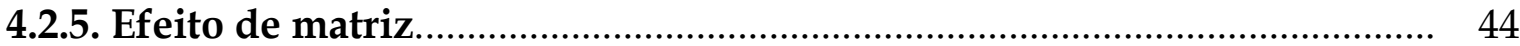

5. CONCLUSÕES

6. REFERÊNCIAS BIBLIOGRÁFICAS ................................ 48

\section{Capítulo 2}

1. INTRODUÇÃO

1.1 NOVAS TÉCNICAS DE EXTRAÇÃO...................................................... 54

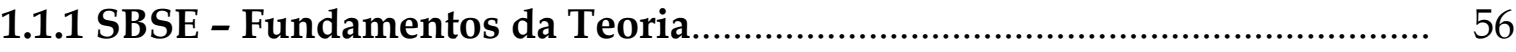

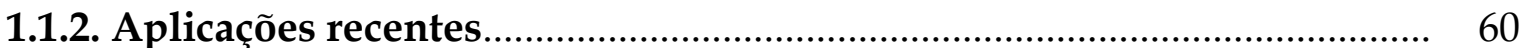

1.1.2.1 Aplicações biológicas recentes..................................................................... 61

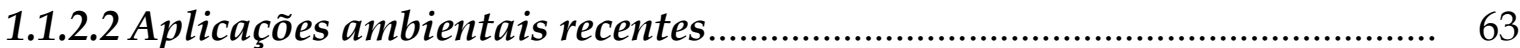

1.1.2.3 Aplicações em alimentos recentes............................................................... 63 
1.3 PLANEJAMENTO DE EXPERIMENTOS .............................................. 70

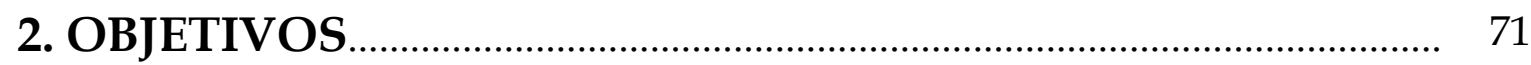

3. PARTE EXPERIMENTAL

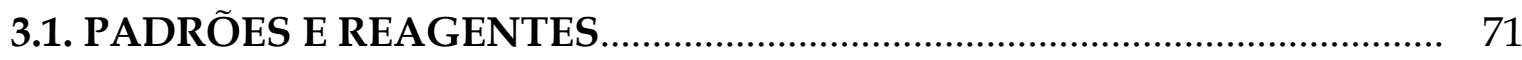

3.2. EQUIPAMENTOS E MATERIAIS UTILIZADOS ................................. 71

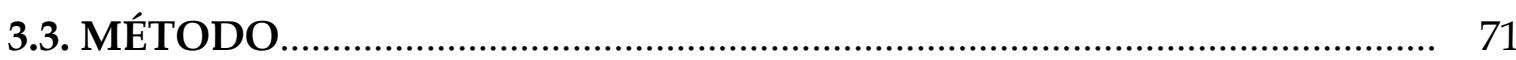

3.3.1. Preparo dos padrões analíticos............................................................... 71

3.3.2. Otimização das condições cromatográficas.......................................... 72

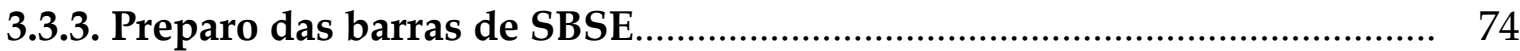

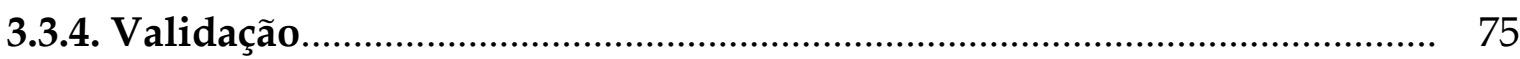

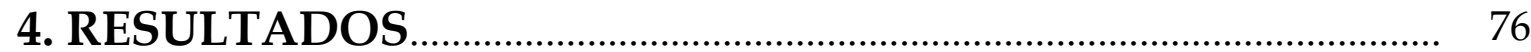

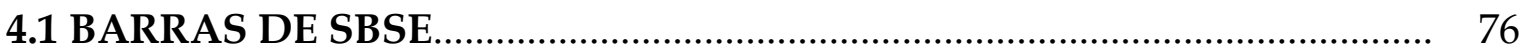

4.2 OTIMIZAÇÃO DO PROCESSO DE EXTRAÇÃO.................................... 76

4.3 PLANEJAMENTO EXPERIMENTAL .................................................. 77

4.4 VALIDAÇÃ

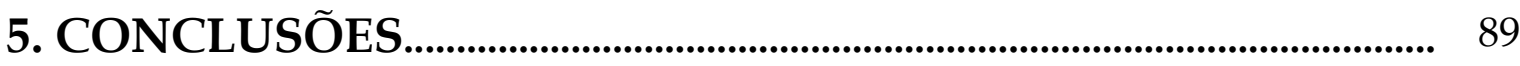

6. REFERÊNCIAS BIBLIOGRÁFICAS .............................. 90 


\section{Capítulo 3}

1. INTRODUÇÃO

1.1 EXTRAÇÃO SORTIVA REFRIGERADA.................................................... 101

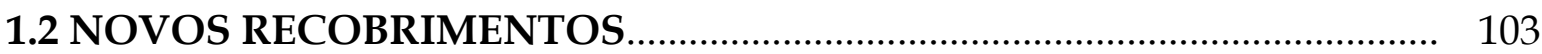

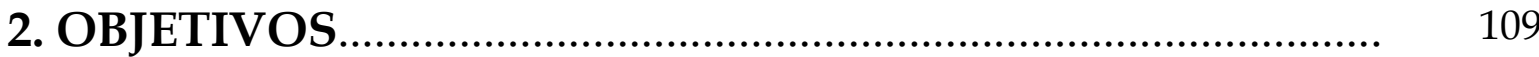

3. PARTE EXPERIMENTAL_........................................................ 110

3.1. PADRÕES E REAGENTES ................................................................. 110

3.2. EQUIPAMENTOS E MATERIAIS UTILIZADOS ....................................... 110

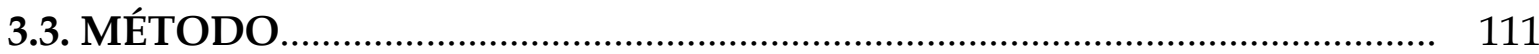

3.3.1. Preparo dos padrões analíticos...................................................................... 111

3.3.2. Otimização das condições cromatográficas................................................. 111

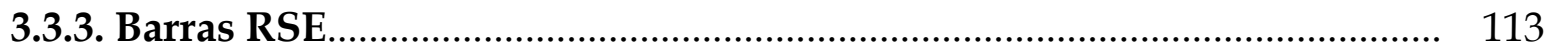

3.3.3.1 Preparo das barras de RSE .................................................................... 113

3.3.3.2. Sistema de miniaturização da RSE........................................................ 114

3.3.3.3. Extraç̃̃es - RSE........................................................................................... 116

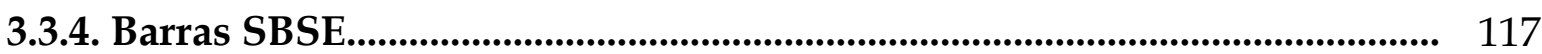

3.3.4.1 Preparo das barras de SBSE .................................................................. 117

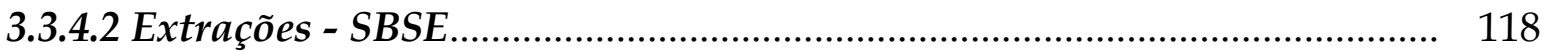

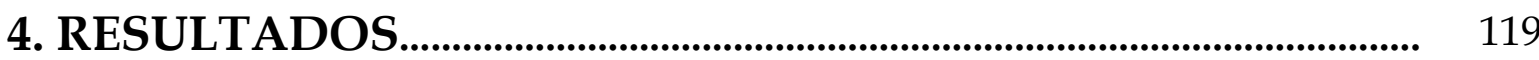

4.1 EXTRAÇÃO SORTIVA REFRIGERADA (RSE).............................................. 119

4.1.1. Sistema RSE........................................................................................................ 119

4.1.2. Extração.................................................................................................................. 119

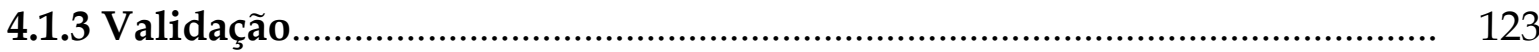


4.2.1 Aplicação em amostra real............................................................. 125

4.2.1.1. Rio Atibaia, Paulínia-SP ...................................................................... 125

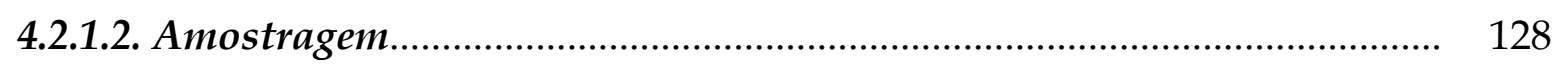

4.2.1.3 Análise das amostras e tratamento de dados............................................ 131

4.3 NOVOS RECOBRIMENTOS TESTADOS........................................... 133

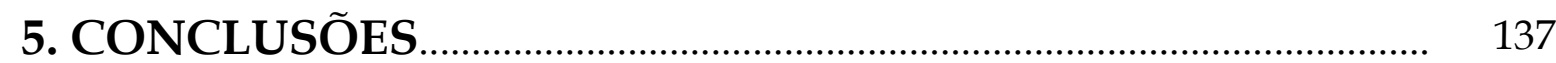

6. REFERÊNCIAS BIBLIOGRÁFICAS .............................. 138

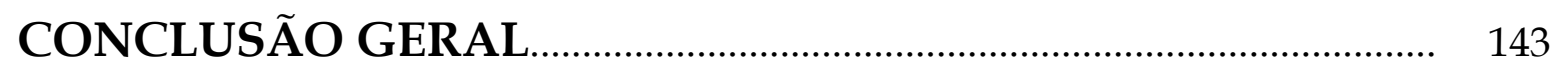

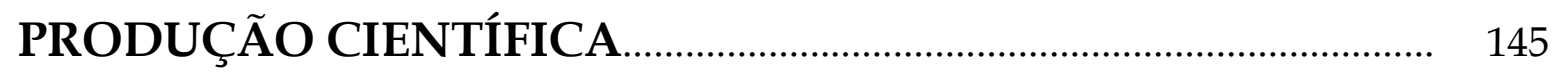




\section{PREFÁCIO}

O presente trabalho foi dividido em diferentes capítulos, nos quais reporta-se o desenvolvimento e aplicação de diferentes técnicas miniaturizadas de preparo de amostras para análises ambientais via GC-MS.

O Capítulo 1 descreve o uso da técnica SPE na análise do regulador de crescimento de plantas, o chamado paclobutrazol (PBZ), em amostras de solo. Um novo método foi desenvolvido, otimizado e validado para o emprego da técnica acoplada GC-MS na análise de PBZ em solo diminuindo assim a geração de resíduos durante a extração e o número de etapas quando comparada a métodos convencionais de análise.

O Capítulo 2 apresenta desenvolvimento de barras para SBSE. A SBSE apresenta várias vantagens em relação às técnicas de extração convencionais, tais como: redução de solvente orgânico, instrumentação analítica simples, as barras de extração reutilizáveis e, principalmente, possuir um volume maior de recobrimento quando comparada com a SPME. As barras foram desenvolvidas "in-house", preparadas com PDMS e aplicadas no modo headspace em amostras de água fortificada com pesticidas organoclorados e analisadas via GC-MS. É uma técnica que mostrou um ótimo custo benefício sendo que o valor da extração é reduzido quando comparado ao da barra comercial.

No Capítulo 3 seguindo a tendência de miniaturização e considerando as vantagens da SBSE devido ao volume de PDMS, superior ao da SPME a qual promove melhores recuperações e limites de detecção, e também as novas tendências de refrigeração em SPME, foi desenvolvido um novo sistema nomeado de Extração 
Sortiva Refrigerada. Este sistema foi construído com equilíbrio similar ao equilíbrio da HSSE e da SPME refrigerada. A técnica apresentou ótimos resultados quando aplicada na extração de OCPs e seguida de análise via GC-MS. Apresentou recuperação exaustiva para os compostos $\mathrm{DDX}$ e baixos limites de deteç̧ão e quantificação. A técnica foi aplicada em amostras de água do rio de Atibaia, coletadas na região de Paulínia-SP.

E finalmente o desenvolveram-se novos recobrimentos para a técnica de SBSE a partir da modificação do PDMS comumente utilizado visando mudanças nas características de polaridade e melhorando assim a capacidade sortiva das barras na aplicação de compostos mais polares. 
Otimização, Validação e Aplicação de Extração em Fase Sólida (SPE) para análise de PBZ em solo 


\section{1 \\ Otimização, Validação e Aplicação de Extração em Fase Sólida (SPE) para análise de PBZ em solo}

\section{INTRODUÇÃO}

A poluição ambiental pode ser apontada atualmente como um grande problema dos países desenvolvidos e em desenvolvimento. É decorrente, não apenas de um, mas de uma série de fatores, como o mau uso dos recursos naturais, a ineficiência da legislação, e a falta de consciência ambiental.

A maioria dos poluentes orgânicos é originada do refino de petróleo, na manufatura de compostos químicos, em indústrias carboníferas, de processamento têxtil e papeleiras, na utilização de óleos para transporte e aquecimento, pesticidas, inseticidas, herbicidas, fertilizantes e detergentes, além dos efluentes de plantas de tratamento de águas residuárias, lançamento incontrolado de rejeitos perigosos e derramamentos ambientais [1].

Nos Estados Unidos, já foram catalogadas aproximadamente 77.000 áreas contaminadas pela Agência de Proteção Ambiental Americana (EPA) [2]. Estas áreas podem estar presentes em diferentes ambientes como rios, lagos, solos e águas subterrâneas, construções civis ou qualquer outro meio onde a deposição de substâncias possa gerar riscos. 
Segundo a CETESB, apenas no estado de São Paulo o número de áreas com solos contaminados totalizou, em novembro de 2006, 1.822 áreas [3]. Devido ao impacto gerado pelas áreas contaminadas, existe grande necessidade de gerenciá-las para que possam ser remediadas adequadamente. Além disso, existe a importância do desenvolvimento de novas técnicas de análise para que um diagnóstico ambiental seja fiel ao problema apresentado.

Além do controle de qualidade em um diagnóstico, o controle ambiental também é de grande importância, uma vez que seria destoante realizar um estudo para verificar o quanto uma determinada atividade antrópica contaminou o solo, sem se preocupar com os controles ambientais deste estudo, que poderiam ser uma nova fonte de contaminação. Este caso pode ser exemplificado com a quantidade de resíduos que pode ser gerada na etapa analítica [4].

A etapa de extração ou preparo de amostra pode ser realizadas por várias técnicas, sendo a extração líquido-líquido (LLE) e a extração em fase sólida (SPE), bastante utilizadas. Técnicas mais recentes como a microextração em fase sólida (SPME) e a extração sortiva em barras de agitação (SBSE) têm sido desenvolvidas visando reduzir o tempo despendido na análise, além de eliminar o consumo de solventes orgânicos.

\subsection{PREPARO DE AMOSTRAS}

A qualidade de um método analítico é determinada pela qualidade de suas etapas, com seus erros experimentais. Por um lado, esta qualidade depende da técnica de amostragem, com a qual seleciona-se uma fração presumivelmente 
representativa da amostra primária. Nesta fração devem-se identificar e quantificar analitos, os quais são os componentes químicos que, também presumivelmente, a definem. É comum não se analisar quimicamente matrizes na forma bruta, pois elas costumam ter e gerar interferências e incompatibilidades com equipamentos analíticos [5]. (Figura 1.1)

Uma etapa muito importante é a de preparo de amostras, onde se procura isolar e concentrar os analitos a níveis adequados e obter um nível de limpeza de amostra que não comprometa sua análise química. Um exemplo na análise que emprega espectroscopia eletrônica (UV) é a eliminação de impurezas da matriz que absorvem no mesmo comprimento de onda do analito de interesse. Caso a impureza não seja eliminada, o resultado obtido será falso, pois expressará a soma da absorção do analito de interesse com a absorção decorrente do contaminante.

No caso de análises cromatográficas, além de evitar a interferência de contaminantes da matriz que possam co-eluir com o analito de interesse, a remoção de interferentes em geral é importante para garantir a longevidade das colunas analíticas e evitar constantes limpezas no sistema de injeção [6].

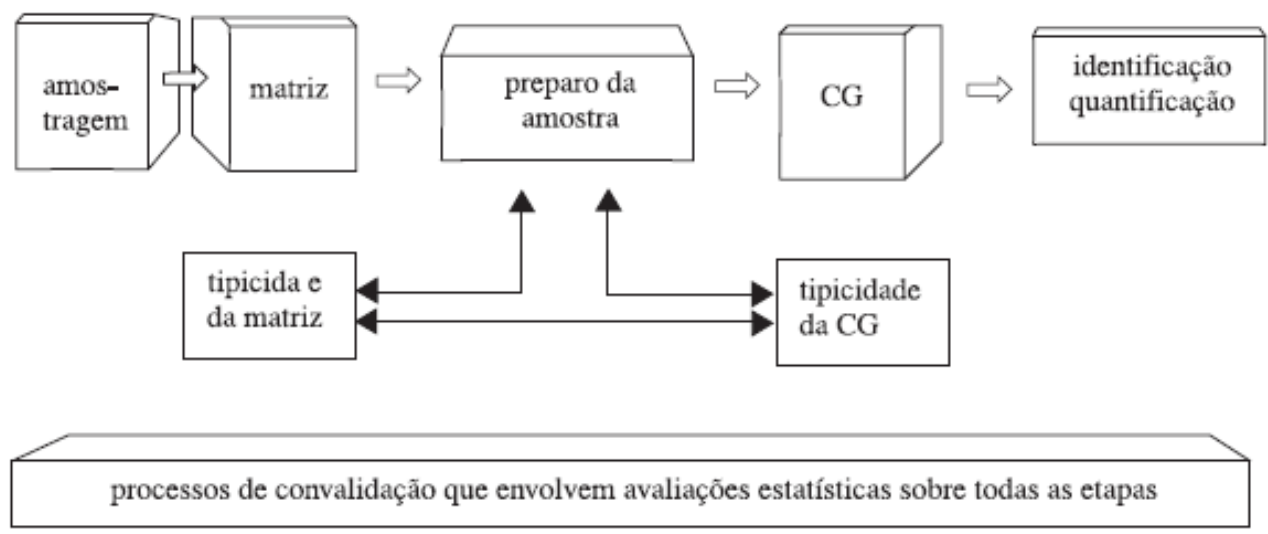

Figura 1.1. Etapas de um procedimento analítico. Extraído de [5]. 
Uma técnica ideal de preparo de amostras deve apresentar facilidade no manuseio, rapidez, baixo custo, ser compatível com a faixa de instrumento de análise e apresentar boa eficiência analítica, incluindo seletividade e aplicabilidade para determinações simultâneas [7].

O princípio do processo de extração utilizado nas diversas técnicas de preparo de amostra é a partição dos analitos entre a amostra e a fase extratante (extrator). Tradicionalmente os métodos de preparo de amostras são laboriosos e utilizam grandes quantidades de solventes. A técnica ideal de preparo de amostra deve ser simples, de baixo custo, rápida e compatível com instrumentos analíticos utilizados na separação e quantificação. Os métodos convencionalmente utilizados são a extração líquido-líquido e a extração em fase sólida (SPE).

A extração líquido-líquido (LLE) é amplamente utilizada para extrair compostos semi-voláteis em matrizes líquidas. Quando o analito é distribuído entre dois líquidos imiscíveis, existe uma relação definida, a constante de equilíbrio (coeficiente de partição ou coeficiente de distribuição), e o valor dessa constante é a razão da solubilidade do analito nos dois solventes. A LLE pode ser realizada manualmente por agitação da amostra com um líquido extrator em um funil de separação, ou automaticamente utilizando um extrator contínuo.

O procedimento clássico para a LLE utiliza volumes de solventes orgânicos, que são, na maioria das vezes, muito mais tóxicos do que os contaminantes em nível de traços que serão determinados. O volume do extrato é, geralmente, grande para a injeção direta em um cromatógrafo, sendo necessária uma etapa de evaporação do solvente. Nesta etapa não somente os analitos voláteis serão perdidos, mas as 
impurezas do solvente serão concentradas podendo mascarar a identificação do analito. Além disso, o excesso de manipulação da amostra pode ocasionar a perda dos analitos [8].

\subsubsection{Extração em Fase Sólida (SPE)}

A extração em fase sólida (SPE) é uma técnica de separação líquido-sólido, que baseia-se na partição entre os analitos da matriz e um adsorvente sólido. A SPE é utilizada para compostos com baixa, média e alta polaridade, dependendo do adsorvente utilizado. Freqüentemente, são utilizados cartuchos de extração empacotados com sílica modificada quimicamente com os grupos octil e octadecil (C8, C18), ou copolímeros como o estireno-divinilbenzeno. A seletividade na extração pode ser obtida pela eluição dos analitos com solventes específicos, ou pelo uso de adsorventes específicos para uma determinada aplicação. A SPE é limitada para compostos semi-voláteis com temperatura de ebulição acima da temperatura de dessorção do solvente.

Além dos cartuchos que são mais utilizados, a SPE pode ser usada na forma de membrana (disco). Recentemente, discos miniaturizados de extração (10 mm de diâmetro) estão sendo utilizados, com os mesmo benefícios do disco maior, mas com a distinta vantagem de utilizar pequenas quantidades de solventes para a dessorção [6]. (Figura 1.2) 


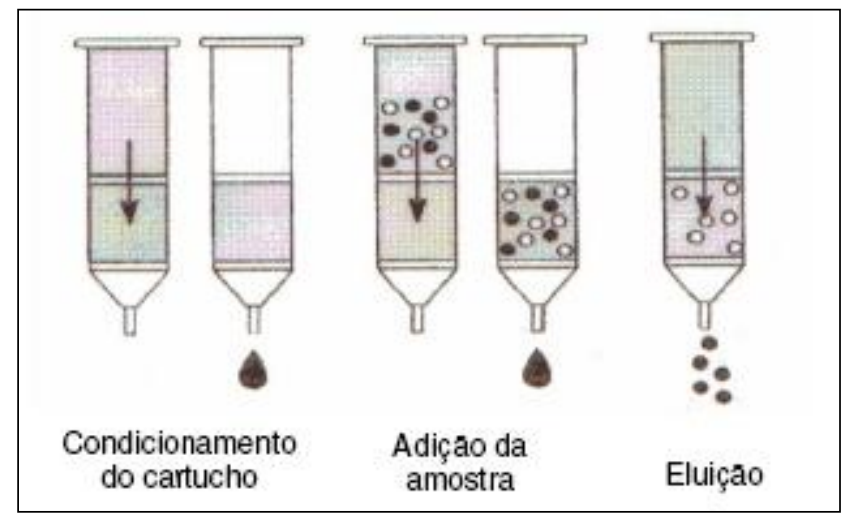

Figura 1.2. Principais etapas em SPE, visando o isolamento de um analito [6].

A extração líquido-líquido envolve grandes quantidades de solventes de alto custo e tóxicos, e também elevado tempo de análise. Já a SPE, embora apresente vantagens em relação à LLE com solventes, tem desvantagens como entupimento, falta de reprodutibilidade e a não reutilização de cartuchos [6].

\subsection{PACLOBUTRAZOL}

O uso de substâncias reguladoras de crescimento vegetal adquiriu grande importância na agricultura e no cultivo da mangueira em especial, possibilitando modificar os processos que estimulam o florescimento e a subseqüente produção de frutos em períodos de baixa oferta dos produtos nos mercados interno e externo. Atualmente, o uso de inibidores de crescimento, como o paclobutrazol (PBZ), tornouse prática importante para a indução do florescimento e produção comercial de manga em todo o território nacional, principalmente na Região Nordeste [9].

A EMBRAPA (Empresa Brasileira de Pesquisa Agropecuária) Semi-Árido, instalada no município de Petrolina - PE (Distrito de irrigação Nilo Coelho), localizada no submédio São Francisco, abriga um dos mais importantes pólos de irrigação da região Nordeste: são 100 mil hectares irrigados e mais de 30 espécies de hortaliças e frutas cultivadas. 
Atualmente, a produção de manga vem sendo realizada com técnicas modernas de indução floral, tecnologia que combina aplicações no mangueiral de substâncias químicas como o PBZ e o etefon, possibilitando escalonar a produção da manga durante todo o ano.

O paclobutrazol ([2RS, 3RS]-1-(4-Clorofenil)-4,4-dimetil-2-(1H-1,2,4-tiazolil1) pentanol3) é um regulador do crescimento de plantas usado no mundo inteiro, tanto para esta finalidade como para aumentar o rendimento de colheitas [10].

O PBZ pode ser aplicado nas folhas ou diretamente no solo. É absorvido passivamente pelas raízes, caule e folhas e tem movimento acropétalo dentro da planta, movendo-se pelo xilema para folhas e brotos. $\mathrm{O} \mathrm{K}_{\mathrm{d}}$ (coeficiente de distribuição linear) variável é proporcional ao conteúdo de matéria orgânica, conteúdo de argila e capacidade de troca catiônica do solo [11]. Seus valores para o coeficiente de adsorção variam de 1,5m em solos arenosos para 22,5m em solos argilosos. Liga-se fortemente à matéria orgânica do solo e sua adsorção aumenta em pH baixo [12]. A perda do grupo funcional polar nesta molécula explica porque ela é pouco solúvel em água e possivelmente adsorvida nos sítios hidrofóbicos da matéria orgânica $[10,13]$.

Este regulador de crescimento permanece ativo no solo por muitos anos podendo afetar severamente o crescimento e desenvolvimento dos cultivos subseqüentes pela redução do vigor vegetativo [14]. A meia-vida do PBZ varia com o tipo de solo e as condições climáticas [13].

Corpos d'água superficiais nas proximidades de pomares, em que o PBZ foi aplicado, são susceptíveis à contaminação por este composto, com o risco de 
promover efeitos adversos em organismos que habitam esses compartimentos ambientais.

A complexidade de ecossistemas aquáticos tem produzido dificuldades na avaliação e predição de efeitos de xenobióticos no meio ambiente. Isto traz complicações na tentativa de determinação de concentrações máximas permissíveis desses agentes em corpos d'água receptores.

Estudos realizados para avaliar os possíveis efeitos do paclobutrazol (Cultar ${ }^{\circledR}$ ) na reprodução e no desenvolvimento animal em ratos jovens, expostos perinatalmente por meio da avaliação de parâmetros físicos e comportamentais mostraram uma toxicidade perinatal em filhotes de ratos. Esta foi demonstrada pela diminuição da sobrevivência ao desmame e por afetar alguns dos indicadores testados relativo ao desenvolvimento neuromotor desses animais [13].

A necessidade de entender e predizer os efeitos dos xenobióticos tem promovido pesquisa de vários indicadores fisiológicos e bioquímicos de compostos tóxicos indutores de estresse [16]. A utilização destes bioindicadores baseia-se no fato de que os distúrbios no meio ambiente levam inicialmente a uma perturbação de uma reação bioquímica em um determinado organismo. Se estas alterações bioquímicas forem observadas com certa antecedência, pode ser possível a identificação de problemas ambientais antes que o ecossistema aquático como um todo seja afetado $[13,17]$.

A Figura 1.3, a seguir, ilustra as propriedades físico-químicas do PBZ. 


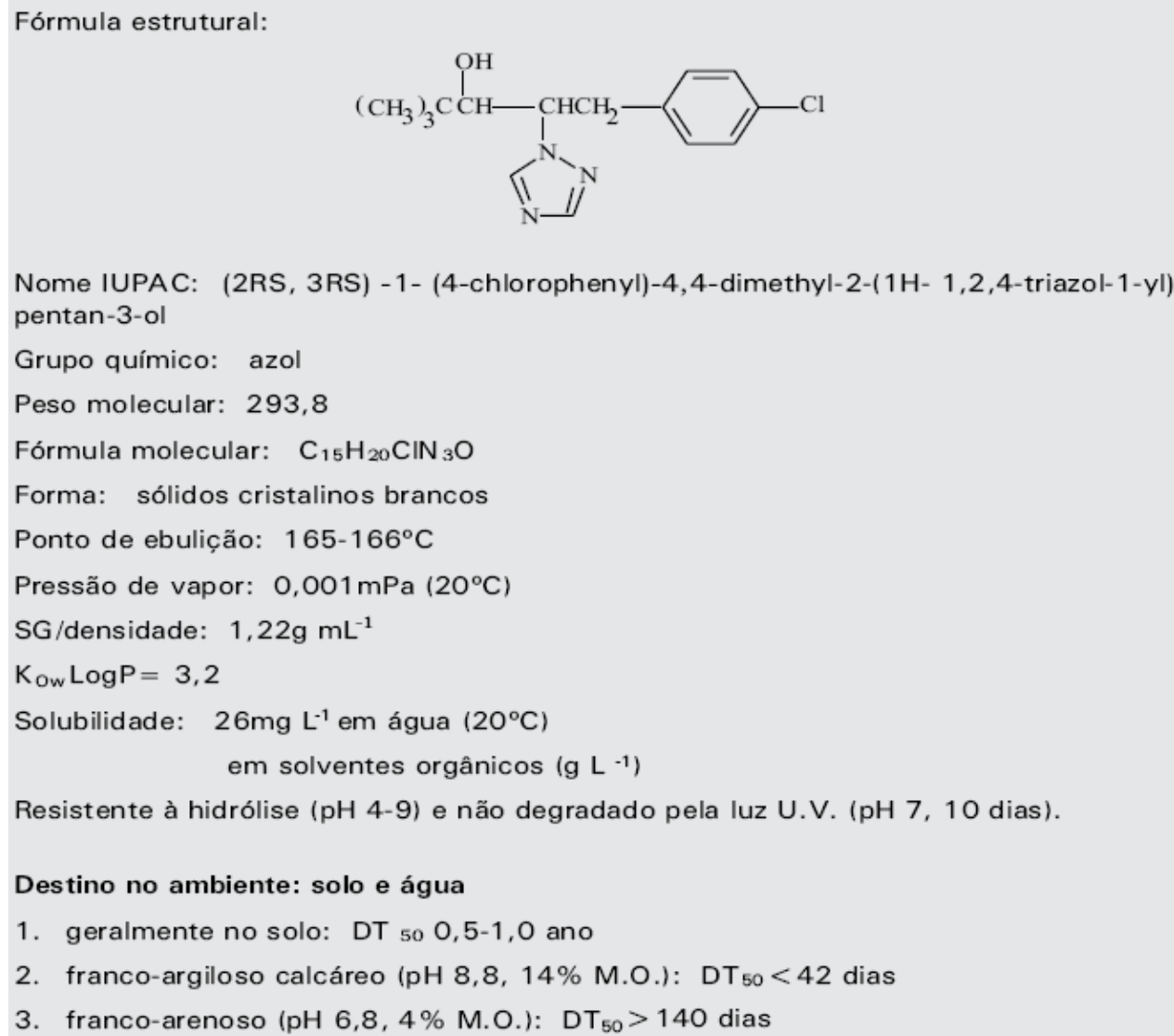

Figura 1.3. Quadro das propriedades físico-químicas do paclobutrazol. Adaptado [15].

Estudos sobre a análise de risco de contaminação das águas superficiais e subterrâneas da região do submédio São Francisco constatou a presença do paclobutrazol em águas subterrâneas, destacando esse composto como um contaminante em potencial para a região [18]. Além disso, Jackson et al [10] relataram que o paclobutrazol permanece no solo por vários anos, podendo afetar o crescimento e desenvolvimento de colheitas subseqüentes, principalmente pela redução do vigor vegetativo. No solo, estudos recentes não detectaram dissipação de PBZ após três meses de aplicação do produto e ainda verificaram um efeito acumulativo [19]. 
Recentemente, Souza et al [20] apresentaram resultados que mostram que o paclobutrazol, utilizado em pomares com manga irrigada cujos solos eram do tipo Argissolo-Amarelo e o Vertissolo, oferece risco real de contaminação das águas subterrâneas da região.

Considerando o papel do PBZ como regulador e a sua persistência no ambiente, o desenvolvimento de métodos analíticos de extração e análise tem um importante papel. A seguir é apresentado um trabalho encontrado na literatura o qual utiliza um longo procedimento analítico, incluindo a extração líquido-líquido, na análise do PBZ.

\subsubsection{Análise de Paclobutrazol}

Sharma e Awasthi [19] estudaram a persistência de resíduos de PBZ em amostras de frutas e solo. Durante o procedimento experimental realizaram uma extração com 50g de amostra em um frasco de Erlenmeyer com 70mL de metanol sob agitação durante 1 hora. $\mathrm{O}$ extrato foi filtrado utilizando um funil de Büchner com papel de filtro; foram realizadas mais 2 extrações consecutivas de 1 hora com adição de $50 \mathrm{~mL}$ de metanol em cada uma delas. Os extratos filtrados foram combinados, diluídos em $30 \mathrm{~mL}$ de água Mili-Q e a fase alcoólica foi evaporada em um rotaevaporador à $35^{\circ} \mathrm{C}$. $\mathrm{O}$ pH foi ajustado para $11 \mathrm{com}$ uma solução de hidróxido de sódio 1 mol.L-1.

Em seguida, realizou-se partição do extrato dissolvido em $3 \times 50 \mathrm{~mL}$ de diclorometano. A fase orgânica foi coletada e rotaevaporada à vácuo até o volume de $5 \mathrm{~mL}$. Em seqüência realizou-se "clean-up" com uma coluna de Florisil em dietil éter 
e o eluato obtido foi evaporado até secura. Este foi imediatamente re-dissolvido em 5 mL de acetona e analisado por um cromatógrafo gás-líquido (GLC).

A recuperação do método foi de $79 \%$ para a amostra de manga e $83 \%$ para a amostra de solo. O pico de PBZ foi posteriormente confirmado utilizando um cromatógrafo gasoso acoplado a um detector de massas (GC-MS).

$\mathrm{Na}$ tentativa de reproduzir o procedimento apresentado no trabalho de Sharma e Awasthi foi observado que, embora o procedimento tenha uma boa recuperação, é muito laborioso, demorado e utiliza uma grande quantidade de solvente. A Figura 1.4 mostra os fragmentos de massa do PBZ.

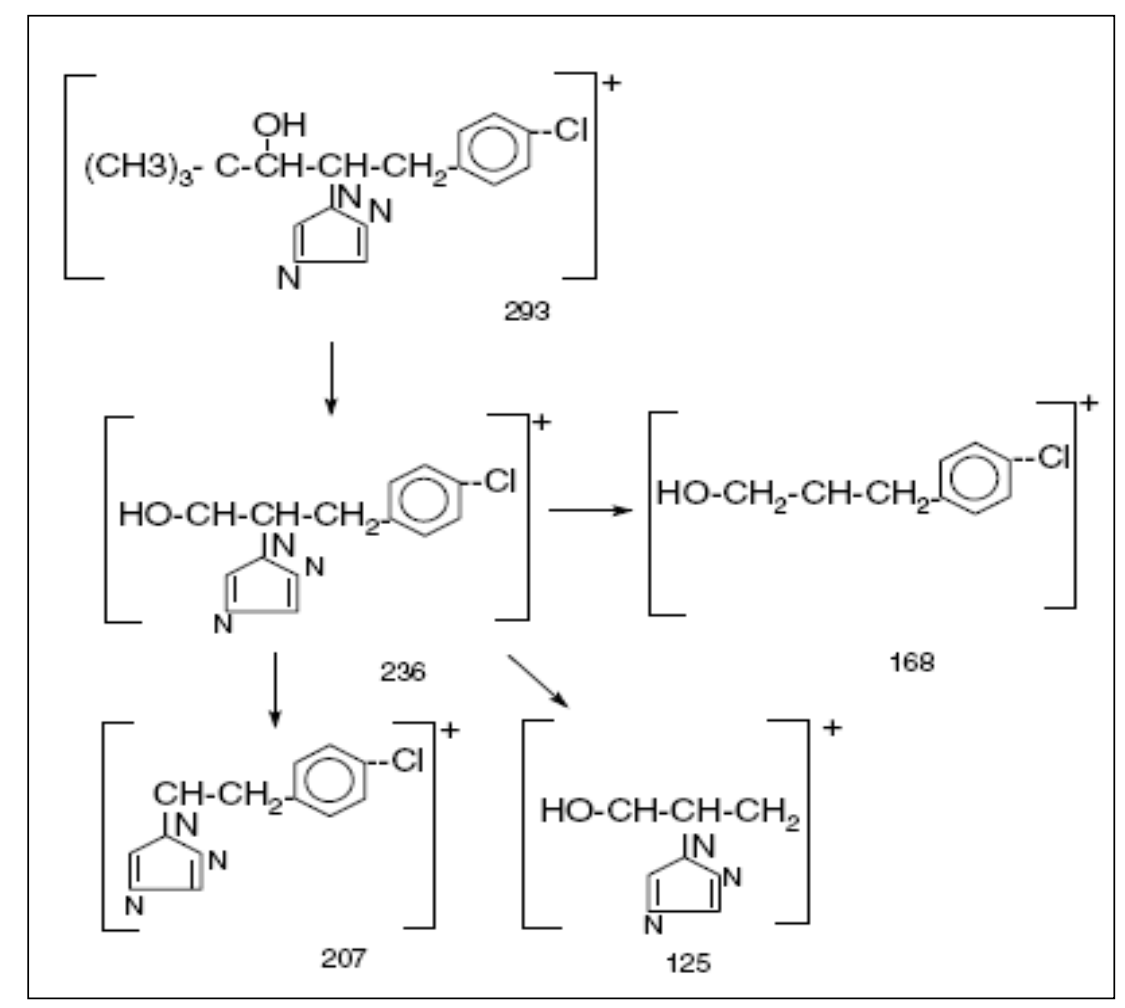

Figura 1.4. Fragmentos de massas do paclobutrazol, adaptado [19]. 


\section{OBJETIVOS}

- Desenvolver método alternativo para análise de paclobutrazol em amostras de solo empregando cromatografia gasosa acoplada à espectrometria de massas.

Empregar a técnica de Extração em Fase Sólida (SPE) diminuindo assim a geração de resíduos durante a extração, quando comparada a outros métodos em que utilizam somente extração líquido-líquido.

Validar o método desenvolvido avaliando os parâmetros: Linearidade; Precisão; Exatidão (Recuperação); Limite de Detecção e Limite de Quantificação. 


\section{PARTE EXPERIMENTAL}

\subsection{PADRÕES E REAGENTES}

O padrão de paclobutrazol foi obtido da Sigma-Aldrich (Alemanha). As soluções foram preparadas em metanol obtido da Tedia (EUA) e acetona grau HPLC obtida da Mallinckrodt (Phillipsbourg, NJ, USA).

O solo, classificado como Latossolo, foi coletado em uma profundidade de 0 a $20 \mathrm{~cm}$, de regiões com plantio de manga (Mangifera indica L. cv. Tommy Atkins) irrigada, sem histórico de aplicação de paclobutrazol, em estação experimental pertencente à EMBRAPA Semi-Árido, localizadas no Vale do São Francisco no Nordeste do Brasil.

\subsection{EQUIPAMENTOS E MATERIAIS UTILIZADOS}

- Centrífuga Excelsa Baby II modelo 206-R, Fanem

- Lavadora Ultra-sônica, Ultra Cleaner Unique

- Rotoevaporador Fisatom

- Extrator SPE - Supelco

- Cartuchos SPE Bakerbond Octadecyl C18

- Tubos de centrífuga de fundo redondo Nalgene

- Balança analítica modelo BL 210S, Sartorius, EUA

- Sistema de purificação de água modelo Milli-Q, Millipore, EUA

- Balões volumétricos de 5, 10, 50 mL, Pyrex, EUA 


\subsection{MÉTODO}

\subsubsection{Preparo dos padrões analíticos}

Inicialmente foi preparada uma solução estoque de PBZ com uma concentração de $100 \mathrm{mg} \cdot \mathrm{L}^{-1}$. Esta solução foi diluída para $10 \mathrm{mg} . \mathrm{L}^{-1}$ e a partir desta foram preparadas as soluções para fortificação das amostras e desenvolvimento do método cromatográfico.

\subsubsection{Condições cromatográficas}

O método cromatográfico foi desenvolvido nas condições descritas abaixo:

* Sistema GC-MS QP5050A, Shimadzu, Japão

Auto-injetor AOC-20i, Shimadzu

- Injetor: split/splitless

Modo injeção: splitless (1,2 minutos)

Volume injetado: $2,0 \mu \mathrm{L}$.

Temperatura do injetor: $260^{\circ} \mathrm{C}$

Temperatura da interface: $280^{\circ} \mathrm{C}$

Coluna: NST-5 $(30 \mathrm{~m} \times 0,25 \mathrm{~mm} \times 0,25 \mu \mathrm{m}), 5 \%$ fenildimetilpolisiloxano

Temperatura da coluna: $50^{\circ} \mathrm{C}$ (durante $5,0 \mathrm{~min}$.), $15^{\circ} \mathrm{C} / \mathrm{min}$. a $290^{\circ} \mathrm{C}$ (durante 3,0min.)

Gás de arraste: Hélio

Pressão na coluna: 118,1 kPa

Velocidade Linear: 51,6 cm.s ${ }^{-1}$

Fluxo Total: 26,9 mL.min ${ }^{-1}$ 
* Fluxo na coluna: 2,0 mL.min ${ }^{-1}$

Modo ionização: impacto eletrônico $(70 \mathrm{eV})$

Modo aquisição: SIM (m/z = 125; 167; 236)

Início do tempo de aquisição: 6,0 min

Solvent cut time: 5,0min

Voltagem - detector: $2,0 \mathrm{kV}$.

\subsubsection{Preparo das amostras}

Para a fortificação $\left(2 \mu \mathrm{g} . \mathrm{g}^{-1}\right)$ das amostras, foi adicionado, em $50 \mathrm{~g}$ de solo, $1 \mathrm{~mL}$ da solução estoque de PBZ (100 mg.L-1). Após vigorosa agitação manual, foram adicionados $70 \mathrm{~mL}$ de metanol, iniciando-se agitação em agitador magnético a 600 rpm, durante 1 hora. Após esse período, o material foi filtrado em funil de vidro utilizando-se papel de filtro qualitativo, e, novamente foi adicionado metanol (50 $\mathrm{mL})$, procedendo-se a agitação por mais 1 hora. Este procedimento foi repetido por mais uma vez. Após combinação dos três extratos metanólicos, foram adicionados 30 mL de água Milli-Q e realizada evaporação do solvente orgânico, em rotaevaporador a $35^{\circ} \mathrm{C}$. O material aquoso foi aplicado em cartucho C-18 previamente condicionado com $10 \mathrm{~mL}$ de metanol. Após lavagem com $10 \mathrm{~mL}$ de água Milli-Q, o analito foi eluído com $30 \mathrm{~mL}$ de acetona.

A extração está ilustrada na Figura 1.5. 


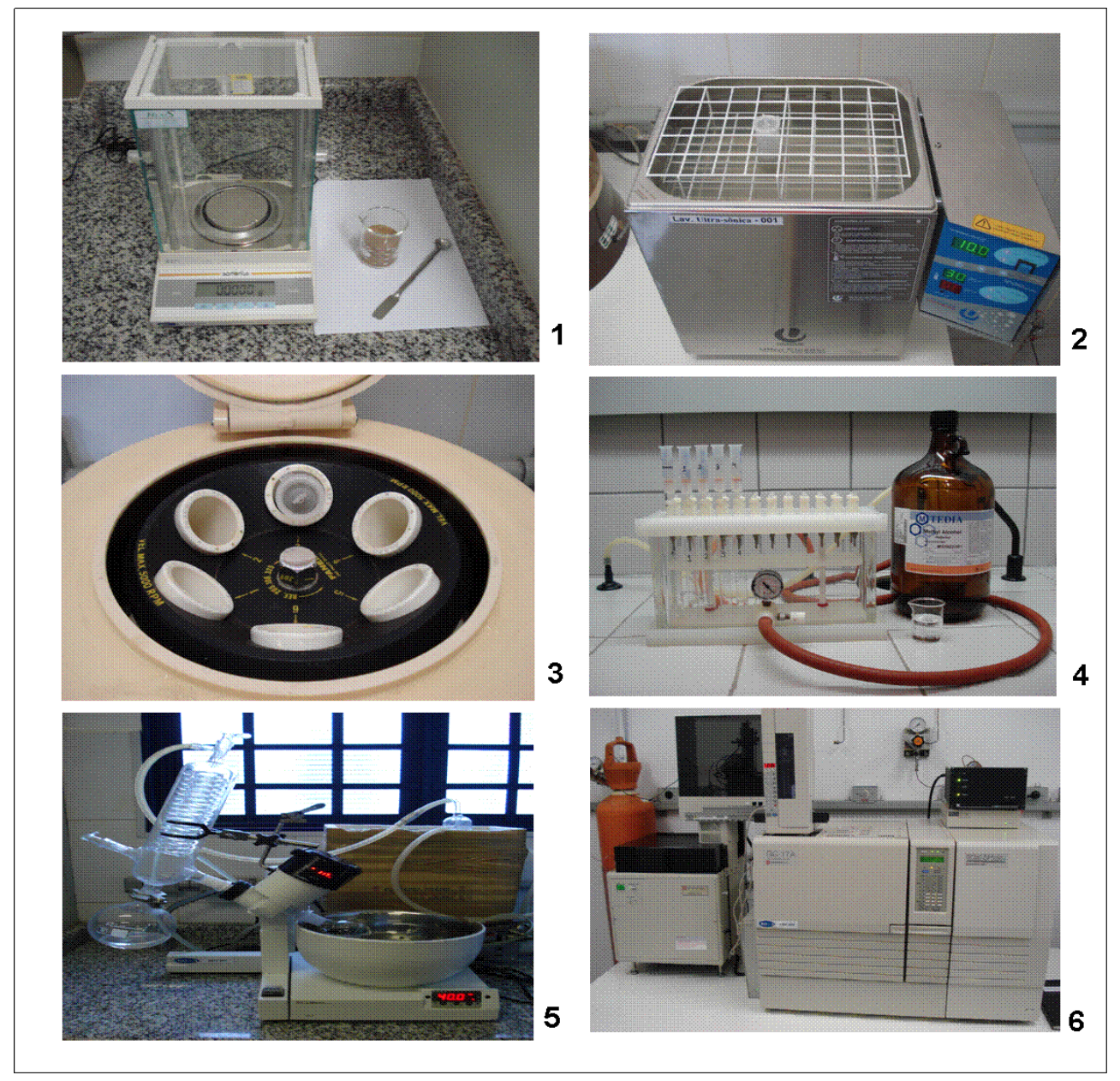

Figura 1.5. Processo de extração do Paclobutrazol: (1) pesagem das amostras; (2) extração em ultra-som; (3) centrifugação; (4) extração em SPE; (5) roto-evaporação à $40^{\circ} \mathrm{C}$; (6) análise por GC-MS Shimadzu QP5050.

Após a primeira etapa de preparo de amostras descrita, devido ao laborioso trabalho, otimizou-se o processo diminuindo a quantidade de amostra de solo utilizada inicialmente; e além disso, realizou-se algumas modificações do processo inicial como a aplicação de ultra-som na etapa de extração. O processo otimizado foi realizado da seguinte forma: pesou-se $2,5 \mathrm{~g}$ de solo em tubos de centrífuga de fundo redondo (para os estudos de recuperação estes foram fortificados em diferentes níveis); adicionou-se $30 \mathrm{~mL}$ de metanol e agitou-se em ultra-som durante 30 minutos; centrifugou-se a $3500 \mathrm{rpm}$ durante 5 minutos, coletou-se o sobrenadante e repetiu-se 
a etapa de ultra-som descrita adicionando novamente metanol; centrifugou-se mais uma vez a $3500 \mathrm{rpm}$ durante 5 minutos, coletou-se o sobrenadante somando este ao primeiro coletado; adicionou-se $10 \mathrm{~mL}$ de água aos extratos coletados e na seqüência foi rota-evaporado, à 40C para eliminar o metanol. Realizou-se então “clean-up" em cartuchos C-18 SPE, condicionados previamente com $5 \mathrm{~mL}$ de metanol seguido de 5 mL de água Mili-Q. O analito foi então eluido em $10 \mathrm{~mL}$ de metanol; o solvente foi rota-evaporado, à $40^{\circ} \mathrm{C}$, até a secura e reconstituiu-se em $1 \mathrm{~mL}$ de acetona; o eluato foi analisado via GC-MS nas condições cromatográficas pré estabelecidas.

\subsubsection{Validação}

Segundo Lanças [21], validar uma metodologia é dar a mesma validade, credibilidade e confiança. Desta maneira, depois de desenvolvida e otimizada uma metodologia para análise de organoclorados através de HS-SBSE-GC-MS, é necessário realizar sua validação dentro de conceitos bem definidos, de maneira a fornecer credibilidade e confiança à metodologia desenvolvida.

Os parâmetros de validação selecionados foram: Linearidade; Limite de Detecção e Limite de Quantificação; Precisão; Exatidão (Recuperação).

\subsubsection{Linearidade}

A linearidade é a resposta obtida em função da concentração do analito, a qual deve ser estudada em um intervalo de concentração apropriado. Na prática, a linearidade é determinada por intermédio de gráficos de calibração, também denominado curva de calibração, que corresponde a um gráfico onde o eixo $x$ 
relaciona-se as concentrações preparadas do padrão analítico da substância de interesse, e o eixo y ao sinal analítico obtido para cada concentração do padrão.

Segundo Lanças [21], o número mínimo de pontos para obtenção da equação da função (usualmente uma reta seguindo a forma $y=a . x+b$ ) varia entre 5 e 6 , sendo que o coeficiente de determinação $\mathrm{r}^{2}$ apresenta valores satisfatórios a partir de 0,98.

\subsubsection{Limite de Detecção (LOD) e Quantificação (LOQ)}

O Limite de Detecção (LOD) corresponde à menor quantidade de uma analito que pode ser detectada, porém, não necessariamente quantificada como um valor exato. Já o Limite de Quantificação (LOQ), corresponde à menor quantidade de uma analito que pode ser quantificada com exatidão e com fidelidade determinada. $\mathrm{Na}$ prática esses limites são calculados de acordo com a concentração do analito capaz de gerar um sinal três vezes maior que a amplitude do ruído (no caso do LOD), e dez vezes maior que a amplitude do ruído (no caso do LOQ).

\subsubsection{Precisão}

A precisão é a expressão da concordância entre vários resultados analíticos obtidos para uma mesma amostra. Ela pode ser determinada em condições de repetibilidade ou reprodutibilidade.

Condições de repetibilidade são aquelas em que resultados independentes são obtidos usando: a) o mesmo método; b) a mesma amostra; c) o mesmo laboratório; d) o mesmo operador; e) o mesmo equipamento; f) um curto intervalo de tempo. 
Já as condições de reprodutibilidade são aquelas em que resultados independentes são obtidos usando: a) o mesmo método; b) a mesma amostra; c) diferentes laboratórios; d) diferentes operadores; e) diferentes equipamentos.

A precisão ainda pode ser determinada no mesmo dia ("intra-day" ou “within-day") ou em diferentes dias ("inter-days" ou "between-days"). Sua medida é realizada por meio do desvio padrão ou coeficiente de variação, através da injeção de amostras com concentrações conhecidas em pelo menos cinco replicatas.

\subsubsection{Exatidão}

A exatidão expressa a concordância entre o valor medido e o aceito como verdadeiro ou aceito como referência. Geralmente é determinada por intermédio do uso de uma amostra certificada, cuja concentração do analito é conhecida. No entanto, quando não disponível, a alternativa é a adição (ou fortificação) de uma quantidade conhecida de um padrão certificado do analito de interesse à matriz, para que o método seja validado. De posse dos valores reais de concentração $(\mathrm{Vr})$ e dos valores determinados pelo método aplicado (Vd) é possível calcular a exatidão.

Para os cálculos dos parâmetros de validação utilizou-se as seguintes equações:

Média Aritmética: determinada pela equação 1

$$
\bar{x}=\frac{x_{1}+x_{2}+\ldots+x_{n}}{n}=\frac{\sum x_{i}}{n}
$$

onde: 


$$
\overline{\mathrm{x}}=\text { média aritmética dos valores; } \mathrm{x}=\text { valor obtido; } \mathrm{n}=\text { números de }
$$

resultados obtidos; $x_{i}=$ índice do valor de $\mathrm{x}$.

Desvio Padrão (s): utilizando o cálculo da média, a estimativa do desvio padrão foi determinada pela equação 2

$$
\mathrm{s}=\sqrt{\frac{\sum\left(\mathrm{x}_{\mathrm{i}}-\overline{\mathrm{x}}\right)^{2}}{(\mathrm{n}-1)}}
$$

onde: $\quad$ s = estimativa do desvio padrão

Coeficiente de Variação (CV): determinado pela equação 3

$$
C V=\frac{s}{\text { médiax } 100}
$$

onde: $\quad$ s = estimativa do desvio padrão

Coeficiente Angular (b) e Linear (a): obtidos em função da equação da reta gerados no cálculo estatístico do software Excel ${ }^{\mathrm{TM}}$.

- Cálculos de coeficiente de correlação (r) e determinação $\left(r^{2}\right)$ : o coeficiente de determinação $\left(\mathrm{r}^{2}\right)$ foi calculado pelo software Excel ${ }^{\mathrm{TM}}$. Para se obter o coeficiente de correlação (r), efetuou-se a equação 4:

$$
\mathrm{r}=\sqrt{\mathrm{r}^{2}}
$$




\section{RESULTADOS E DISCUSSÃO}

\subsection{PREPARO DE AMOSTRAS}

O preparo de amostras descrito no item 3.3.3 está ilustrado na Figura 1.5 já demonstrada.

\subsection{VALIDAÇÃO}

\subsubsection{Linearidade}

Estudos de linearidade foram realizados em dois intervalos de concentração diferentes, conforme descrito na Tabela 1.1 Para verificar a linearidade, as soluções foram analisadas no GC-MS nas condições descritas no item 3.3.2.

Os resultados do estudo de linearidade estão apresentados nas Figuras 1.6 e 1.7, indicando um comportamento exponencial para o intervalo de concentrações de 0,1, 0,2, 0,3, 0,4 e 0,5mg.L-1 (Figura 1.6). O coeficiente de correlação foi maior que 0,980 demostrando haver uma correlação entre concentração e resposta obtida. A equação de regressão linear obtida foi y=201624,8068.e $e^{7,4391 x}$. Já para o intervalo de concentrações $0,5,1$,0, 2,0, 3,0 e 4,0 mg.L-1 (Figura 1.7) o coeficiente de correlação foi maior que 0,999 demonstrando haver também uma correlação entre a concentração e a resposta obtida; a equação linear foi $y=4023787,2236 x-1061884,9695$. 
Tabela 1.1 Concentração de Paclobutrazol em dois intervalos para estudo de linearidade.

\begin{tabular}{|c|c|}
\hline \multicolumn{2}{|c|}{ Concentração de Paclobutrazol (mg.L-1) } \\
\hline \multirow{3}{*}{ Linearidade 1 } & 0,1 \\
& 0,2 \\
& 0,3 \\
& 0,4 \\
Linearidade 2 & 0,5 \\
\hline & 0,5 \\
& 1,0 \\
& 2,0 \\
& 3,0 \\
& 4,0 \\
\hline
\end{tabular}

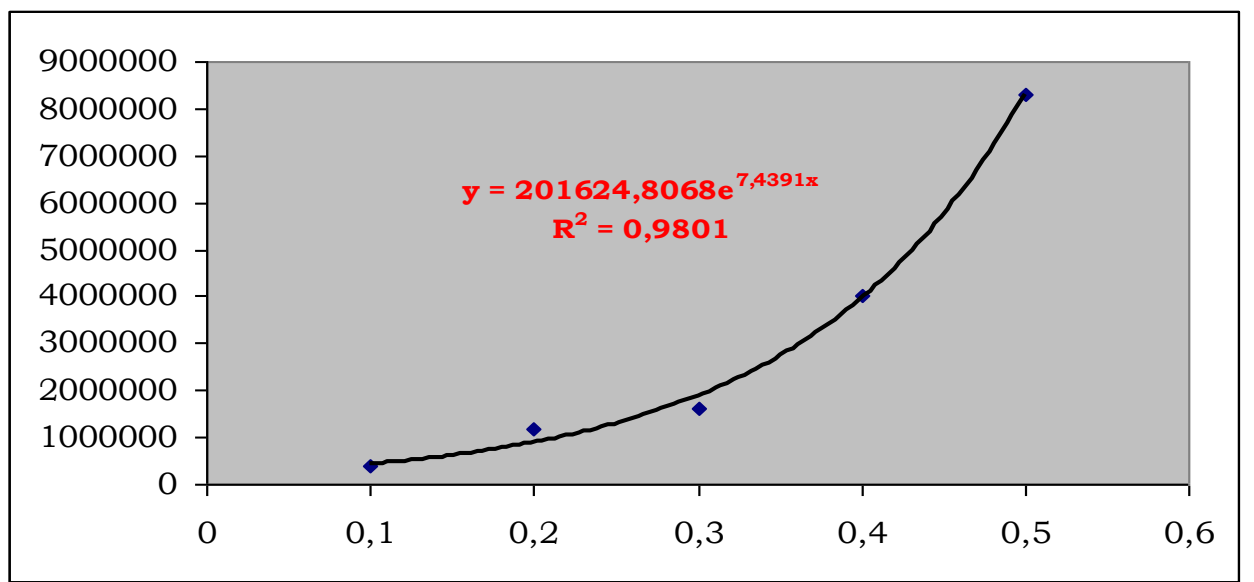

Figura 1.6. Curva de calibração, faixa não linear entre 0,1 e $0,5 \mathrm{mg} . \mathrm{L}^{-1}$.

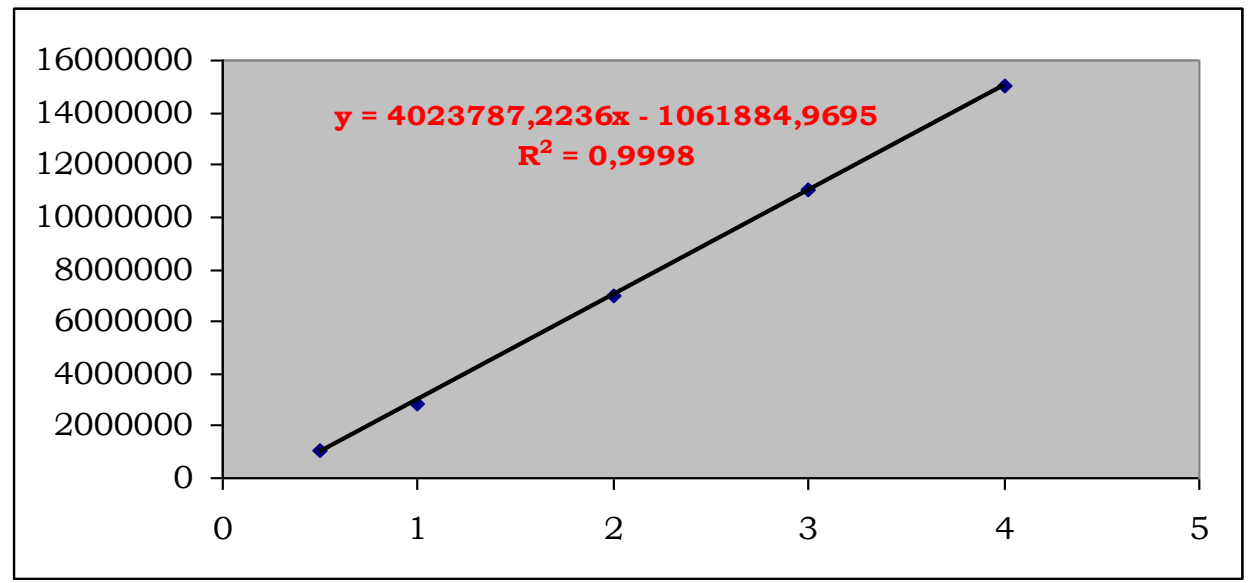

Figura 1.7. Curva de calibração, faixa linear entre 0,5 e 4 mg.L-1. 


\subsubsection{Recuperação / Exatidão}

Os estudos da recuperação de paclobutrazol em solo foram realizados em 03 níveis diferentes $\left(0,5,1,0\right.$ e 2,0 mg. $\left.\mathrm{L}^{-1}\right)$, obtendo resultados satisfatórios quando comparados aos critérios estabelecidos pela EPA [21] (Tabela 1.2).

Tabela 1.2. Estudos de recuperação: níveis de fortifação, áreas obtidas, recuperação obtida e critérios EPA.

\begin{tabular}{c|c|c|c}
\hline Nível de Fortificação & Áreas & Recuperação & Critérios EPA [21] \\
\hline \multirow{2}{*}{0,5} & 3307051 & \multirow{2}{*}{$92,16 \%$} & \\
& 3684667 & & \\
\hline \multirow{2}{*}{1} & 8728916 & & \multirow{2}{*}{$80 \%$ à $120 \%$} \\
& 8706674 & & \\
\hline \multirow{2}{*}{2} & 6628513 & $84,10 \%$ & \\
\hline & 6859732 & & \\
\hline
\end{tabular}

\subsubsection{Precisão}

Os estudos de precisão foram realizados pela análise de 07 replicatas de amostras fortificadas à $2 \mathrm{mg}$. $\mathrm{L}^{-1}$, obtendo resultados satisfatórios quando comparados aos critérios estabelecidos pela EPA (Tabela 1.3). 
Tabela 1.3. Estudos de precisão: níveis de fortifação, áreas obtidas, recuperação obtida, precisão (coeficiente de variação) e critérios EPA.

\begin{tabular}{c|c|c|c|c}
\hline $\begin{array}{c}\text { Nível de Fortificação } \\
\text { (mg.L-1) }\end{array}$ & Áreas & Recuperação & Precisão (CV) & Critérios EPA [21] \\
\hline & 529485 & 79,10 & & \\
& 600582 & 82,63 & & \\
2 & 670920 & 86,13 & & \\
& 573564 & 81,29 & $6,27 \%$ & \\
& 388430 & 72,09 & & \\
& 679808 & 86,57 & & \\
& 717563 & 88,45 & & \\
\hline
\end{tabular}

\subsubsection{Limites de Quantificação e Detecção}

O LOQ foi estabelecido como sendo 7,0 $\mu \mathrm{g}$. L-1 . O LOD foi estabelecido como sendo $2,5 \mu \mathrm{g} \cdot \mathrm{L}^{-1}$.

\subsubsection{Efeito de matriz}

Realizou-se um estudo do efeito da matriz sobre o composto. Para isso fortificou-se amostras de solo em 5 diferentes concentrações e estas foram submetidas ao processo de extração e posteriormente o eluato final foi analisado via GC-MS. Os padrões nas $5\left(0,1 ; 0,2 ; 0,5 ; 1\right.$ e $\left.2 \mathrm{mg}^{-L^{-1}}\right)$ diferentes concentrações das amostras fortificadas foram também injetados para estudo da linearidade conforme Figura 1.8. 


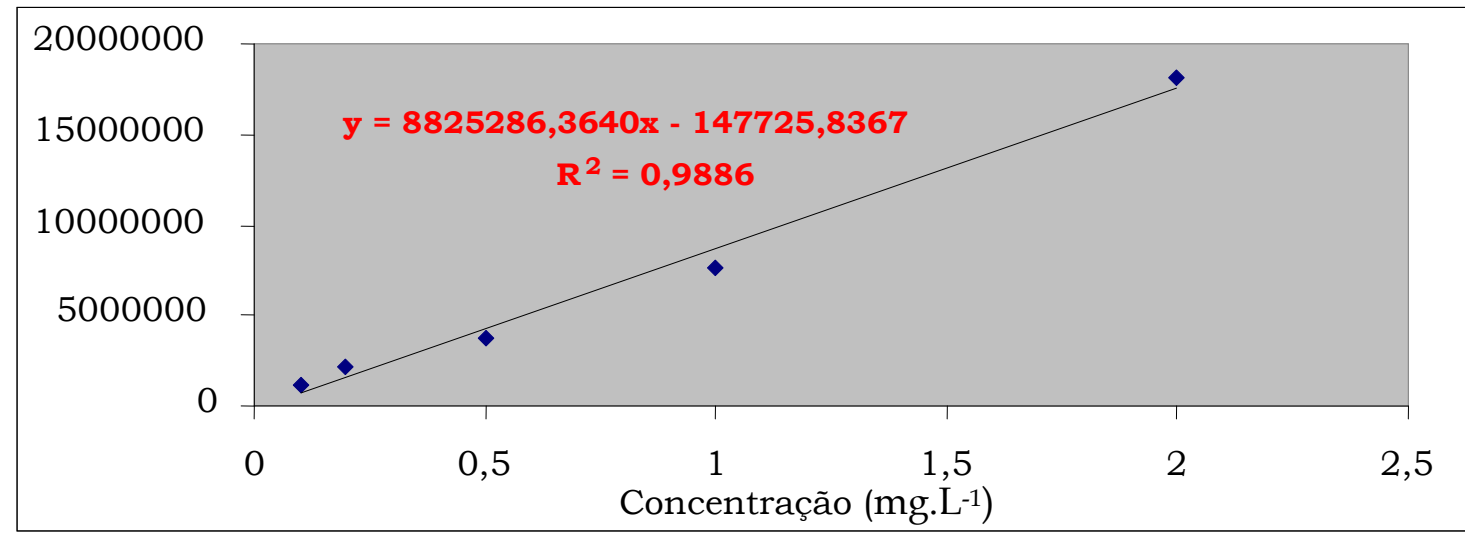

Figura 1.8. Estudo da linearidade: concentração de PBZ (mg.L-1) versus área.

Podemos verificar através da Figura 1.9 uma comparação entre as áreas cromatográficas obtidas e os resultados dos padrões e da extração da matriz fortificada são muito próximos demonstrando que não existe efeito da matriz sobre o analito de interesse. As Figuras 1.10 e 1.11 ilustram o fragmentograma e cromatograma obtidos.

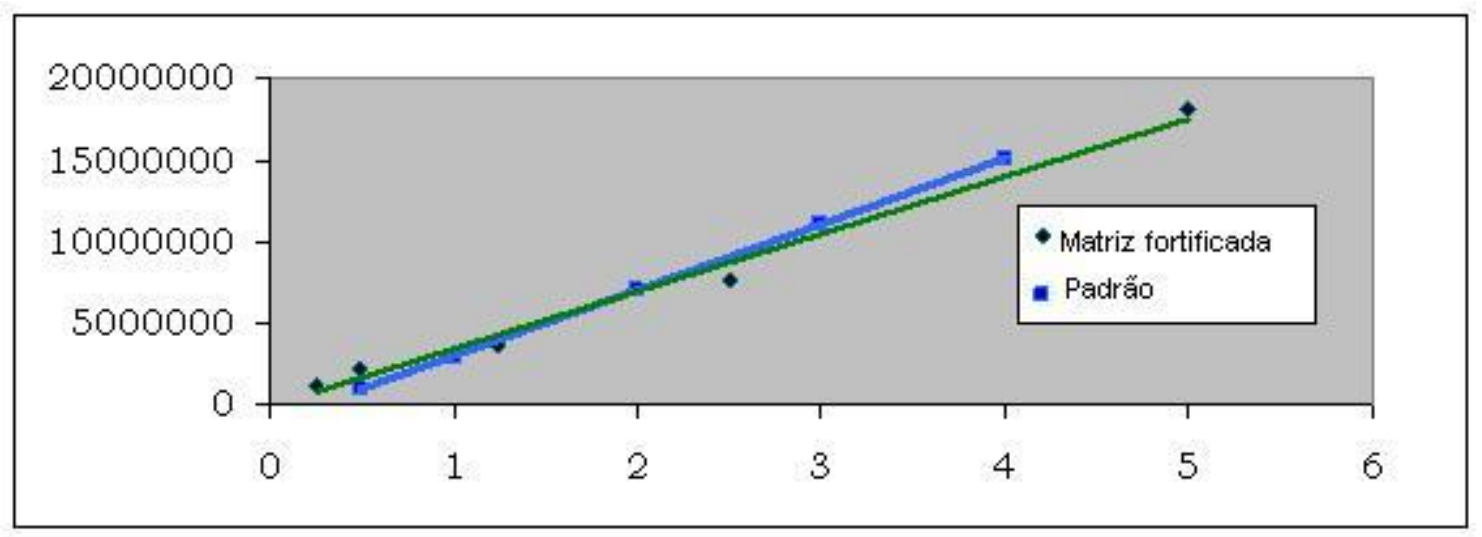

Figura 1.9. Comparação entre a linearidade através dos padrões e matriz fortificada. Concentração PBZ (mg.L-1) versus área cromatográfica obtida. 


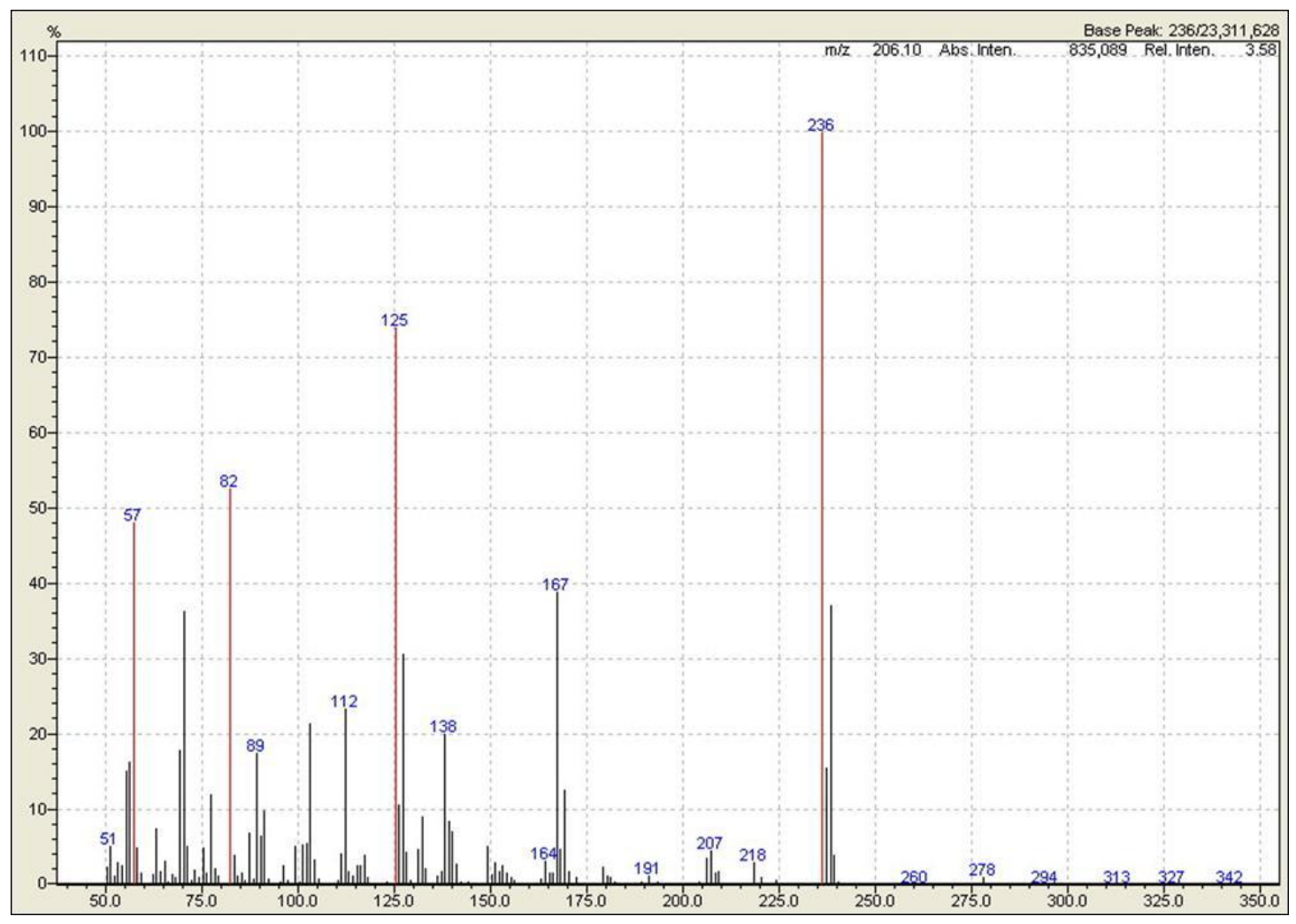

Figura 1.10. Fragmentograma do paclobutrazol.

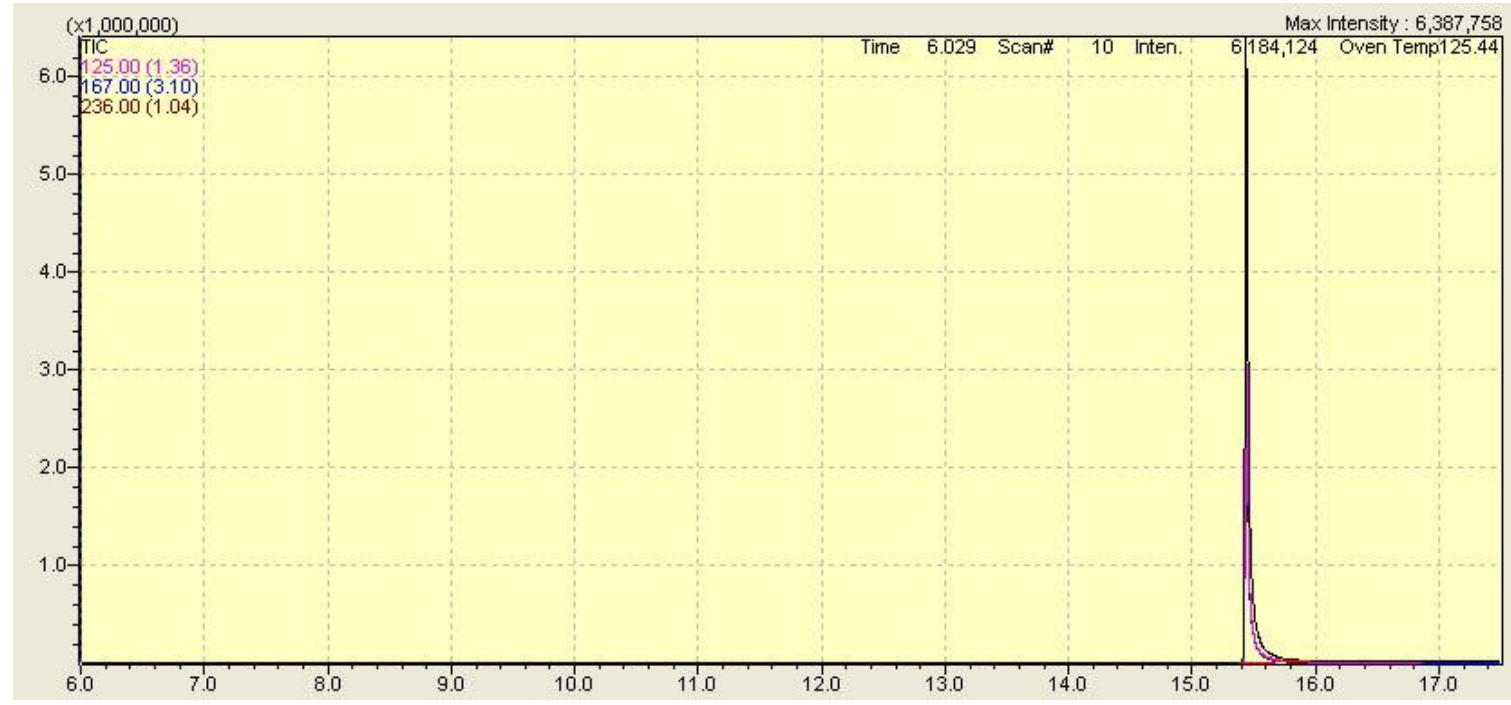

Figura 1.11. Cromatograma representativo da extração de paclobutrazol em solo na concentração de $2 \mathrm{mg} . \mathrm{L}^{-1}$. 


\section{CONCLUSÕES}

O método desenvolvido apresentou linearidade, precisão, exatidão/recuperação e limites de quantificação e detecção adequados para análise de paclobutrazol em solo.

O estudo do efeito de matriz mostrou que não existe interferência da matriz solo, do tipo latossolo, na extração do composto.

O método é apresentado como uma alternativa viável na determinação de PBZ em solo já que utiliza quantidade de solvente reduzida e menor número de etapas de preparo de amostras quando comparado com trabalho anterior apresentado na literatura. Além disso, permite o uso da cromatografia gasosa acoplada à espectrometria de massas, o que auxilia na confirmação de identidade do extrato. 


\section{REFERÊNCIAS BIBLIOGRÁFICAS}

[1] OLLIS, D. F., PELIZZETTI, E., SERPONE, M. Heterogeneous photocatalysis in the environment: application to water purification in Photocatalysis:

Fundamentals and Applications. Serpone N. Pelizzetti E. (eds), New York: Wiley, pp. 604-637, 1989.

[2] Environmental Protection Agency (EPA). Guidelines for Ecological Risk Assessment U.S. Environmental Protection Agency, Risk Assesstment Forum, Washington, DC. EPA/630/R095/002F. 1998. Disponível em

<http:// oaspub.epa.gov/eims/eimscomm.getfile?p_download_id=36512> Acesso em: 29 jun. 2007.

[3] Companhia de Tecnologia de Saneamento Ambiental (CETESB). Relação de Áreas Contaminadas no Estado de São Paulo. 2007 Disponível em <http://www.cetesb.sp.gov.br/Solo/areas_contaminadas/relacao_areas.asp > Acesso em: 29 jun. 2007.

[4] OLIVARES, I. R. B. Desenvolvimento, otimização e validação da técnica HSSPME-GC/MS para análise de amostras obtidas do Rio Atibaia através da aplicação de uma sistemática "ISO" para diagnóstico ambiental de áreas contaminadas.2006. 191f.Tese (Doutorado em Química Analítica) - Instituto de Química de São Carlos, USP, São Carlos, 2006.

[5] VALENTE, A. L. P., AUGUSTO, F. Solid Phase Microextraction. Química Nova, v.23, n.4, p.523-530, 2000.

[6] LANÇAS, F. M. Extração em Fase Sólida (SPE). Métodos Cromatográficos de Análise. São Carlos: Rima, 2004. 96p.

[7] PAWLISZYN, J. Solid Phase Microextraction theory and practice, Wiley-VHC. Ontário. 1997.

[8] LACERDA, C. A. Desenvolvimento de fibras para SPME: caracterização e aplicação. 2003. 127f. Tese (Doutorado em Físico-Química) - Instituto de Química de São Carlos, Universidade de São Paulo, São Carlos, 2003.

[9] FONSECA, N. et al. Ciências Agrotec., Lavras, v.28, n.4, p. 807-814, 2004.

[10] JACKSON, M. J., LINE, M. A., HASAN, O. Soil Biology and Biochemistry, 28, 1265-1267, 1996.

[11] LEVER, B. G. Cultar - a technical overview. Acta Horticulturae, v.179, p. 459-466, 1986. 
[12] LEONARD, W. F. Cultar - A plant growth regulator for horticulture. New Zealand Agriculture Science. v.20, p. 195-202, 1986.

[13] SILVA, C. M. M. S. Impacto ambiental do regulador de crescimento vegetal paclobutrazol. Jaguariúna: Embrapa Meio Ambiente, 2003

[14] ATTIYA, H. J., FIELD, R. J., HILL, G. D. Proceedings of Agronomy Society of New Zealand, v.13, p.82-87, 1983.

[15] WORTHING, C. R.; HANCE, R. H. (Ed.). The pesticide manual. 11. ed. Farnham: The British Crop Protection Council, 1994. p. 765-766.

[16] JIMENEZ, B. D.; STEGEMAN, J. J. American Fisheries Society Symposium, v. 8, p. 67-69, 1990.

[17] BUCHELI, T. D., FENT, K. Critical Reviews in Environmental Science and Technology, v. 25, n. 3, p. 201-268, 1995.

[18] FERRACINI, V. L., PESSOA, M. C. Y. P., SILVA, A. S., SPADOTTO, C. A. Pesticidas: Revista de Ecotoxicologia e Meio Ambiente, v. 11, 1-16, 2001.

[19] SHARMA, D., AWASTHI, M. D. Chemosphere, v. 60, 164-169, 2005.

[20] SOUZA, M. L. B. M. (2006). Transporte e sorção do agroquímico paclobutrazol em solos irrigados cultivados com manga. Tese de Doutorado, Programa de Pósgraduação em Tecnologias Energéticas e Nucleares (Proten-DEN), Recife, PE, 144p., 2006.

[21] ENVIRONMENTAL PROTECTION AGENCY (EPA). Guidance for Methods Development and Methods Validation for the RCRA Program - Phase 2: Formal Validation. 2006. Disponível em:

<http://www.epa.gov/SW846/pdfs/methdev.pdf>. Acesso em: 18 de dezembro de 2007. 


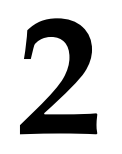

Desenvolvimento e Otimização da extração por "Headspace" e Extração Sortiva em Barras de Agitação (HS-SBSE) para análise de OCPs em água 


\section{2 \\ Desenvolvimento e Otimização da extração por "Headspace" e Extração Sortiva em Barras de Agitação (HS-SBSE) para análise de OCPs em água}

\section{INTRODUÇÃO}

Os pesticidas, conhecidos também como defensivos agrícolas, produtos fitossanitários, praguicidas, agrotóxicos ou biocidas, são substâncias, ou misturas destas, usadas para eliminar formas de vida vegetal ou animal indesejáveis nas plantações, rebanhos e ainda na saúde pública, no combate de vetores de doenças transmissíveis [1].

Os pesticidas não podem ser considerados um fenômeno característico do século XX. Enxofre e arsênio têm sido usados há séculos, mistura de óxido de cálcio e sulfato de cobre, foi introduzida como primeiro fungicida sintético em 1875. Porém, só nos anos 1940, o número e a extensão de uso destes compostos aumentaram grandemente com a introdução dos inseticidas organoclorados, tais como DDT.

A indústria da guerra acabou impulsionando a pesquisa e descoberta de compostos com ação biocida. Coube ao químico alemão Schrader sintetizar, em plena Segunda Guerra Mundial, o composto organofosforado schradan ou OMPA, posteriormente vendido como inseticida agrícola. Outro exemplo mais recente é o 
“agente laranja”, mistura de 2,4-D, 3,4,5-T e dioxinas, que foi utilizado como arma química no Vietnã e que ainda hoje tem um dos seus componentes, o 2,4-D, largamente empregado em culturas como a de cana-de-açúcar [2].

Assim, após a Segunda Guerra, observou-se a introdução no mercado de vários novos compostos. Esta nova geração de pesticidas prometia elevada produção e perdas muito inferiores a $30 \%$ das lavouras e afirmava contribuir para atender a demanda de alimentos de uma população crescente que obrigava a expansão de áreas cultivadas, bem como a otimização de técnicas agrícolas em todo o mundo [3].

A classificação dos compostos biocidas pode ser feita de várias formas, por exemplo, de acordo com sua composição química, função ou modo de ação nos organismos [4]. Com relação à composição química estes compostos podem ser divididos em três grupos, a saber, os inorgânicos; os de origem vegetal, bacteriana ou fúngica e, por últimos, os orgânicos. O terceiro grupo, maior e com marcante atividade fisiológica, é constituído pelos compostos organoclorados, benzoiluréicos, dentre outros [2].

Os organoclorados podem ser obtidos através da reação de Diels-Alder entre o hexaclorociclopentadieno e uma substância insaturada apropriada, resultando em produtos como aldrin, dieldrin, endrin, ou mesmo heptacloro. Outros podem ser preparados por meio de cloração do benzeno, como o hexaclorobenzeno, e por sua posterior saturação para a obtenção dos isômeros de hexaclorocicloexano. Geralmente, os organoclorados apresentam solubilidade baixa em água e considerável em solventes orgânicos, propriedade que facilita o armazenamento nos tecidos lipídicos e o acúmulo sucessivo em organismos de uma cadeia alimentar, 
importante processo conhecido como biomagnificação ou bioacumulação. Embora sejam mais estáveis e resistentes à degradação que muitos compostos de outras classes, podem sofrer reações como decloração, epoxidação, rearranjos ou hidrólise, especialmente em processos bioquímicos e fotobioquímicos. Porém o uso de organoclorados foi proibido, ou pelo menos controlado, em muitos países devido à sua elevada ação residual. Além de serem absorvidos pelo homem por via oral, respiratória ou dérmica, atuam ainda no sistema nervoso central e periférico [5].

No Brasil, o uso de pesticidas aumentou da mesma forma que na maioria dos países agrícolas. $\mathrm{O}$ controle de pragas, anteriormente feito por inimigos naturais, foi substituído por compostos sintéticos, aumentando a produtividade agrícola.

Embora atualmente controlada, a utilização de pesticidas organoclorados tem sido uma das principais fontes de contaminação nas últimas décadas. As grandes plantações, particularmente as monoculturas, favorecem o aumento de espécies consideradas pragas. Para combater as pragas foram desenvolvidos inseticidas, herbicidas, fungicidas, etc.; produtos que, quando utilizados de maneira indiscriminada, contaminam grandes regiões. O mais clássico deles, o DDT (diclorodifenil-tricloroetano), foi o primeiro pesticida organo-halogenado desenvolvido. Nos primeiros anos de uso, o DDT foi elogiado como de grande contribuição à saúde da humanidade, e o seu uso foi incentivado indiscriminadamente. Os efeitos da acumulação do DDT no organismo humano não foram percebidos imediatamente; somente após 20 anos é que apareceram os primeiros sintomas patogênicos. Hoje sabe-se que o DDT é resistente à degradação, possui propriedades cancerígenas, mutagênicas e teratogênicas, além de outros efeitos na formação uterina [6]. 


\subsection{NOVAS TÉCNICAS DE EXTRAÇÃO}

Novas tendências no preparo de amostras têm buscado métodos de extração que não utilizam solventes, ou que empreguem apenas um volume reduzido destes. Assim a miniaturização obtém um papel importante na química analítica. Nos últimos anos Pawliszyn [7] e colaboradores desenvolveram a Microextração em Fase Sólida (SPME), técnica que está se tornando popular devido à facilidade de uso, alta sensibilidade e reprodutibilidade. A SPME tem apresentado aplicações em diferentes áreas como, por exemplo, análises de: fármacos [8-12], alimentos [13], pesticidas [1417], fungicidas [18], entre outros.

Uma nova técnica de extração empregando PDMS, denominada Stir Bar Sorptive Extraction (extração sortiva em barras de agitação) foi recentemente desenvolvida por Baltussen e colaboradores [19]. Esses autores encontraram consideráveis discrepâncias entre os dados da literatura e aqueles obtidos por SPME para o coeficiente de partição octanol-água de compostos de elevada massa molecular e de caráter apolar, propondo que isso deveria ser relacionado à adsorção na mistura, especialmente e nos frascos de vidro. Empregando uma mistura de bifenilas policloradas (PCBs) e de hidrocarbonetos poliaromáticos (PAHs), ambos de baixíssima solubilidade em água nas condições usadas em SPME, demonstraram que a quantidade desses compostos encontrada na barra de agitação empregada em SPME foi dez vezes superior à existente na fibra.

A partir desse estudo desenvolveram uma nova técnica (SBSE), similar à SPME, empregando em vez de fibras, uma barra de agitação recoberta com poli dimetilsiloxano (PDMS). De maneira simplificada, o procedimento pode ser 
resumido da seguinte forma: a barra magnética é inserida na fase aquosa a ser analisada e a extração/concentração dos compostos de interesse ocorre durante o processo de agitação. Após certo período, esta é removida da solução aquosa e os compostos são extraídos e posteriormente analisados [20].

Esta particular barra de agitação compreende um magneto inserido no interior de um tubo de vidro, o qual é recoberto por uma camada de PDMS de $1 \mathrm{~mm}$ de espessura (Figura 2.1). O material disponível comercialmente apresenta um diâmetro total de 3,2mm, comprimento de 10 ou $40 \mathrm{~mm}$ e volume de PDMS variável de 55 e $219 \mu \mathrm{L}$. Em geral, maiores volumes de filme polimérico são empregados para a extração de compostos presentes em amostras com até $250 \mathrm{~mL}$ de fase aquosa [21].

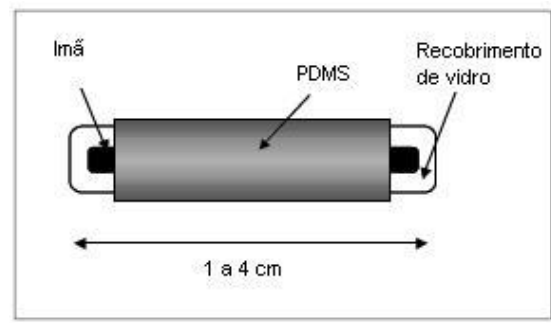

Figura 2.1. Esquema de barras magnéticas agitadoras recobertas com PDMS utilizadas em SBSE comercial.

Devido às suas características, PDMS tem demonstrado ser um excelente meio de extração. Em primeiro lugar, os analitos não são retidos nas superfícies ativas do material extrator tão fortemente como no caso dos adsorventes comuns, mas são particionados ou dissolvidos no filme polimérico, retidos em toda a sua extensão e espessura. Como este processo de dissolução ou associação é relativamente fraco, a degradação de analitos instáveis é significativamente menor ou ausente em PDMS quando comparada às associações com fases como sílica, alumina ou Florisil. Em segundo lugar, devido às fracas interações com os analitos, estes podem ser 
desorvidos em temperaturas moderadas, minimizando as perdas de analitos termolábeis. Em terceiro, os fragmentos de degradação do filme de PDMS são facilmente reconhecidos por um detector seletivo de massas, e em tese, a capacidade de retenção de PDMS para certos compostos não é influenciada pela presença de grande quantidade de água ou outros analitos, pois todos os solutos possuem seu próprio equilíbrio de partição na fase polimérica e o deslocamento não ocorre [2].

\subsubsection{SBSE - Fundamentos da Teoria}

A teoria da SBSE é simples e muito similar àquela da SPME. Além disso, todos os parâmetros que afetam a extração por SPME, tais como $\mathrm{pH}$, temperatura, força iônica, tempo de extração, velocidade de agitação e presença de solvente também atuam sobre a extração por SBSE [22].

Considerando que os coeficientes de partição PDMS-água (KPDMS/W) são proporcionais aos coeficientes de partição octanol-água $\left(K_{O / W}\right)$, pode ser estabelecido que:

$$
K_{O / W} \sim K_{P D M S / W}=\frac{C_{S B S E}}{C_{W}}=\frac{M_{S B S E}}{m_{W}} \times \frac{V_{W}}{V_{S B S E}}
$$

onde $C_{S B S E}$ e $C_{W}$ são as concentrações do analito na barra SBSE e na fase aquosa, respectivamente, $m_{S B S E}$ e $m_{W}$ são as massas dos analitos na barra SBSE e na fase aquosa, respectivamente, e $V_{S B S E}$ e $V_{W}$ são os volumes das fases SBSE e aquosa, respectivamente. Introduzindo o termo $\beta$, denominado razão de fases $\left(V_{W} / V_{S B S E}\right)$, pode-se reescrever a equação acima como: 


$$
K_{O / W}=\frac{m_{S B S E}}{\beta}=\frac{m_{S B S E}}{m_{W}}=\frac{m_{S B S E}}{m_{0}-m_{S B S E}}
$$

onde $m_{0}$ é a quantidade total de analito originalmente presente na amostra aquosa. Finalmente, a equação pode ser transformada de forma a expressar a eficiência de extração ou recuperação:

$$
\operatorname{Eficiência}(\%)=\frac{m_{S B S E}}{m_{0}}=\frac{\left(K_{O / w} / \beta\right)}{1+\left(K_{O / w} / \beta\right)}
$$

Durante o processo de extração os analitos se distribuem entre a fase aquosa da matriz e a camada de PDMS, sendo a razão da constante de partição do analito e a relação entre as duas fases (PDMS e água) o único parâmetro que governa a recuperação [22].

Em SPME, o volume máximo de PDMS na fibra é de aproximadamente $0,5 \mu \mathrm{L}$ (para uma fibra de $100 \mu \mathrm{m}$ de espessura). Para uma amostra típica de $10 \mathrm{~mL}$ o valor médio de $\beta$ é de $2.10^{4}$. Isso significa que uma extração quantitativa só será obtida para compostos com um $K_{O / W}$ maior que $10^{5}$.

Em SBSE a condição se torna mais favorável. Uma barra de $100 \mu \mathrm{L}$ de PDMS pode ser facilmente utilizada para extrair $10 \mathrm{~mL}$ de fase aquosa $(\beta=100)$. Nesse caso, analitos com Ko/w maiores que 500 são quantitativamente extraídos da barra.

A Figura 2.2 reproduz justamente este comportamento, ilustrando a eficiência obtida por SBSE comparativamente à SPME em função do $\log K_{O} /$, demonstrando que a primeira é bem descrita pelos coeficientes, sendo a recuperação extrativa quantitativamente superior em idênticas condições experimentais. De acordo com a 
literatura, para analitos com valores de $\log K_{O / W}$ superiores a 3, são normalmente obtidas recuperações quantitativas por SBSE. No entanto, no caso de extração incompleta, que genericamente pode ocorrer para compostos com log $K_{O / W}$ inferior a 3 ou ainda em situações de não equilíbrio, a calibração continua a ser válida na SBSE [23].

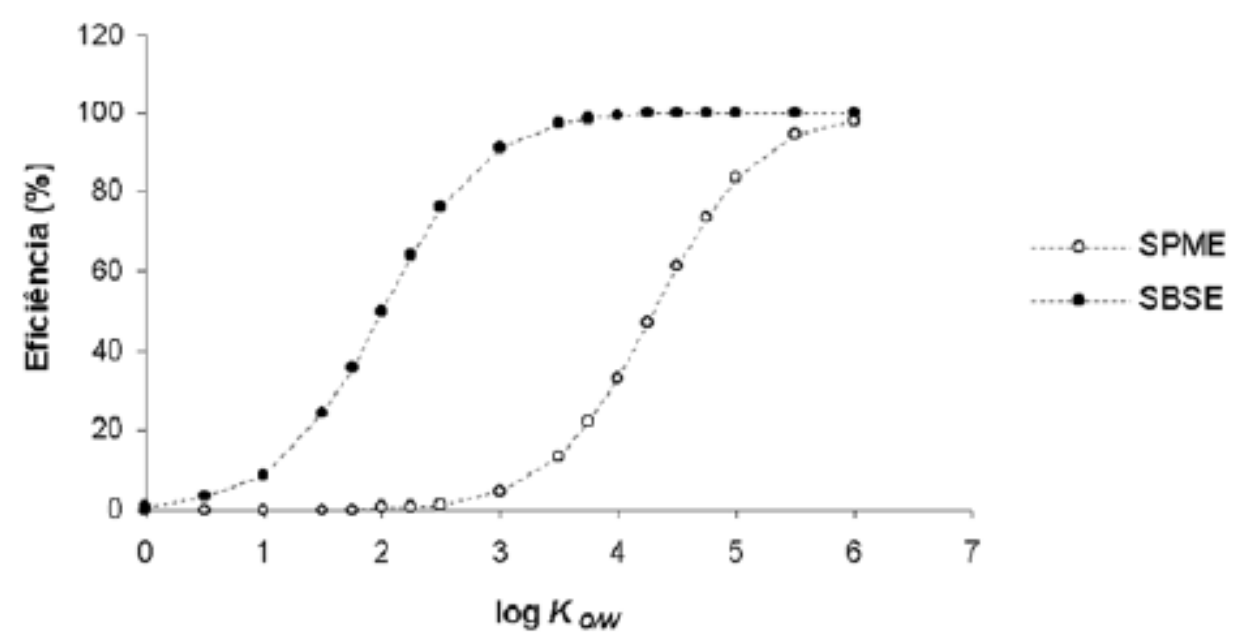

Figura 2.2. Comparação da eficiência extrativa por SPME (PDMS: 0,5 $\mu \mathrm{L}$ ) e SBSE (PDMS: 47 $\mu \mathrm{L})$ em função do coeficiente de partição octanol/água, em idênticas condições experimentais. (Extraído de Almeida et al [11]).

Contrariamente à SPME, para a qual já existem no mercado diversos tipos de revestimentos poliméricos, na SBSE apenas são comercializadas barras de agitação revestidas com PDMS contendo um volume compreendido entre 24 e $126 \mu \mathrm{L}$ que apresenta, no entanto, uma quantidade substancialmente superior à disponibilizada na fibra de SPME mais comum $(0,5 \mu \mathrm{L})$. A maior relação de fase entre a matriz da amostra e o PDMS, proporciona desta forma um aumento da capacidade extrativa e conseqüentemente, da sensibilidade da técnica de SBSE para uma ordem de grandeza compreendida entre 50 e 250, comparativamente a SPME. 
Em analogia com a SPME, as condições experimentais da SBSE têm de ser otimizadas para cada tipo específico de aplicação. Além das características de polaridade dos analitos e da fase de revestimento, a eficiência de recuperação é igualmente influenciada por parâmetros como o tempo de extração, a velocidade de agitação, temperatura, força iônica e pH, no sentido do analito de interesse atingir o equilíbrio de distribuição entre a matriz da amostra e o revestimento polimérico.

Após um determinado período de agitação, a barra é posteriormente inserida num tubo de vidro e colocada numa unidade de dessorção térmica (TD) on-line com um injetor de temperatura programada, onde os analitos voláteis e semi-voláteis são termicamente desorvidos e analisados por cromatografia gasosa. Alternativamente, a barra pode ser colocada num volume reduzido $(0,1-2 \mathrm{~mL})$ de um solvente orgânico polar compatível com o PDMS para dessorção líquida (LD), de maneira a promover a extração eficaz dos analitos da barra sem destruir a fase polimérica, seguido de análise por cromatografia gasosa ou líquida.

Em condições não agressivas, as barras de agitação apresentam como vantagem o fato de poderem efetuar dezenas ou mesmo centenas de extrações consecutivas sem manifestarem sinais de deterioração, podendo a SBSE ser genericamente aplicada diretamente na matriz da amostra ou alternativamente via headspace.

Além disso, a técnica SBSE apresenta a vantagem sobre a técnica de SPME de que a razão de fase é muito maior (razão de volume de PDMS para o volume de fase aquosa) porque o volume de sorvente é muito maior tornando, assim, a capacidade de extração maior que em SPME. 
A SPME no modo headspace tem sido utilizada para determinar pesticidas in amostras de água e de fluidos biológicos mostrando bom desempenho. A amostragem no modo headspace apresenta vantagem significativa em termos de seletividade porque apenas compostos orgânicos voláteis e semi-voláteis podem ser levados ao headspace. Desde que a fase não esteja em contato com a amostra, efeito de matriz pode ser reduzido também na SBSE, além de aumentar a vida útil das barras[24-32].

\subsubsection{Aplicações recentes}

Depois de uma publicação inicial em 1999 [19], discutindo a teoria e os princípios da técnica de SBSE, diferente aplicações foram desenvolvidas em análises ambientais, alimentos e fármacos. Um trabalho de revisão [33] recente mostra a aplicação extensa da SBSE em diferentes áreas. Novas aplicações desde este trabalho de revisão foram buscadas e apresentadas a seguir [34]. Depois do desenvolvimento da SBSE, diferentes aplicações foram desenvolvidas nas análises ambientais, principalmente porque esta técnica foi inicialmente desenvolvida para ser aplicada em amostras de água. Buscando as aplicações da SBSE, desde seu surgimento, é possível encontrar 236 trabalhos, nos últimos 5 anos aproximadamente 180 trabalhos, nos últimos 2 anos foram 21 trabalhos com aplicação biológica, 20 com ambiental e 8 com alimentos. (Figura 2.3) 


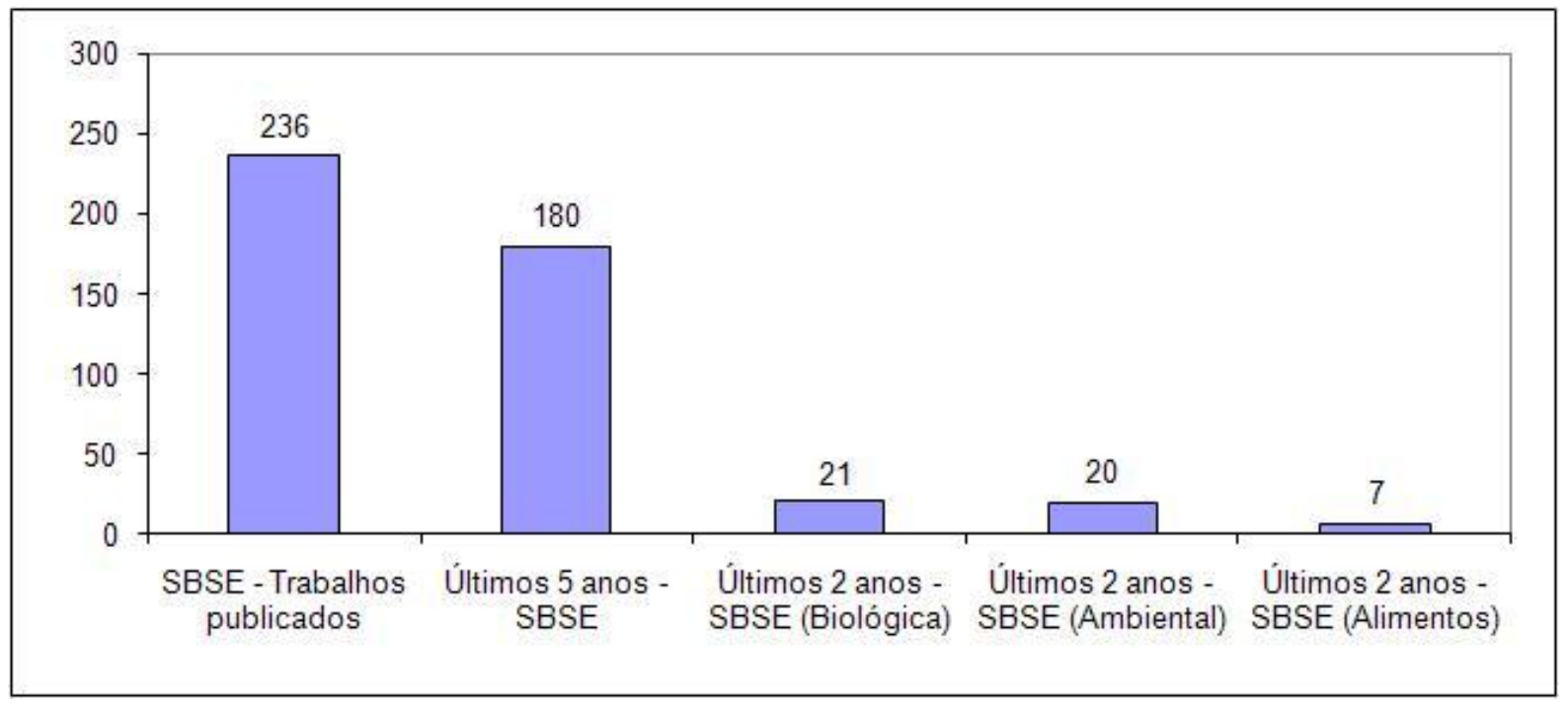

Figura 2.3 Estatística de publicação dos trabalhos que aplicam SBSE encontrados no ScienceDirect (http://www.sciencedirect.com).

\subsubsection{Aplicações biológicas recentes}

Uma visão geral das aplicações biológicas da SBSE é apresentada na Tabela 2.1 A maioria dos métodos descritos mostra alta seletividade cromatográfica, linearidade, precisão e alta sensibilidade, de acordo com os critérios de validação internacionais atendendo o monitoramento de drogas terapêuticas, toxicologia clínica, bio-disponibilidade e farmacocinética. 
Tabela 2.1. Algumas aplicações biológicas recentes.

\begin{tabular}{|c|c|c|c|c|}
\hline Analitos & Matriz (volume) & (LOD) & Observações & Referências \\
\hline Barbitúricos & Urina (5 mL) & $\begin{array}{l}\text { GC-MS (SIM) } \\
12 \text { pg.mL-1 }\end{array}$ & $\mathrm{TD}$ & [35] \\
\hline Ftalatos, metabólicos & Fluidos biológicos (5 mL) & GC-MS (SIM) & TD & [36] \\
\hline Farmacêuticos & Urina $(5 \mathrm{~mL})$ & $\begin{array}{l}\text { GC-MS (scan) } \\
<1 \text { ng.mL } \text { mL }^{-1}\end{array}$ & $\begin{array}{l}\text { TD, Derivatização in situ anidrido } \\
\text { acético }\end{array}$ & [37] \\
\hline Drogas de abuso & $\begin{array}{l}\text { Sangue, urina, bile } \\
\qquad(5 \mathrm{~mL})\end{array}$ & $\begin{array}{l}\text { GC-MS } \\
<5 \mu \mathrm{g} . \mathrm{L}^{-1}\end{array}$ & $\begin{array}{c}\text { TD, Hidrólise, } \\
\text { Derivatização in situ anidrido } \\
\text { acético }\end{array}$ & [38] \\
\hline Fenóis & $\begin{array}{l}\text { Urina, plasma } \\
(1 \mathrm{~mL})\end{array}$ & $\begin{array}{l}\text { GC-MS (SIM) } \\
0.4-4 \text { ng.L-1 }\end{array}$ & $\mathrm{TD}$ & [39] \\
\hline Antidepressivos & Plasma (1 mL) & $\begin{array}{c}\text { LC-UV } \\
\text { LOQ: } \\
\text { 10-40 } \mathrm{ng} \mathrm{mL}^{-1} \\
\end{array}$ & LD & [40] \\
\hline Hormônios sexuais & Urina & $\begin{array}{c}\text { LC-DAD } \\
0,062-0,38 \text { ng.mL } \mathrm{mL}^{-1}\end{array}$ & LD & [41] \\
\hline Fluoxetina & Plasma (1 mL) & $\begin{array}{c}\text { GC-MS (SIM) } \\
0,46 \mathrm{pg} \mathrm{mL}^{-1} \text { (TD) } \\
10,0 \mathrm{pg} \mathrm{mL}^{-1}(\mathrm{LD}) \\
\end{array}$ & $\begin{array}{c}\text { TD eLD } \\
\begin{array}{c}\text { Derivatização in situ anidrido } \\
\text { acético }\end{array} \\
\end{array}$ & {$[42]$} \\
\hline Anticonvulsivantes & Plasma (1 mL) & $\begin{array}{l}\text { LC-UV } \\
\text { LOQ: intervalo } \\
\text { terapêutico } \\
\end{array}$ & LD & [43] \\
\hline
\end{tabular}




\subsubsection{Aplicações ambientais recentes}

Uma revisão recente mostra referência de 39 artigos sobre aplicação em análises ambientais publicados principalmente em poluentes ambientais como pesticidas, PAHs (Hidrocarbonetos Poliaromáticos), VOCs (Compostos Orgânicos Voláteis) e outros em amostras de água. Uma busca realizada no período após este trabalho de revisão mostra publicações com a aplicação da SBSE em poluentes tradicionais e outros poluentes específicos, na Tabela 2.2 podem ser observados alguns destes trabalhos.

\subsubsection{Aplicações alimentos recentes}

Na revisão de SBSE publicada por David [19] existem exemplos de aplicação em análises alimentícias com 56 referências e Ridgway et al [52] mostram técnicas de preparo de amostras para determinação de traços de resíduos e contaminantes em alimentos com 6 artigos de referência em que utilizam SBSE. Alguns exemplos destes trabalhos podem ser observados na Tabela 2.3 . 
Tabela 2.2. Algumas aplicações ambientais recentes.

\begin{tabular}{|c|c|c|c|c|}
\hline $\begin{array}{c}\text { Analito } \\
\text { (matriz) }\end{array}$ & Modo de extração & LOQ ou LOD & Observações & Referências \\
\hline Benzofenona (BP) & DI (PDMS) & $\begin{array}{c}\text { GC-MS } \\
\text { (LOD: } 0,5-2 \text { ng.L-1) }\end{array}$ & Derivatização in situ, TD & [44] \\
\hline 80 pesticidas & DI (PDMS) & $\begin{array}{c}\text { GC-MS } \\
\text { (LOD: } 2,1-74 \text { ng.L-1) }\end{array}$ & $\mathrm{TD}$ & [45] \\
\hline 6 Fenóis polares & $\begin{array}{c}\text { DI (VE: } \\
\text { vinilpiridina- } \\
\text { etileno } \\
\text { dimetilacrilato) }\end{array}$ & $\begin{array}{c}\text { HPLC/DAD } \\
\text { (LOD: } 0,98-2,20 \mu \mathrm{g} \cdot \mathrm{L}^{-1} \text { ) }\end{array}$ & LD & [46] \\
\hline Triclosan & DI (PDMS) & $\begin{array}{c}\text { LC/ DAD } \\
\text { (LOD: } 0.1 \text { g.L.-1) }\end{array}$ & LD & [47] \\
\hline Filtros solares orgânicos & DI (PDMS) & $\begin{array}{c}\text { GC-MS } \\
\text { (LOD: } 0.2-63 \text { ng. } \text { L }^{-1} \text { ) }\end{array}$ & TD & [48] \\
\hline Hormônios & DI (PDMS) & $\begin{array}{c}\text { GC-MS } \\
\text { (LOD: } \\
\text { Amostras sólidas: } 0,02 \\
\text { ng.g-1 } \\
\text { água: } 2 \text { ng.L-1) } \\
\end{array}$ & $\mathrm{TD}$ & [49] \\
\hline Repelente de insetos & DI (PDMS) & $\begin{array}{c}\text { GC-MS } \\
\text { (LOD: } 0.5-150 \mathrm{ng} / \mathrm{L}^{-1} \text { ) }\end{array}$ & TD & [50] \\
\hline 15 PAHs & DI (PDMS) & $\begin{array}{c}\text { HPLC- detector } \\
\text { fluorescência (FLD) } \\
\text { (LOD: } 0,2-1,5 \mathrm{ng} \mathrm{L}^{-1} \text { ) }\end{array}$ & LD & {$[51]$} \\
\hline
\end{tabular}


Tabela 2.3. Algumas aplicações em alimentos recentes.

\begin{tabular}{|c|c|c|c|c|}
\hline $\begin{array}{l}\text { Analito } \\
\text { (matriz) }\end{array}$ & Modo de extração & LOQ ou LOD & Observações & Referências \\
\hline Pesticidas (Vinagres) & $\begin{array}{c}\text { DI } \\
\text { (PDMS) }\end{array}$ & $\begin{array}{c}\text { GC-MS } \\
\left.\text { (LOD: } 0.13-0.81 \mu \mathrm{g} . \mathrm{L}^{-1}\right)\end{array}$ & TD-PTV & [53] \\
\hline $\begin{array}{l}\text { Fração volátil (Pesto } \\
\text { genovese) }\end{array}$ & $\begin{array}{l}\text { HSSE } \\
\text { (PDMS) }\end{array}$ & GC-MS & TD & [54] \\
\hline $\begin{array}{l}\text { Monoterpenos e } \\
\text { Norisoprenoides } \\
\text { (Framboesa) }\end{array}$ & $\begin{array}{c}\text { DI } \\
\text { (PDMS) }\end{array}$ & MDGC-MS & TD & [55] \\
\hline $\begin{array}{l}\text { Resveratrol (Vinho, suco e } \\
\text { mosto) }\end{array}$ & $\begin{array}{c}\text { DI } \\
\text { (PDMS) }\end{array}$ & $\begin{array}{c}\text { LC-UV } \\
\text { (LOD: } 0.1 \text { ng.mL-1) }\end{array}$ & $\begin{array}{l}\text { LD (Derivatização in situ } \\
\text { anidrido acético) }\end{array}$ & [56] \\
\hline $\begin{array}{l}\text { Fungicidas (Vinhos e } \\
\text { sucos) }\end{array}$ & $\begin{array}{c}\text { DI } \\
\text { (PDMS) }\end{array}$ & $\begin{array}{c}\text { UPLC } \\
\text { (LOD: } 0.05-2.5 \text { ng.mL-1) }\end{array}$ & LD & [57] \\
\hline Fungicidas (Vinho tinto) & $\begin{array}{c}\text { DI } \\
(\mathrm{PDMS})\end{array}$ & $\begin{array}{c}\text { GC-MS } \\
\text { (LOD: } 0.01-2.03 \mathrm{mg} . \mathrm{L}^{-1} \text { ) }\end{array}$ & $\mathrm{TD}$ & [58] \\
\hline Ácidos graxos (Cerveja) & $\begin{array}{c}\text { DI } \\
\text { (PDMS) }\end{array}$ & GC-FID & LD & [59] \\
\hline Revisão - alimentos & - & - & 6 trabalhos & [52] \\
\hline Revisão - SBSE & - & - & 56 trabalhos & [33] \\
\hline
\end{tabular}




\subsection{DESENVOLVIMENTO “IN-HOUSE” DAS BARRAS}

As primeiras barras de SBSE, desenvolvidas no Laboratório de Cromatografia, foram produzidas durante a dissertação de mestrado com o título de “Desenvolvimento, avaliação e aplicações de novas fases para extração por sorção em barra de agitação (SBSE)" desenvolvida por Nogueira [60]. Após testes iniciais não eficientes no procedimento das barras desenvolveu-se um molde de teflon cilíndrico bipartido, no qual o recobrimento era feito diretamente em uma barra de aço magnetizada. Assim, o problema de fragilidade encontrada com o capilar de sílica inicialmente utilizado foi eliminado. A Figura 2.4 ilustra o projeto do suporte e molde desenvolvidos. Em 2.4.a. ilustra o suporte utiliza o suporte para prender a barra de aço para recobrimento; 2.4.b. corte lateral do molde, fixação da barra; 2.4.c. vista superior do molde, mostrando o encaixe das duas faces do cilindro, os quais fixam a barra magnética em seu interior. Na posição onde se encontra a barra, existe um espaço vazio no molde, preenchido com polímero; 2.4.d. molde fechado, utilizando para tal o suporte de aço.

As barras produzidas "in-house" descritas no trabalho de Nogueira [60] apresentou resultados eficientes na extração de anticonvulsivantes, antidepressivos e anti-helmínticos em amostras biológicas, assim como seletividade algumas vezes superior à da barra comercial devido ao uso de novas fases poliméricas. Além da relevância científica do trabalho este também apresentou relevância econômica. As barras produzidas comercialmente pela empresa alemã Gerstel em um kit contendo 10 unidades custam em torno de $\mathrm{R} \$ 10.000,00$ e, embora este custo seja elevado, a 
durabilidade destas é pequena. Uma barra "in-house" com recobrimento de PDMS tem um custo bastante inferior, em torno de $\mathrm{R} \$ 20,00$ a unidade.

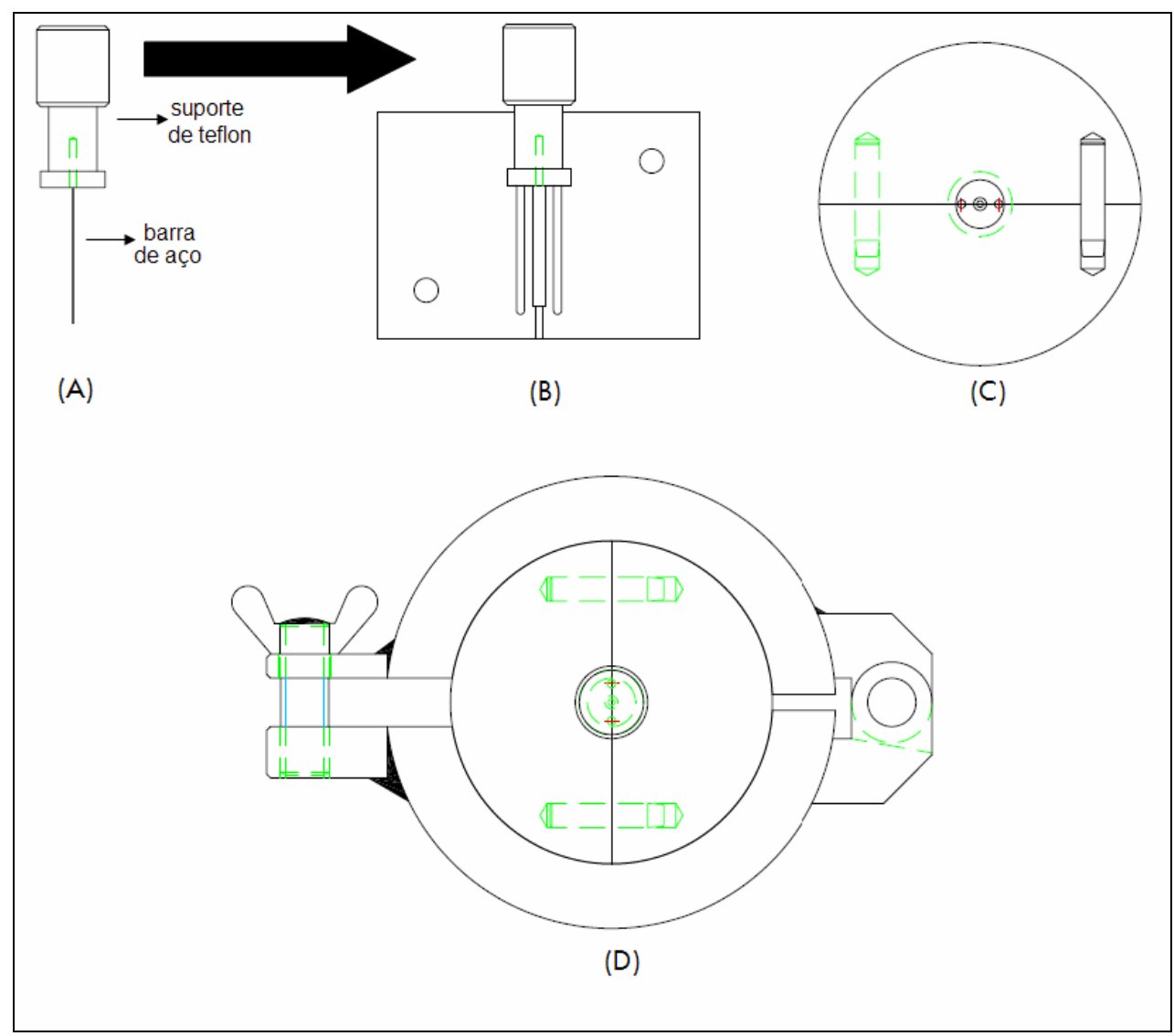

Figura 2.4. Esquema do molde utilizado para o desenvolvimento das barras "in-house". (Extraído de [60])

\subsection{PLANEJAMENTO DE EXPERIMENTOS}

O número de dados na pesquisa vem aumentando progressivamente nos últimos anos devido à instrumentação que permite uma resposta mais rápida. Assim, a aplicação de ferramentas estatísticas é de fundamental importância, principalmente para explorar e compreender os dados adquiridos. 
O Planejamento de Experimentos (em inglês Design of Experiments, DOE) é uma técnica utilizada para se planejar experimentos, ou seja, para definir quais dados, em que quantidade e em que condições devem ser coletados durante um determinado experimento, buscando, basicamente, satisfazer dois grandes objetivos: a maior precisão estatística possível na resposta e o menor custo.

Para executar um planejamento fatorial, deve-se começar especificando-se os níveis em que cada fator deve ser estudado, isto é, os valores que serão atribuídos aos fatores para realizar os experimentos. Normalmente são atribuídos valores para os níveis baixos (-) e valores para os níveis altos (+), fazendo-se todas as combinações possíveis como, por exemplo, no caso de otimização da temperatura de um experimento, onde as temperaturas estudadas estarão em um intervalo de 20 a $60^{\circ} \mathrm{C}$. Neste caso, a menor temperatura de $20^{\circ} \mathrm{C}$ será o nível baixo e a $60^{\circ} \mathrm{C}$ o nível alto.

Em geral, se houver $n_{1}$ níveis do fator $1, n_{2}$ do fator $2 \ldots$. e $n_{k}$ do fator $k$, o planejamento será um fatorial $n_{1} \times n_{2} \times n_{k}$. Para $k$ fatores, isto é, $k$ variáveis, um planejamento completo de dois níveis exige a realização de $2 \times 2 \times 2 \times 2 \times \ldots . . \times 2=2^{k}$ ensaios diferentes, sendo por isso chamado de planejamento fatorial. A vantagem do planejamento fatorial completo é que se podem estimar efeitos principais e todos os efeitos de interação de todas as variáveis nas repostas. A lista dessas combinações é chamada de matriz de planejamento [61-68].

Durante o trabalho foi empregado planejamento fatorial fracionado $\left(2^{4-1}\right)$ com objetivo de otimizar os parâmetros da extração por SBSE, variando-se as condições de tempo de extração (1 e 4 horas), temperatura (60 e $\left.85^{\circ} \mathrm{C}\right)$, concentração de sal (0 e $10 \%$ de $\mathrm{NaCl}$ ) e tempo de dessorção da barra de SBSE em ultra-som (5 e $20 \mathrm{~min})$. O 
software Statistica 6.0 foi utilizado para construção do modelo e este foi avaliado por ANOVA. A Tabela 2.4 apresenta o esquema de planejamento realizado.

Tabela 2.4. Planejamento Fatorial fracionado $\left(2^{4-1}\right)$ usado para otimizar as extrações por SBSE.

\begin{tabular}{|c|c|c|c|c|}
\hline Variáveis & \multicolumn{2}{|c|}{ Nível Baixo (-) } & \multicolumn{2}{|c|}{ Nível Alto (+) } \\
\hline Tempo de extração (h) & \multicolumn{2}{|c|}{1} & \multicolumn{2}{|c|}{4} \\
\hline Temperatura $\left({ }^{\circ} \mathrm{C}\right)$ & \multicolumn{2}{|c|}{60} & \multicolumn{2}{|c|}{85} \\
\hline $\begin{array}{c}\text { Força Iônica } \\
(\% \mathrm{NaCl})\end{array}$ & \multicolumn{2}{|c|}{0} & \multicolumn{2}{|c|}{10} \\
\hline Tempo de dessorção (min) & \multicolumn{2}{|c|}{5} & \multicolumn{2}{|c|}{20} \\
\hline Experimento & $\begin{array}{l}\text { Tempo de } \\
\text { Extração }\end{array}$ & Temperatura & $\begin{array}{c}\text { Força } \\
\text { Iônica }\end{array}$ & $\begin{array}{l}\text { Tempo de } \\
\text { dessorção }\end{array}$ \\
\hline 1 & - & - & - & - \\
\hline 2 & - & - & + & + \\
\hline 3 & - & + & - & + \\
\hline 4 & + & - & - & + \\
\hline 5 & - & + & + & - \\
\hline 6 & + & + & - & - \\
\hline 7 & + & - & + & - \\
\hline 8 & + & + & + & + \\
\hline
\end{tabular}




\section{OBJETIVOS}

* Utilizar um molde de Teflon para preparo de barras de SBSE “in-house”.

* Desenvolver barras para SBSE “in-house" utilizando o polímero polidimetilsiloxano (PDMS) como fase.

Aplicar a barra desenvolvida e otimizá-la para extração de 13 pesticidas organoclorados $(\alpha \mathrm{HCH}, \beta \mathrm{HCH}, \gamma \mathrm{HCH}, \Delta \mathrm{HCH}$, heptacloro, aldrin, heptacloro epóxido, $\alpha$ endosulfan, DDE, dieldrin, endrin, DDD e DDT) em água.

Validar a barra desenvolvida avaliando os parâmetros: Linearidade; Precisão; Exatidão (Recuperação); Limite de Detecção e Limite de Quantificação. 


\section{PARTE EXPERIMENTAL}

\subsection{PADRÕES E REAGENTES}

Os padrões de pesticidas organoclorados (pureza $>98 \%$ ) foram obtidos da Supelco, (Bellefonte, PA, EUA). Os solventes acetonitrila, tolueno, acetato de etila, metanol e diclorometano (grau analítico) foram obtidos da Mallinckrodt (Phillipsbourg, NJ, USA). Cloreto de sódio foi obtido da Merck (Darmstadt, Alemanha). O polímero PDMS Sylgard 184 e seu agente de cura foram obtidos da Dow Corning Corporation (Midland, USA).

\subsection{EQUIPAMENTOS E MATERIAIS UTILIZADOS}

- Lavadora Ultra-sônica, Ultra Cleaner Unique

Balança analítica modelo BL 210S, Sartorius, EUA

Sistema de purificação de água modelo Milli-Q, Millipore, EUA

Balões volumétricos de 5, 10, 50 mL, Pyrex, EUA

Agitador magnético, Scientific, EUA

Banho de água, Quimis

\subsection{MÉTODO}

\subsubsection{Preparo dos padrões analíticos}

Inicialmente foi preparada uma solução estoque de OCPs com uma concentração de $100 \mathrm{mg} . \mathrm{L}^{-1}$. Esta solução foi diluída para $10 \mathrm{mg} . \mathrm{L}^{-1}$ e a partir desta foram preparadas as soluções para fortificação das amostras e desenvolvimento do método cromatográfico. 


\subsubsection{Otimização das condições cromatográficas}

Para as condições cromatográficas (utilizando o equipamento GC-MS Shimadzu QP 5000), buscando uma maior sensibilidade para identificação de 13 pesticidas organoclorados, foi utilizada uma mistura de solução padrão com os pesticidas de interesse, a qual foi injetada no cromatógrafo. Os compostos foram analisados nas seguintes condições:

Detector Volts: $1,85 \mathrm{kV}$

Sampling Rate: 0,2

Forma de aquisição de íons: Modo SIM programando a aquisição de três íons, recomendados pelo método 8270D da EPA (EPA Method 8270d, 1998) em uma janela de tempo referente ao tempo de eluição de cada composto.

Quanto aos demais parâmetros de análise, os melhores resultados foram obtidos nas seguintes condições:

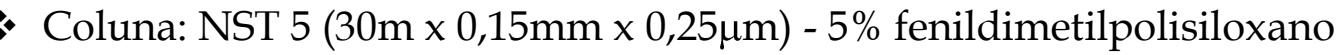

Modo injeção: splitless (5 minutos)

Volume injetado: $2,0 \mu \mathrm{L}$.

Temperatura da coluna:

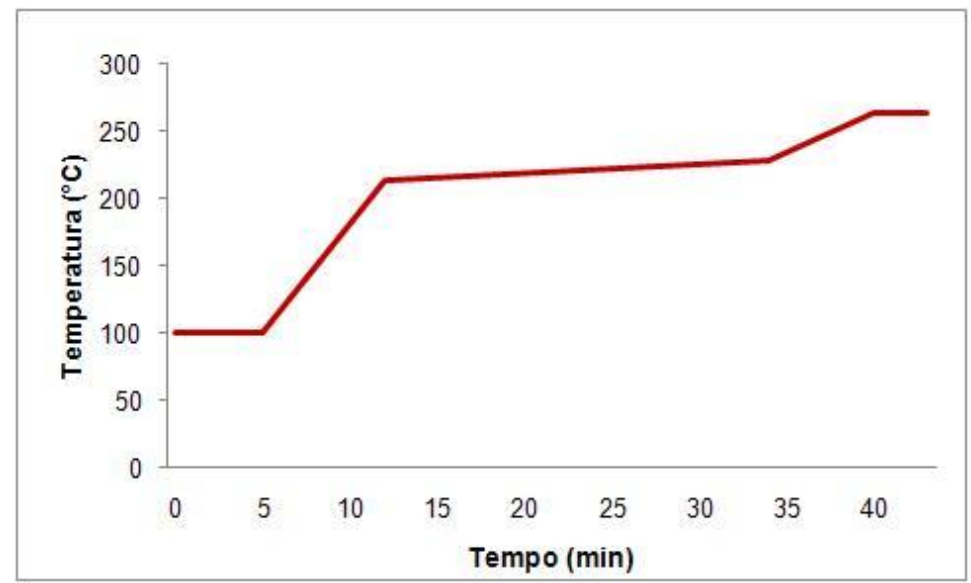


Gás de arraste: He (1,1 mL.min $\left.{ }^{-1}\right)$

Velocidade Linear: 38,6 mL.min ${ }^{-1}$

Temperatura do injetor: $270^{\circ} \mathrm{C}$

Temperatura da interface: $280^{\circ} \mathrm{C}$

Modo ionização: impacto eletrônico $(70 \mathrm{eV})$

Início do tempo de aquisição: 9,1 min

Solvent cut time: 9,0 min

Os íons monitorados, tempos de retenção e log de $\mathrm{K}_{\mathrm{o} / w}$ de cada composto são apresentados na Tabela 2.5 .

Tabela 2.5. Coeficientes de partição octanol-água $\left(\log \mathrm{k}_{\mathrm{O} / \mathrm{w}}\right)$, íons selecionados $(\mathrm{m} / \mathrm{z})$ e respectivos tempos de retenção $\left(t_{R}\right)$ de cada analito. Os íons foram selecionados de acordo com a inspeção dos fragmentogramas.

\begin{tabular}{|c|c|c|c|}
\hline Analito & $\log \mathrm{k}_{\mathrm{O} / \mathrm{w}^{\mathrm{a}}}$ & $m / z$ & $t_{R}, \min$ \\
\hline$\alpha \mathrm{BHC}$ & 4,26 & $183 ; 181 ; 109$ & 16,15 \\
\hline$\beta \mathrm{BHC}$ & 3,68 & $183 ; 181 ; 109$ & 17,01 \\
\hline ү BHC & 4,26 & $183 ; 181 ; 109$ & 17,33 \\
\hline$\triangle \mathrm{BHC}$ & 3,68 & $183 ; 181 ; 109$ & 18,14 \\
\hline Heptacloro & 5,86 & $100 ; 272 ; 274$ & 20,73 \\
\hline Aldrin & 6,75 & $66 ; 263 ; 220$ & 22,82 \\
\hline Heptacloro Epóxido & 4,56 & $353 ; 355 ; 351$ & 25,51 \\
\hline$\alpha$ Endosulfan & 3,50 & $195 ; 339 ; 341$ & 28,47 \\
\hline DDE & 6,00 & $246 ; 248 ; 176$ & 30,33 \\
\hline Dieldrin & 5,45 & 79;263;279 & 30,88 \\
\hline Endrin & 5,45 & $263 ; 82 ; 81$ & 32,99 \\
\hline DDD & 5,87 & $235 ; 237 ; 165$ & 34,59 \\
\hline DDT & 6,79 & $235 ; 237 ; 165$ & 39,05 \\
\hline
\end{tabular}

a Referência [69]. 


\subsubsection{Preparo das barras de SBSE}

Para o preparo das barras de SBSE utilizou-se um molde de Teflon desenvolvido (Figura 2.5) em uma oficina de ferramentaria, para recobrir uma barra magnética com PDMS, e para esta ser utilizada durante o processo de extração. $\mathrm{O}$ PDMS obtido comercialmente consiste de uma fase viscosa e seu agente de cura. Para formar o polímero na consistência desejada para o prepare do recobrimento das barras de SBSE foi realizada uma mistura de ambos na proporção 10:1 (m/m). Aproximadamente $0,3 \mathrm{~g}$ da fase viscosa foi vigorosamente misturada com $0,03 \mathrm{~g}$ do agente de cura em um frasco de vidro. A mistura foi levada ao vácuo durante 15 minutos para eliminar as bolhas formadas na homogeneização. O polímero foi então adicionado nas cavidades do molde de Teflon desenvolvido e em seguida adicionouse a barra magnética. $\mathrm{O}$ molde foi fechado, pressionado com um suporte de aço, com ajuste manual, para evitar vazamento. O conjunto foi levado ao forno durante 1 hora a temperatura de $60^{\circ} \mathrm{C}$.

O molde foi então resfriado a temperatura ambiente e a barra foi retirada e voltou novamente ao forno, sem o molde, nas seguintes condições: $40{ }^{\circ} \mathrm{C}$ durante 30 minutos, $10^{\circ} \mathrm{C} \cdot \mathrm{min}^{-1}$ até $250^{\circ} \mathrm{C}$ durante 2 horas.

As barras foram recobertas in-house com um filme fino de PDMS com o objetivo de serem aplicadas no modo headspace, conforme o trabalho desenvolvido [70]. A camada de PDMS tinha um volume de $35 \mu \mathrm{L}$. As extrações foram realizadas através da suspensão da barra no headspace de um frasco de $20 \mathrm{~mL}$ contendo água fortificada com pesticidas organoclorados e lacrado com um septo de PTFE e lacre de alumínio. 

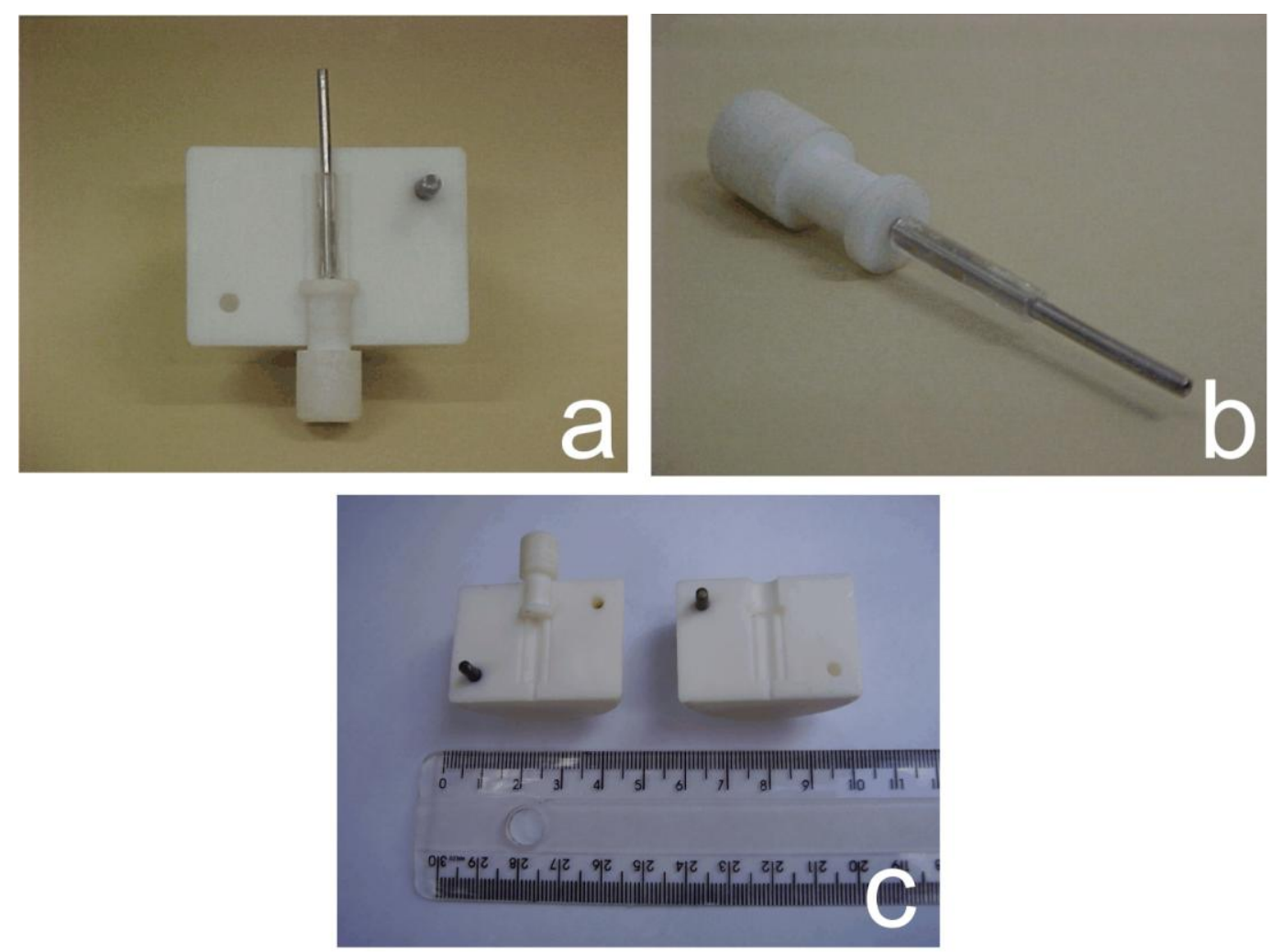

Figura 2.5. a) Frasco de "headspace" e barra de SBSE utilizados na extração. b) Serpentina aquecida e agitador magnético onde o frasco de extração é colocado. Extraído de [13].

A Figura 2.5 ilustra uma barra de aço inox e um molde de Teflon utilizado no procedimento de preparo das barras; a Figura 2.5b a barra já recoberta enquanto a Figura 2.5c mostra as duas partes do molde e uma régua para comparar as suas dimensões.

\subsubsection{Validação}

O estudo de validação foi realizado utilizando os parâmetros descritos na seção 3.3.4 do Capítulo 1. 


\section{RESULTADOS}

\subsection{BARRAS DE SBSE}

As barras obtidas recobertas "in-house" foram ilustradas na Figura 2.5 anterior.

\subsection{OTIMIZAÇÃO DO PROCESSO DE EXTRAÇÃO}

Com as condições cromatográficas otimizadas, iniciou-se a otimização do processo de extração, utilizando a técnica de SBSE (Stir Bar Sorptive Extraction) em modo Headspace (HS-SBSE), para posterior análise em GC-MS. Diversos experimentos foram realizados variando os parâmetros para a otimização do processo de extração.

Utilizou-se uma matriz isenta de organoclorados para ser fortificada e, a seguir, analisada. Amostras de água foram fortificadas com padrão analítico de organoclorados. Para isso adicionou-se uma solução contendo o padrão em um frasco de "headspace", e o excesso de solvente foi evaporado com vapor de nitrogênio, em condições controladas. Em seguida adicionou-se $10 \mathrm{~mL}$ de água de milli-Q. A barra extratora de SBSE foi suportada por uma garrinha ("jacaré”) e um septo de silicone. Esta foi colocada na parte superior do frasco, acima da solução. Em seguida vedou-se o frasco com tampa de alumínio utilizando alicate apropriado e este foi colocado dentro de uma serpentina, em banho aquecido e sob agitação constante (600 rpm), durante os períodos de 1 hora.

Após a extração, a barra de SBSE foi retirada do frasco de headspace e colocada dentro de um cilindro de um pequeno frasco de amostra. Adicionou-se 
$200 \mu \mathrm{L}$ de acetonitrila e colocou-se no ultra-som por um período 20 minutos. Após este período, o frasco foi retirado do ultra-som, a barra de SBSE foi removida e a solução analisada no CG-MS.

\subsection{PLANEJAMENTO EXPERIMENTAL}

Após a otimização do sistema a ser utilizado, a etapa seguinte consistiu no estudo da influência das variáveis no resultado. Inicialmente, um estudo univariado para verificar a influência dos efeitos da temperatura, tempo de extração e tempo de dessorção foi realizado para obtenção das condições mais apropriadas. Para a temperatura foram testadas as extrações a $70,75,80,85^{\circ} \mathrm{C}$, e o resultado avaliado com a soma das áreas (Figura 2.6)

Selecionou-se a temperatura de $85^{\circ} \mathrm{C}$ como melhor resultado e, assim, foi construída uma curva para avaliar a cinética de extração dos compostos organoclorados nos tempos de 1, 2, 3 e 4 horas, a fim de avaliar o tempo necessário para que o equilíbrio fosse atingido. A Figura 2.7 apresenta a curva cinética de extração, onde se pode perceber que o tempo de 2 horas foi suficiente para se atingir o equilíbrio. A Figura 2.8 mostra o efeito do tempo de dessorção dos analitos após a extração destes na barra, o melhor resultado é obtido após 15 minutos de dessorção nas condições empregadas. 


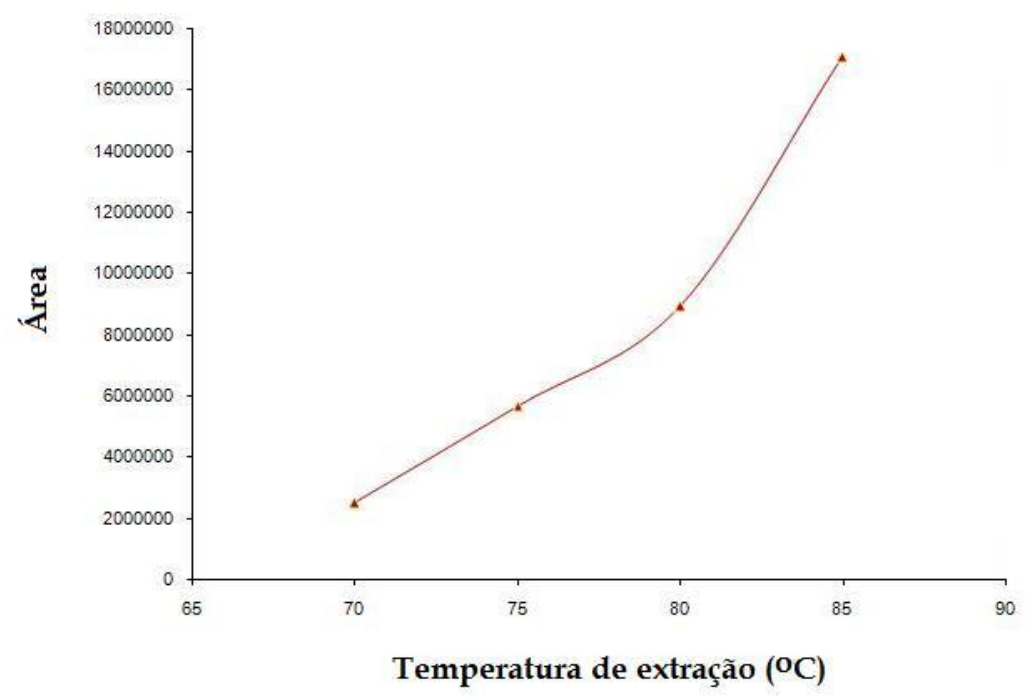

Figura 2.6. Efeito da temperatura do banho de aquecimento utilizado na extração.

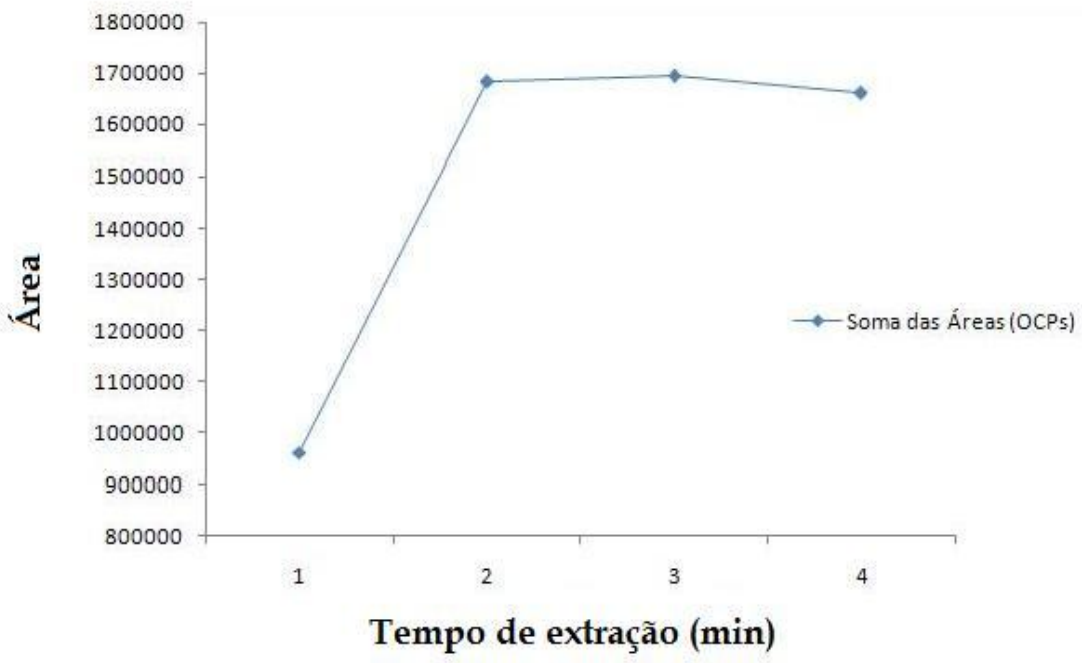

Figura 2.7. Curva cinética de extração para pesticidas organoclorados utilizando HS-SBSE (PDMS), $85^{\circ} \mathrm{C}$. 


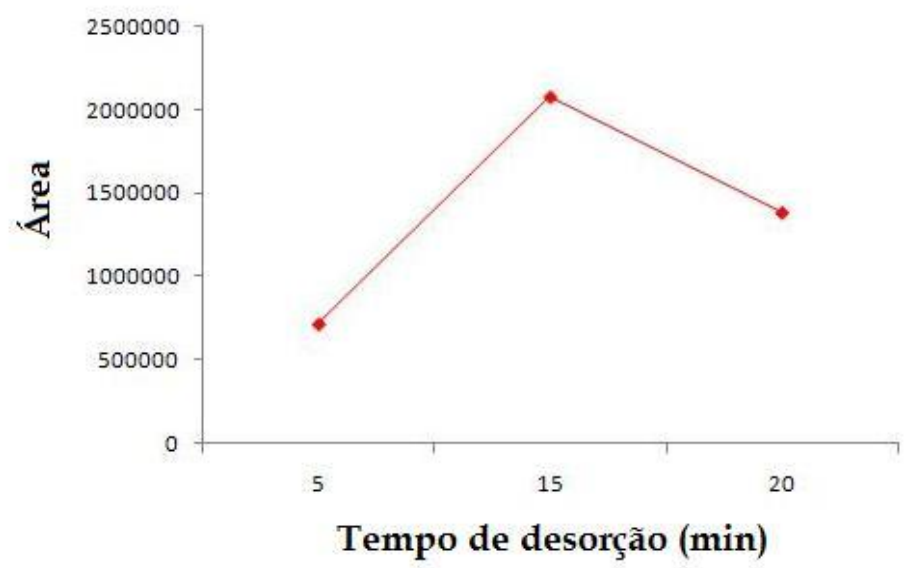

Figura 2.8. Efeito do tempo na dessorção da barra de SBSE.

O planejamento experimental foi realizado incluindo os seguintes parâmetros: tempo de extração ( 60 e $240 \mathrm{~min}$ ), temperatura de extração (60 e 85 $\mathrm{C}$ ), adição de sal (0 e 10\%) e tempo de dessorção (5 e 20min). Conforme detalhado na Tabela 2.6 um planejamento fatorial fracionado $2^{4-1}$ foi utilizado para determinar a influência dos fatores selecionados e suas interações. As respostas obtidas pelo planejamento proposto foram analisadas utilizando o software Statistica 6.0. A resposta, baseada na soma das áreas dos picos, é um dos mais úteis parâmetros para a otimização. A análise de variância (ANOVA) foi realizada para determinar se os fatores estudados eram significativos no desempenho do sistema HS-SBSE.

Na Figura 2.9 é apresentado o diagrama de Pareto com a influência de cada parâmetro avaliado e suas interações sobre a quantidade extraída. A linha tracejada indica a região acima da qual os efeitos são significativos (com limite de confiança de 95\%). Neste tipo de gráfico quanto maior a barra, maior é a influência (positiva ou negativa) na resposta de interesse. 
Tabela 2.6. Resultados dos experimentos do Planejamento Fatorial fracionado (24-1).

\begin{tabular}{lcccccccc}
\hline \multicolumn{1}{c}{ Organoclorados } & $\mathbf{1}$ & $\mathbf{2}$ & $\mathbf{3}$ & $\mathbf{4}$ & $\mathbf{5}$ & $\mathbf{6}$ & $\mathbf{7}$ & $\mathbf{8}$ \\
\hline Alfa BHC & 474599 & 2554358 & 1211279 & 2204740 & 2384648 & 1804007 & 1740963 & 2412913 \\
Beta BHC & 31272 & 214642 & 118409 & 249091 & 287148 & 323723 & 283744 & 837506 \\
Gama BHC & 190166 & 1168025 & 556807 & 1140015 & 1237902 & 1066416 & 1080674 & 1546247 \\
Delta BHC & 17570 & 162279 & 102181 & 212407 & 234967 & 295225 & 249805 & 597834 \\
Heptacloro & 859054 & 1745926 & 937853 & 2592653 & 1492234 & 1432207 & 1126377 & 1584547 \\
Aldrin & 1229741 & 1654368 & 2730099 & 3805004 & 2350417 & 4029351 & 1603440 & 5093559 \\
Heptacloro epóxido & 381163 & 1431577 & 1001087 & 1494346 & 1479399 & 1933865 & 831432 & 2609538 \\
Alfa endosulfan & 91498 & 427230 & 275860 & 464832 & 423708 & 524291 & 255454 & 660068 \\
DDE & 619785 & 926571 & 2390795 & 2686190 & 1664590 & 5775753 & 927178 & 5493943 \\
Dieldrin & 623778 & 2202671 & 1770619 & 2492270 & 2533561 & 3792759 & 1622064 & 5124245 \\
Endrin & 34930 & 253933 & 185099 & 365075 & 362670 & 727438 & 215404 & 1220990 \\
DDD & 132187 & 911913 & 1704580 & 2136877 & 1927277 & 5864839 & 1087322 & 7028765 \\
DDT & 34077 & 218706 & 706905 & 961026 & 502969 & 3637999 & 192349 & 3789419 \\
\hline
\end{tabular}




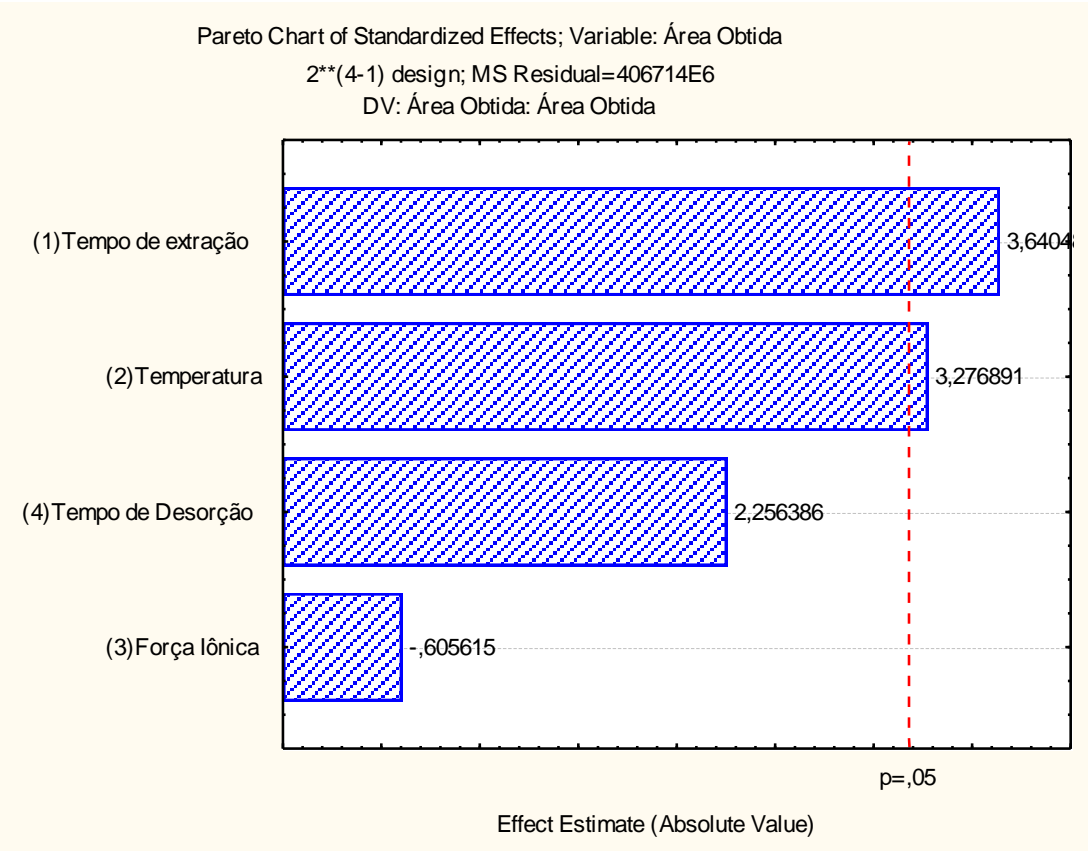

Figura 2.9. Diagrama de Pareto para os efeitos estimados.

O tempo de extração é uma variável que apresenta influência pronunciada na extração. Atua de maneira positiva, ou seja, com o aumento do tempo produz um aumento na extração concordando, assim, com dados da literatura, pois a SBSE baseia-se na partição do analito entre duas fases requerendo tempo necessário para que haja sorção do analito na camada de polímero da barra.

A temperatura também apresenta efeito positivo na extração. $O$ aumento da temperatura atua de dois modos: aumentando a difusão dos analitos e, como conseqüência, aumentando a extração; e diminuindo o coeficiente de partição do analito entre a barra e a matriz, diminuído a extração.

O tempo de dessorção apresenta uma variação positiva sobre a extração, porém segundo o modelo não apresenta influência significativa. 
Já a força iônica é uma variável que apresenta valor negativo, mostrando que o processo de sorção dos compostos não é afetado pela força iônica da solução, ajustada pela adição de sal. Durante a adição de sal na amostra avaliada observou-se uma redução nas áreas dos picos cromatográficos.

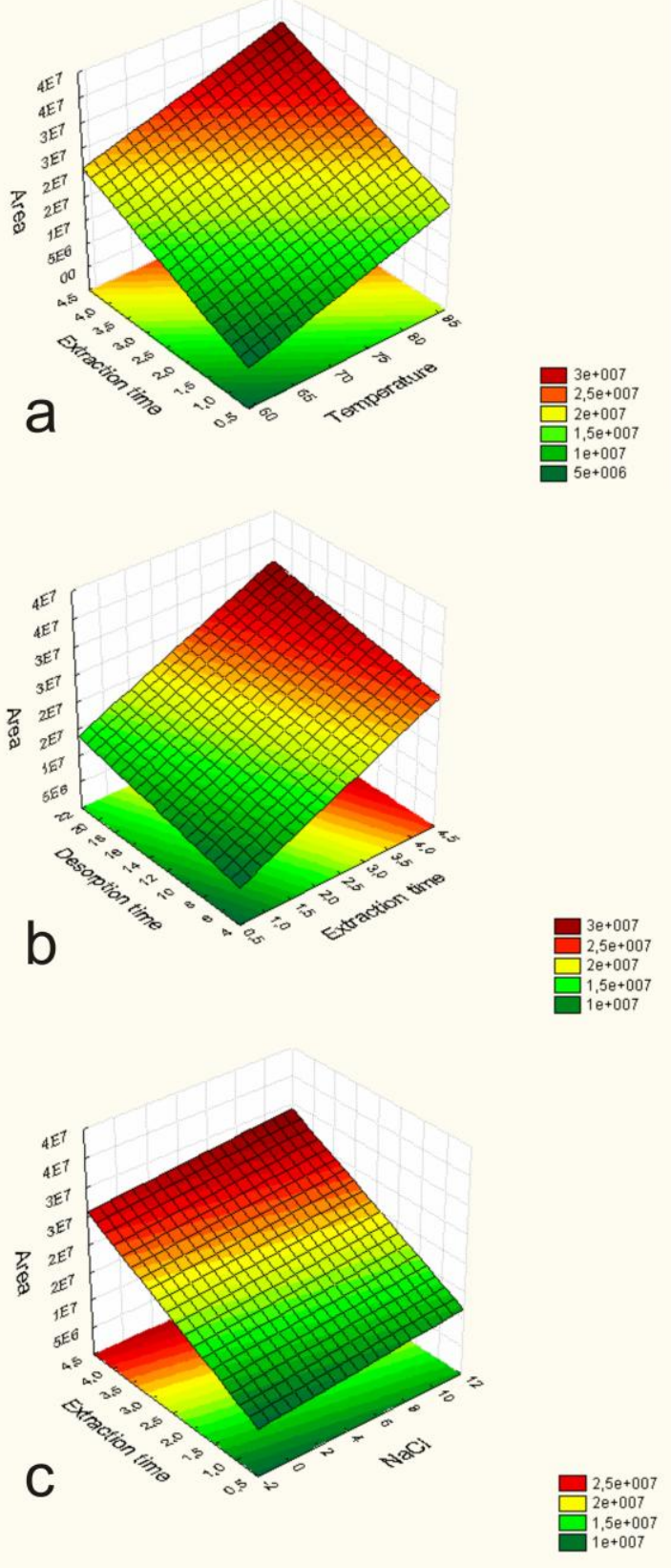

Figura 2.10. Gráficos de superfície de resposta para (a). temperatura de extração $\left({ }^{\circ} \mathrm{C}\right)$ versus tempo de extração (min), (b). tempo de extração (min) versus tempo de dessorção (min), (c). tempo de extração (min) versus força iônica $(\mathrm{NaCl} \%)$. 
A Figura 2.10 mostra um gráfico de superfície tridimensional obtido através da plotagem de diferentes parâmetros. A Figura 2.10a representa o gráfico do tempo de extração versus temperatura de extração. A Figura 2.10 b mostra a superfície de resposta do tempo de extração e dessorção. E a Figura 2.10c mostra o tempo de extração versus força iônica.

Através da análise das superfícies de resposta, as melhores condições, dentro das condições experimentais foram determinadas. Estas condições correspondem a temperatura de extração de $8^{\circ} \mathrm{C}$, tempo de extração e dessorção de 120 e 15 minutos. Em estudos prévios [71-73], condições experimentais específicas têm demonstrado efeito importante no desempenho da SBSE com dessorção líquida (LD) quando utilizada para extração de uma série de compostos em matriz aquosa. Solventes como: metanol, acetonitrila, diclorometano, acetato de etil, tolueno e misturas tolueno: acetonitrila 10:90 e 10:80 foram utilizados para estudo na dessorção. Devido à ampla faixa de polaridade (Tabela 2.7) utilizou-se estes solventes com o objetivo de verificar qual teria melhor capacidade de remoção de pesticidas da barra de SBSE. Metanol mostrou uma capacidade de dessorção bem inferior aos demais solventes testados. Acetato de etila, tolueno e diclorometano embora tenham apresentado uma maior capacidade de dessorção não foram selecionados porque causaram deterioração da fase de PDMS. O solvente acetonitrila apresentou bom resultado, mas inferior ao obtido com tolueno. A partir disso, foram testadas misturas do solvente tolueno e acetonitrila, obtendo assim boa capacidade de remover os compostos da barra sem que essa fosse deteriorada. A mistura de tolueno:acetonitrila 
20:80 apresentou o melhor desempenho de dessorção para a maioria dos pesticidas estudados (Figura 2.11).

Tabela 2.7. Diferentes solventes utilizados na dessorção dos analitos.

\begin{tabular}{ccc}
\hline Solvente & Fórmula & Polaridade \\
\hline Metanol & $\mathrm{MeOH}$ & \\
Acetonitrila & $\mathrm{CH}_{3} \mathrm{CN}$ & \\
Diclorometano & $\mathrm{CH}_{2} \mathrm{Cl}_{2}$ \\
Acetato de etila & $\mathrm{CH}_{3} \mathrm{COOCH}_{2} \mathrm{CH}_{3}$ \\
Tolueno & $\mathrm{C}_{7} \mathrm{H}_{8}$ & \\
& &
\end{tabular}

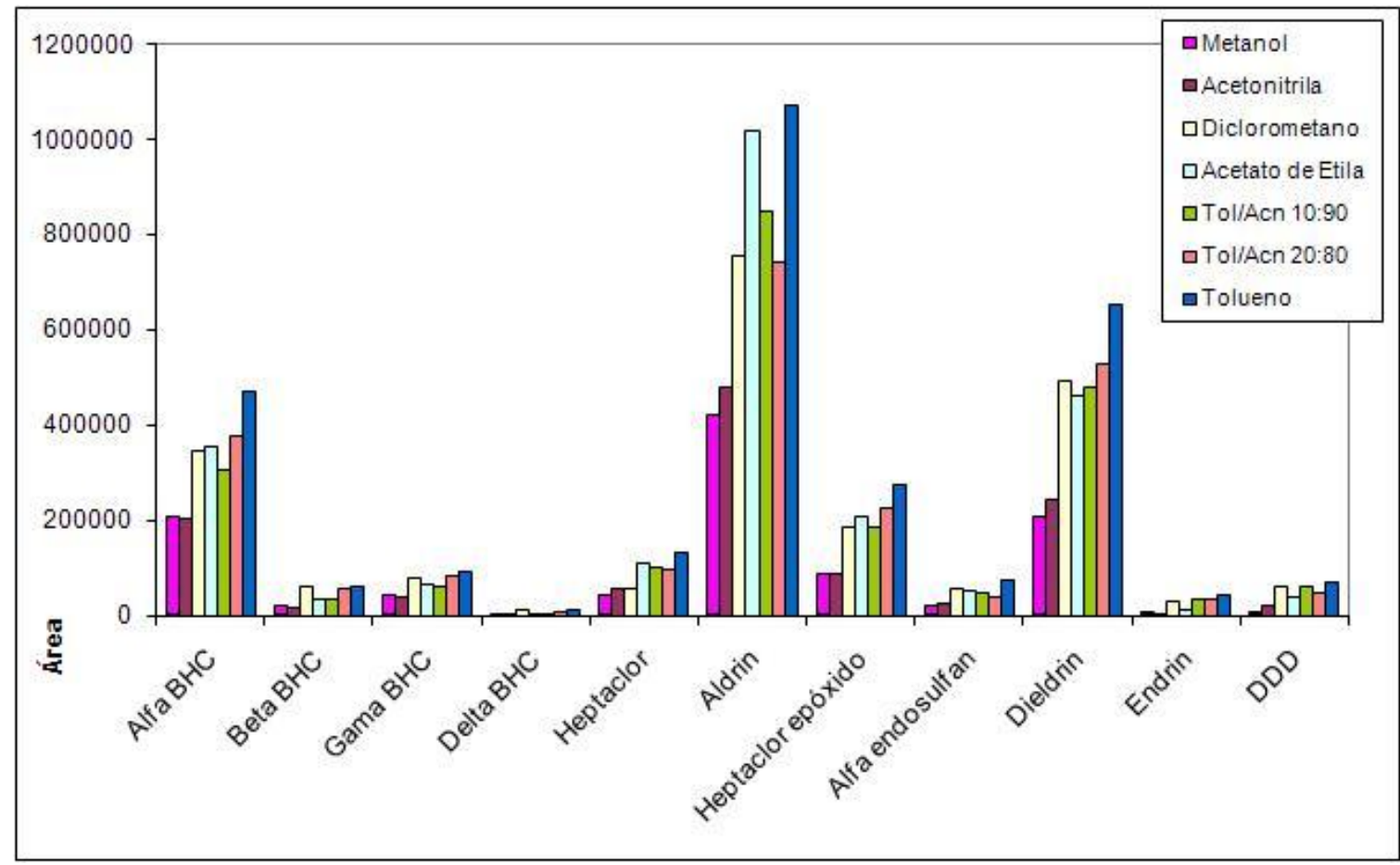

Figura 2.11. Influência de diferentes solventes no processo de dessorção dos analitos.

O uso de barra de SBSE preparadas "in-house" tem a vantagem de diminuir o custo de extração durante avaliação de diferentes solventes utilizados na LD, o que pode causar na maioria das vezes a deterioração da fase de PDMS. 
A quantidade de solvente utilizada no processo de dessorção também precisou ser avaliada. No início utilizou-se $200 \mu \mathrm{L}$ de solvente, mas quando esta quantidade foi aumentada para 1,5 mL, evaporado até secura, e reconstituído à $50 \mu \mathrm{L}$ ocorreu um aumento de área do pico cromatográfico, como pode ser observado na Figura 2.12.
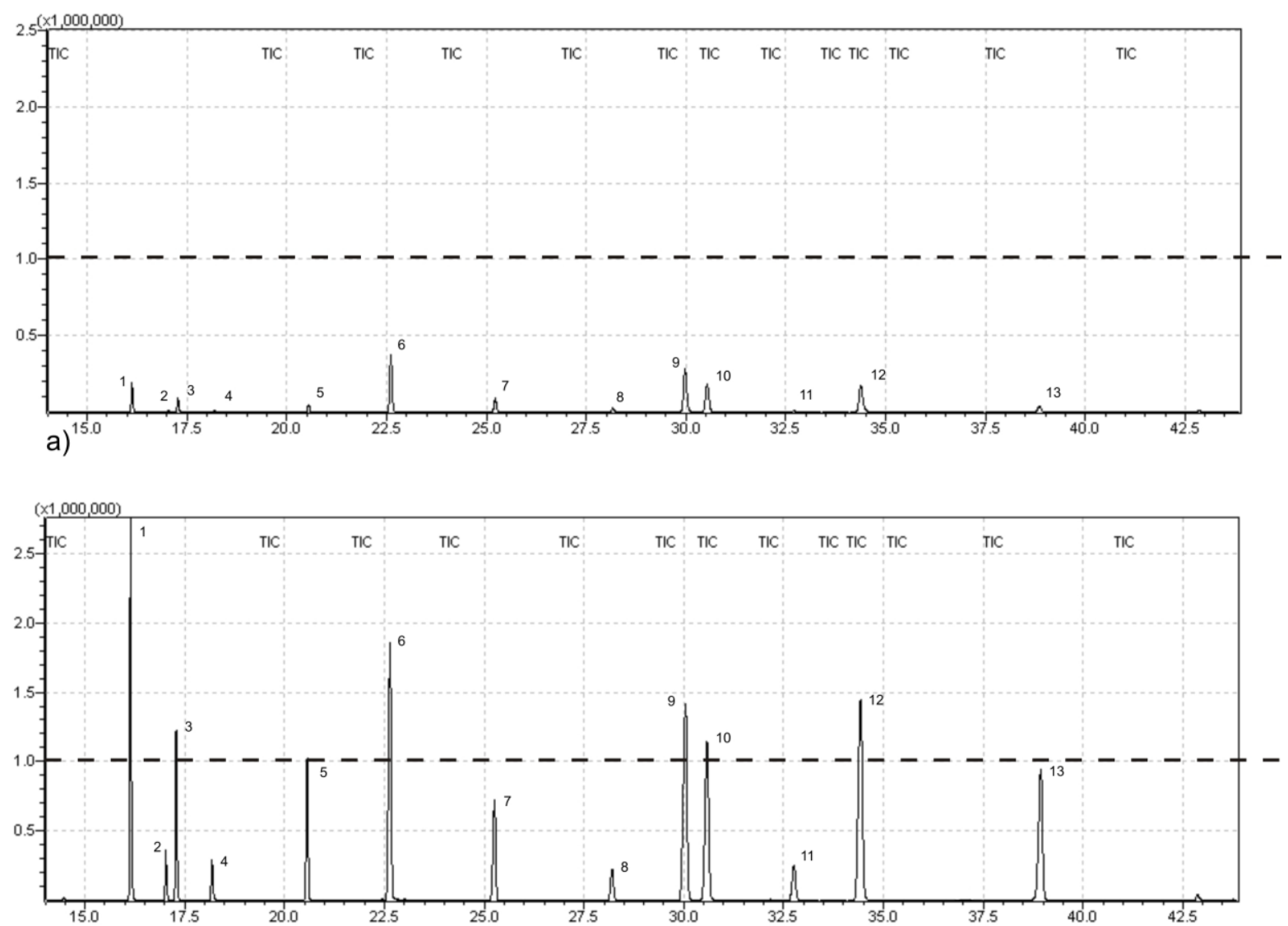

b)

Figura 2.12. Cromatograma representativo obtido por HS-SBSE-GC-MS de uma amostra de água fortificada (100ppb) com 13 pesticidas organoclorados $(1 . \alpha \mathrm{HCH} ; 2 . \beta \mathrm{HCH} ; 3$. $\gamma \mathrm{HCH}$; 4. $\triangle \mathrm{HCH}$; 5. heptacloro; 6. aldrin; 7. heptacloro epóxido; $8 . \alpha$ endosulfan; 9. DDE; 10. dieldrin; 11. endrin; 12. DDD; 13.DDT) a). Cromatograma mostra a dessorção com $200 \mu . \mathrm{L}$ de solvente b). Cromatograma com dessorção em 1,5mL de solvente, evaporado até secura e reconstituído em $50 \mu \mathrm{L}$. Em ambos os casos, $2 \mu \mathrm{L}$ da solução final foram injetados no GC-MS para comparar as áreas obtidas. A linha pontilhada nos cromatogramas foi inserida para permitir uma comparação visual das áreas. 


\subsection{VALIDAÇÃO}

Os parâmetros de limites de detecção, limites de quantificação, precisão e linearidade foram avaliados como descrito no item 3.3.4 do Capítulo 1.

Para determinação da precisão, foi utilizado o cálculo através do coeficiente de variação nos resultados de cinco amostras fortificadas, analisadas nas mesmas condições e no mesmo dia. Os resultados deste estudo estão apresentados na Tabela 2.8. Os valores obtidos foram comparados com os valores especificados pela Agência de Proteção Ambiental dos EUA (EPA), a Agência Nacional de Vigilância Sanitária (ANVISA) e o Ministério da Agricultura, Pecuária e Abastecimento (MAPA).

Tabela 2.8. Resultados da precisão para os 13 pesticidas organoclorados estudados.

\begin{tabular}{lcccc}
\hline \multicolumn{1}{c}{ Analitos } & Precisão & Requisitos EPA & $\begin{array}{c}\text { Requisitos } \\
\text { ANVISA }\end{array}$ & $\begin{array}{c}\text { Requisitos } \\
\text { MAPA }\end{array}$ \\
\hline Alfa BHC & 7,2 & & & \\
Beta BHC & 3,6 & & & \\
Gama BHC & 2,1 & & & \\
Delta BHC & 5,3 & & $<15 \%$ & \\
Heptacloro & 14,8 & & & \\
Aldrin & 6,5 & $<15 \%$ & & \\
Heptacloro epóxido & 10,7 & & & \\
Alfa endosulfan & 7,8 & & & \\
DDE & 6,0 & & & \\
Dieldrin & 4,9 & & & \\
Endrin & 12,5 & & & \\
DDD & 12,5 & & & \\
DDT & 7,3 & & & \\
\hline
\end{tabular}

Inicialmente, para determinação da linearidade, foram utilizadas as concentrações de 5, 8, 11, 14 e 17 ppb (ng.g-1). Os resultados foram graficados diretamente no programa Excel ${ }^{\mathrm{TM}}$, o qual automaticamente traça a curva, expressa a 
equação da função e o coeficiente de determinação. Os resultados dos coeficientes de determinação encontrados estão na Tabela 2.9.

Tabela 2.9. Resultados da linearidade expressos pelo coeficiente de determinação $\left(\mathrm{r}^{2}\right)$ para os 13 pesticidas organoclorados estudados.

\begin{tabular}{lccc}
\hline Analitos & $\begin{array}{c}\mathbf{r}^{2} \\
\text { encontrado }\end{array}$ & $\begin{array}{c}\text { Requisitos } \\
\text { ANVISA }\end{array}$ & $\begin{array}{c}\text { Recomendações } \\
\text { Lanças }\end{array}$ \\
Alfa BHC & 1,0000 & & \\
Beta BHC & 0,9993 & & \\
Gama BHC & 0,9969 & & \\
Delta BHC & 0,9971 & & \\
Heptacloro & 0,9866 & & \\
Aldrin & 0,9748 & & \\
Heptacloro epóxido & 0,9956 & $>0,98$ & \\
Alfa Endosulfan & 0,9994 & & \\
DDE & 0,9776 & & \\
Dieldrin & 0,9990 & & \\
Endrin & 0,9713 & & \\
DDD & 0,9602 & & \\
DDT & 0,9857 & & \\
\hline
\end{tabular}

O principal objetivo deste trabalho foi o desenvolvimento e aplicação das barras de SBSE produzidas "in-house”. Os limites de detecção e quantificação encontrados (Tabela 2.10) foram limitados pelo modo de injeção e não pela técnica de extração. Existem sistemas específicos de injeção para a técnica de SBSE como o injetor de grande volume (LVI) onde se poderia ter injetado todo o analito e solvente da solução final e também a dessorção térmica (TD) onde os analitos são desorvidos da barra com o aumento da temperatura e todos são diretamente analisados, aumentando assim o LOQ. Neste trabalho os analitos foram desorvidos da barra e concentrados em uma solução final de $50 \mu \mathrm{L}$ de solvente sendo que foi injetado, com seringa convencional de cromatografia, somente $2 \mu \mathrm{L}$ dentro da coluna. Apesar da proposta original do trabalho não ter sido executada na íntegra, assim como a não 
otimização dos limites de deteç̧ão e quantificação, fica claro que os valores podem ser melhorados apenas com modos apropriados de injeção.

De acordo com a teoria da SBSE, os coeficientes de distribuição dos analitos entre a fase de PDMS e a matriz (K $\mathrm{KDMS}_{\mathrm{P} / \mathrm{w}}$ ) estão fortemente correlacionados com o $\mathrm{K}_{\mathrm{o} / \mathrm{w}}$ correspondente. É esperado que pesticidas apolares $\left(\log \mathrm{K}_{\mathrm{o} / \mathrm{w}}>5\right)$ devem ter afinidade significativa em barras com recobrimento polimérico de PDMS. Assumindo um volume de amostragem de $15 \mathrm{~mL}\left(\mathrm{~V}_{\mathrm{w}}\right)$ e o recobrimento da barra desenvolvida de $35 \mu \mathrm{L}$ ( $\mathrm{V}_{\text {SBSE}}$ ), a razão de fase $(\beta)$ pode ser calculada através da fórmula, $b=V_{\mathrm{w}} / \mathrm{V}_{\mathrm{SBSE}}$, e pode ser estabelecida como sendo 428,6 . Utilizando a razão de fase é possível calcular a recuperação teórica correspondente a cada analito (Tabela 2.10). De acordo com a literatura [70] existe uma correspondência entre a recuperação teórica e os valores experimentais; baseado nesta afirmação, pode-se prever que a nova barra, "in-house", atinge resultados satisfatórios de extração.

Tabela 2.10. Dados obtidos de Limites de Detecção (LOD) e Quantificação (LOQ) e Recuperação.

\begin{tabular}{lccc}
\hline Analito & LOD (ng.g- $\mathbf{~}^{-1}$ & LOQ (ng.g-1) & Recuperação (\%) \\
$\alpha$ BHC & 0,02 & 0,07 & 97,7 \\
$\beta$ BHC & 1,59 & 4,76 & 91,8 \\
$\gamma$ BHC & 0,31 & 0,93 & 97,7 \\
$\Delta$ BHC & 0,09 & 0,28 & 99,8 \\
Heptacloro & 0,07 & 0,23 & 99,9 \\
Aldrin & 0,21 & 0,63 & 100 \\
Heptacloro epóxido & 0,26 & 0,77 & 98,8 \\
$\alpha$ Endosulfan & 0,11 & 0,33 & 88,1 \\
DDE & 0,01 & 0,04 & 100 \\
Dieldrin & 0,35 & 1,1 & 99,8 \\
Endrin & 0,58 & 1,73 & 99,8 \\
DDD & 0,38 & 1,13 & 99,9 \\
DDT & 0,3 & 0,9 & 100 \\
\hline
\end{tabular}

a Recuperação teórica baseada no log ko/w (Tabela 2.5) de cada pesticida. 


\section{CONCLUSÕES}

Os resultados mostraram que as barras de SBSE desenvolvidas (in-house) aplicadas no modo headspace, seguidas de dessorção líquida e cromatografia gasosa acoplada à espectrometria de massas, oferecem excelente aplicação para extração de OCPs em amostras de água. É uma técnica que apresenta uma boa relação custo/benefício sendo que o valor da extração é reduzido quando comparado ao da barra comercial. Além disso, o desenvolvimento de barras possui uma vantagem adicional com a possibilidade da utilização de diferentes materiais e espessuras de recobrimento com características específicas adequadas para diferentes tipos de extrações e analitos de interesse. 


\section{REFERÊNCIAS BIBLIOGRÁFICAS}

[1] ZWEIG, G.; ASPELIN, A. L. The role of pesticides in developing countries. In. Formulation of pesticides in developing countries. New York: UNITED NATIONS, 1983. 13p.

[2] ZUIN, V. G. Desenvolvimento de metodologias para a análise de pesticidas em plantas medicinais brasileiras (passiflora L.): métodos convencionais vs.

Modernos. 2001. 248f. Tese (Doutorado em Química Analítica) - Instituto de Química de São Carlos, USP, São Carlos, 2001.

[3] KIDD, H., HARTLEY, D. UK pesticides for farmers and growers. Nottinghan: The Royal Society of Chemistry, 1987. 207p.

[4] HASKELL, P. T. Pesticide application: principles and practice. Oxford: Oxford University Press, 1985. 494p.

[5] CHAU, A.S.Y, AFGHAN, B.K. Analysis of pesticide in water. Boca Raton: CRC Press, 1977. 154p.

[6] FREIRE, R. S., TEIXEIRA, R., KUBOTA, L. T., DURÁN, N., PERALTA-ZAMORA, $P$. New trends for treatment of industrial effluents containing organochloride species. Quím. Nova, v. 23, n. 4, p. 504-511, 2000.

[7] PAWLISZYN, J., ARTHUR, C. L. Solid Phase Microextraction with Thermal Desorption Using Fused Silica Optical Fibers. Anal. Chem., v. 62, p. 2145-2148, 1990.

[8] QUEIROZ, M. E. C., LANCAS, F. M. Practical tips on preparing plasma samples for drug analysis using SPME. LC-GC North America, v. 22, n. 10, p. 970-980, 2004.

[9] TAKESHI, K., LEE, X., SATO, K., SUZUKI, O. Solid-phase microextraction and liquid chromatography/mass spectrometry in drug analysis Anal. Chim. Acta, v. 492, n. 1, p. 49-67, 2003.

[10] QUEIROZ, M. E. C., VALADÃO, C. A. A., FARIAS, A., CARVALHO, D., LANCAS, F. M. Determination of amitraz in canine plasma by solid-phase microextraction-gas chromatography with thermionic specific detection. J. Chromatogr. B, v. 794, p. 337-342, 2003. 
[11] QUEIROZ, M. E. C., SILVA, S. M., CARVALHO, D., LANCAS, F. M. Solid-phase microextraction-liquid chromatography (SPME-LC) determination of lamotrigine simultaneously with carbamazepine and carbamazepine 10,11-epoxide in human plasma. J. Sep. Sci., v. 25, n. 1, p. 91-95, 2002.

[12] QUEIROZ, M. E. C., SILVA, S. M., CARVALHO, D., LANCAS, F. M. Determination of lamotrigine simultaneously with carbamazepine, carbamazepine epoxide, phenytoin, phenobarbital, and primidone in human plasma by SPME-GCTSD. J. Chrom. Sci., v. 40 , n. 4, p. 219-223, 2002.

[13] ARESTA, A., CIOFFI, N., PALMISANO, F., ZAMBONIN, C. G. Simultaneous determination of ochratoxin A and cyclopiazonic, mycophenolic, and tenuazonic acids in cornflakes by solid-phase microextraction coupledto high-performance liquid chromatography. J. Agric. Food Chem., v.51, p. 5232-5237, 2003.

[14] RODRIGUES, M. V. N., REYES, F. G. R., REHDER, V. L. G., RATH, S. An SPMEGC-MS Method for Determination of Organochlorine Pesticide Residues in Medicinal Plant Infusions. Chromatographia, v. 61, p. 291-297, 2005.

[15] ZENG, E. Y., TSUKADA, D., NOBLET, J. A., PENG, H. Determination of polydimethylsiloxane-seawater distribution coefficients for polychlorinated biphenyls and chlorinated pesticides by solid-phase microextraction and gas chromatography-mass spectrometry. J. Chromatogr. B, v.1066, n.1-2, p. 165-175, 2005.

[16] ALBANIS, A. T., HELA, D. G., LAMBROPOULOU, D. A., SAKKAS, V. A. Gas chromatographic-mass spectrometric methodology using solid-phase microextraction for the multiresidue determination of pesticides in surface waters. Int. J. Environ. Anal. Chem., v. 84, p. 1079-1092, 2004.

[17] BELTRAN, J., LÓPEZ, F. J., HERNANDÉZ, F. Solid-phase microextraction in pesticide residue analysis. J. Chromatogr. A, v. 885, p. 389-404, 2000.

[18] BLASCO, C., FONT, G., MANES, J., PICO, Y. Solid-phase microextraction liquid chromatography/tandem mass spectrometry to determine postharvest fungicides in fruits. Anal. Chem., v.75, p. 3606-3615, 2003. 
[19] BALTUSSEN, E., SANDRA, P., DAVID, F., CRAMERS, C. Stir Bar sorptive extraction (SBSE), a novel extraction technique or aqueous samples: theory and principles. J. Microcol. Sep., v.11, p.737-747, 1999.

[20] BICCHI, C., CORDERO, C., IORI, C., RUBIOLO, P. Headspace sorptive extraction (HSSE) in the headspace analysis of aromatic and medicinal plants. J. High Resolut. Chrom., v.23, n.9, p. 539-546, 2000.

[21] GERSTEL, Inc. Stir Bar Extraction Technique: A fast, simple, sensitive and efficient means of analyte extraction without solvents. Disponível em:

< http://www.gerstelus.com/twister/twisbod.html > Acesso em: 10 fevereiro 2007.

[22] FERNANDES, C. Otimização da extração, separação cromatográfica, identificação e quantificação de fármacos em fluidos biológicos. 2006. 220f. Tese (Doutorado em Química Analítica) - Instituto de Química de São Carlos, USP, São Carlos, 2006.

[23] ALMEIDA, C., ROSÁRIO, P., SERÔDIO, P., NOGUEIRA, J. M. F. Novas perspectivas na preparação de amostras para análise cromatográfica. Química, v. 95, p. 69-77, 2004.

[24] PAGE, B. D., LACROIX, G. J. Application of solid-phase microextraction to the headspace gas chromatographic analysis of semi-volatile organochlorine contaminants in aqueous matrices J. Chromatogr. A, v. 757, p. 173-182, 1997.

[25] NG, W. F., TEO, M. J. K., LAKSO, H. A. Determination of organophosphorus pesticides in soil by headspace solid-phase microextraction. Fresenius J. Anal. Chem., v. 363, p. 673-679, 1999.

[26] GUAN, F., WATANABE, K., ISHII, A., SENO, H., KUMAZAWA, T., HATTORI, H. , SUZUKI, O. Headspace solid - phase microextraction and gas chromatographic determination of dinitroaniline herbicides in human blood, urine and environmental water. J. Chromatogr. B, v. 714, p. 205-213, 1998.

[27] DOONG, R.-A., LIAO, P.-L. Determination of organochlorine pesticides and their metabolites in soil samples using headspace solid-phase microextraction. J. Chromatogr. A, v. 918, p. 177-188, 2001.

[28] LI, H.-P, LI, G.-C., JEN, J.-F. Determination of organochlorine pesticides in water using microwave assisted headspace solid-phase microextraction and gas chromatography. J. Chromatogr. A, v. 1012, p. 129-137, 2003. 
[29] FERNANDEZ-ALVAREZ, M., LLOMPART, M., LAMAS, J.P., LORES, M., GARCIA-JARES, C., CELA, R., DAGNAC, T. Simultaneous determination of traces of pyrethroids, organochlorinated and other main plants protection agents in agricultural soils by headspace solid-phase microextraction-gas chromatography. J.

Chromatogr. A, v. 1188, p. $154-163,2008$.

[30] DEROUICHE, A., DRISS, M.R., MORIZUR, J.-P., TAPHANEL, M.-H.

Simultaneous analysis of polychlorinated biphenyls and organochlorine pesticides in water by headspace solid-phase microextraction with gas chromatography-tandem mass spectrometry. J. Chromatogr. A., v. 1138, p. 231 - 243, 2007.

[31] YOU, J., LYDY, M. J. Headspace solid-phase microextraction of pesticides. Int. J. Environ. Anal. Chem. v. 86, p. 381 - 389, 2006.

[32] ZHAO, R. S., WANG, X., FU, S., YUAN, J. P., JIANG, T., XU, S. B. A novel headspace solid-phase microextraction method for the exact determination of organochlorine pesticides in environmental soil samples.

Anal. Bioanal. Chem., v.384, p. 1584-1589, 2006.

[33] DAVID, F., SANDRA, P. Stir bar sorptive extraction for trace analysis. J. Chromatogr. A, v.1152, p. 54-69, 2007.

[34] LANCAS, F. M., QUEIROZ, M. E. C., GROSSI, P., OLIVARES, I. R. B. Recent Developments and Applications of Stir Bar Sorptive Extraction. J. Sep. Sci., 2009 (Aceito jan/2009).

[35] WAHL, H. G., PETERFI, C., WERNER, R., LIEBICH, H. M. Analysis of barbiturates in urine by Stir Bar Sorptive Extraction and Thermal Desorption GC-MS. Clin. Chem., v. 48, B9, 2002.

[36] WAHL, H. G., WERNER, R., PETERFI, C., LIEBICH, H. M. Analysis of di(2ethylhexyl) phthalate and other plasticizers in body fluids and infusates by Stir Bar Sorptive Extraction and Thermal Desorption GC-MS. Clin. Chem. v. 48, B10, 2002.

[37] TIENPONT, B., DAVID, F., BENIJTS, T., SANDRA, P. Stir bar sorptive extraction thermal desorption-capillary GC-MS for profiling and target component analysis of pharmaceutical drugs in urine. J. Pharm. Biomed. Anal. v. 32, 569-579, 2003.

[38] TIENPONT, B., DAVID, R., STOPFORTH, A., SANDRA, P. Recent Applications in Multidimensional Chromatography LC-GC Eur., v. 16, p. 5-13, 2004.

[39] KAWAGUCHI, M., INOUE, K., SAKUI, N., ITO, R., IZUMI, S., MAKINO, T., OKANOUCHI, N., NAKAZAWA, H. Stir bar sorptive extraction and thermal desorption-gas chromatography-mass spectrometry for the measurement of 4nonylphenol and 4-tert-octylphenol in human biological samples. J. Chromatogr. B, v. 799, p. 119-125, 2004. 
[40] CHAVES, A. R., SILVA, S. M., QUEIROZ, R. H., LANCAS, F. M., QUEIROZ, M. E. C. Stir bar sorptive extraction and liquid chromatography with UV detection for determination of antidepressants in plasma samples . J. Chromatogr. B, v. 850, p. 295-302, 2007.

[41] HUANG, X., YUAN, D., HUANG, B. Determination of steroid sex hormones in urine matrix by stir bar sorptive extraction based on monolithic material and liquid chromatography with diode array detection. Talanta, v. 75, p. 172-177, 2008.

[42] FERNANDES, C., HOECK, E. V., SANDRA, P., LANCAS, F. M. Determination of fluoxetine in plasma by gas chromatography-mass spectrometry using stir bar sorptive extraction. Anal. Chim. Acta, v. 614, 201-207, 2008.

[43] QUEIROZ, R. H., BERTUCCI, C., MALFARÁ, W. R., DREOSSI, A. S., CHAVES, A. R., QUEIROZ, M. E. C. Quantification of carbamazepine, carbamazepine-10,11epoxide, phenytoin and phenobarbital in plasma samples by stir bar-sorptive extraction and liquid chromatography. J. Pharm. Biomed. Anal., v. 48, p. 428-434, 2008.

[44] KAWAGUCHI, M., ITO, R., HONDA, H., ENDO, N., OKANOUCHI, N., SAITO, K., SETO, Y. NAKAZAWA, H. Simultaneous analysis of benzophenone sunscreen compounds in water sample by stir bar sorptive extraction with in situ derivatization and thermal desorption-gas chromatography-mass spectrometry. J. Chromatogr. A, v. 1200, p. 260-263, 2008.

[45] OCHIAI, N., SASAMOTO, K., KANDA, H., PFANNKOCH, E. Sequential stir bar sorptive extraction for uniform enrichment of trace amounts of organic pollutants in water samples. J. Chromatogr. A, v. 1200, p. 72-79, 2008.

[46] HUANG, X., QIU, N., DONGXING, Y. Direct enrichment of phenols in lake and sea water by stir bar sorptive extraction based on poly (vinylpyridine-ethylene dimethacrylate) monolithic material and liquid chromatographic analysis. J.

Chromatogr. A, v. 1194, p. 134-138, 2008.

[47] SILVA, A. R. M., NOGUEIRA, J. M. F. New approach on trace analysis of triclosan in personal care products, biological and environmental matrices. Talanta, v. 74, p.1498-1504, 2008.

[48] RODIL, R., MOEDER, M. Development of a method for the determination of UV filters in water samples using stir bar sorptive extraction and thermal desorption-gas chromatography-mass spectrometry. J. Chromatogr. A, v. 1179, p. 81-88, 2008.

[49] TAN, B. L. L., HAWKER, D. W., MÜLLER, J. F., TREMBLAY, L. A., CHAPMAN, H. F. Stir bar sorptive extraction and trace analysis of selected endocrine disruptors 
in water, biosolids and sludge samples by thermal desorption with gas chromatography-mass spectrometry. Water Res. , v. 42, p. 404-412, 2008.

[50] RODIL, R., MOEDER, M. Stir bar sorptive extraction coupled to thermodesorption-gas chromatography-mass spectrometry for the determination of insect repelling substances in water samples. J. Chromatogr. A, v. 1178, p. 9-16, 2008.

[51] BOURDAT-DESCHAMPS, M., DAUDIN, J. J., BARRIUSO, E. An experimental design approach to optimise the determination of polycyclic aromatic hydrocarbons from rainfall water using stir bar sorptive extraction and high performance liquid chromatography-fluorescence detection. J. Chromatogr. A, v. 1167, p. 143-153, 2007.

[52] RIDGWAY, K., LALLJIE, S. P. D., SMITH, R. M. Sample preparation techniques for the determination of trace residues and contaminants in foods. J. Chromatogr. A, v. 1153, p. 36-53, 2007.

[53] GUERRERO, E. D., MEJÍAS, R. C., MARÍN, R. N., BARROSO, C. G. Optimization of stir bar sorptive extraction applied to the determination of pesticides in vinegars. J. Chromatogr. A, v. 1165, p. 144-150, 2007.

[54] SALVADEO, P., BOGGIA, R., EVANGELISTI, F., ZUNIN, P. Analysis of the volatile fraction of "Pesto Genovese" by headspace sorptive extraction (HSSE). Food Chemistry, v. 105, p. 1228-1235, 2007.

[55] HAMPEL, D., SWATSKI, A., MOSANDL, A., WÜST, M. Biosynthesis of Monoterpenes and Norisoprenoids in Raspberry Fruits (Rubus idaeus L.): The Role of Cytosolic Mevalonate and Plastidial Methylerythritol Phosphate Pathway. J. Agric. Food Chem., v. 55, p. 9296-9304, 2007.

[56] VINÃS, P., CAMPILLO, N., HERNÁNDEZ-PÉREZ, M., HERNÁNDEZCÓRDOBA, M. A comparison of solid-phase microextraction and stir bar sorptive extraction coupled to liquid chromatography for the rapid analysis of resveratrol isomers in wines, musts and fruit juices. Anal. Chim. Acta, v. 611, p. 119-125, 2008.

[57] VINÃS, P., AGUINAGA, N., CAMPILLO, N., HERNÁNDEZ-CÓRDOBA, M. Comparison of stir bar sorptive extraction and membrane-assisted solvent extraction for the ultra-performance liquid chromatographic determination of oxazole fungicide residues in wines and juices. J. Chromatogr. A, v. 1194, p. 178-183, 2008.

[58] OLIVA, J., ZALACAIN, A., PAYÁ, P., SALINAS, M. R., BARBA, A. Effect of the use of recent commercial fungicides [under good and critical agricultural practices] on the aroma composition of Monastrell red wines. Anal. Chim. Acta, v. 617, p. 107-118, 2008. 
[59] HORÁK, T., CULÍK, J., JURKOVÁ, M., CEJKA, P., KELLNER, V. Determination of free medium-chain fatty acids in beer by stir bar sorptive extraction. J.

Chromatogr. A, v. 1196-1197, p. 96-99, 2008.

[60] NOGUEIRA, A. M. Desenvolvimento, avaliação e aplicações de novas fases para extração por sorção em barra de agitação (SBSE). 2007. 118f. Dissertação (Mestrado em Química Analítica) - Instituto de Química de São Carlos, USP, São Carlos, 2007.

[61] BARROS NETO, B., SCARMINIO, I. S., BRUNS, R. E. Como fazer experimentos: Pesquisa e Desenvolvimento na Ciência e na Indústria. Campinas, Editora da Unicamp. 2002. 401p.

[62] KUEHL, R. O. Design of Experiments: Statistical Principles of Research Design and Analysis, Duxbury Press, Belmont 1994.

[63] MONTGOMERY, D. C., Design an Analysis of Experiments, Wiley \& Sons, New York 1997.

[64] SERÔDIO, P., CABRAL, M. S., NOGUEIRA, J. M. F. Use of experimental design in the optimization of stir bar sorptive extraction for the determination of polybrominated diphenyl ethers in environmental matrices. J. Chromatogr. A., v. 1141, p. 259-270, 2007.

[65] QUINTANA, J. B., RODIL, R., LORENZO, S. M., LÓPEZ-MAHÍA, P., PRADARODRIGUÉZ, D. Multiresidue analysis of acidic and polar organic contaminants in water samples by stir-bar sorptive extraction-liquid desorption-gas chromatography-mass spectrometry. J. Chromatogr. A., v. 1174, p. 27-39, 2007.

[66] PRIETO, A., ZULOAGA, O., USOBIAGA, A., ETXEBARRIA, N., FERNÁNDEZ, L. A., Development of a stir bar sorptive extraction and thermal desorption-gas chromatography-mass spectrometry method for the simultaneous determination of several persistent organic pollutants in water samples. J. Chromatogr. A., v. 1174, p. 40-49, 2007.

[67] ATKINSON, A. C., TOBIAS, R. D. Optimal experimental design in chromatography. J. Chromatogr. A, v. 1177, p. 1-11, 2008.

[68] CARASEK, E., CUDJOE, E., PAWLISZYN, J. Fast and sensitive method to determine chloroanisoles in cork using an internally cooled solid-phase microextraction fiber. J. Chromatogr.A, v. 1138, p. 10-17, 2007.

[69] SERÔDIO, P., NOGUEIRA, J. M. F. Multi-residue screening of endocrine disrupters chemicals in water samples by stir bar sorptive extraction-liquid desorption-capillary gas chromatography-mass spectrometry detection. Anal. Chim. Acta, v. 517, p. 21 - 32, 2004. 
[70] GROSSI, P., Olivares, I. R. B., DE FREITAS, D. R., LANCAS, F. M. A novel HSSBSE system coupled with gas chromatography and mass spectrometry for the analysis of organochlorine pesticides in water samples. J. Sep. Sci. v. 31, n. 20, p. 3630-3637, 2008.

[71] VERCAUTEREN, J., PERES, C., DEVOS, C., SANDRA, P., VANHAECKE, F., MOENS, L. Stir Bar Sorptive Extraction for the Determination of ppq-Level Traces of Organotin Compounds in Environmental Samples with Thermal DesorptionCapillary Gas Chromatography-ICP Mass Spectrometry. Anal. Chem., v. 73, p. 1509 - 1514, 2001.

[72] KOLAHGAR, B., HOFFMANN, A., HEIDEN, A. Application of stir bar sorptive extraction to the determination of polycyclic aromatic hydrocarbons in aqueous samples J. Chromatogr. A, v. 963, p. 225 - 230, 2002.

[73] SANDRA, P., TIENPONT, B., DAVID, F. Multi-residue screening of pesticides in vegetables, fruits and baby food by stir bar sorptive extraction-thermal desorptioncapillary gas chromatography-mass spectrometry. J. Chromatogr. A, v. 1000, p. 299 309, 2003. 
3

\section{Novos Desenvolvimentos em Extração Sortiva}




\section{3 \\ Novos Desenvolvimentos em Extração Sortiva}

\section{INTRODUÇÃO}

A Extração Sortiva em Barras de Agitação (SBSE) é uma técnica de preparo de amostras com alta capacidade de concentração sem uso de solvente. Seu conceito foi primeiramente introduzido pelo grupo liderado por Pat Sandra [1] para extrair analitos orgânicos de amostras aquosas e seus princípios foram descritos no capítulo anterior desta tese.

A técnica de SPME, desenvolvida por Pawliszyn [2] e colaboradores, também descrita no capítulo anterior, é uma técnica de preparo de amostras anterior e que se tornou uma alternativa à métodos clássicos de extração. A SPME tem atraído um aumento da atenção na área de análises ambientais devido à simplicidade, eficiência, boa precisão e baixos limites de detecção [3]. Devido a estas vantagens, a técnica de SPME é um ponto de referência nas técnicas de microextração sortiva e pode ser utilizada como tendência para novos desenvolvimentos.

Um dos trabalhos recentes utilizando a SPME como técnica de análise foi a extração no modo headspace utilizando uma fibra refrigerada [4] onde a extração é baseada no aquecimento da matriz e simultâneo refrigeração da fibra. Este sistema facilita não apenas a transferência de massa e a remoção dos analitos para o 
headspace como também aumenta a diferença de temperatura entre a fibra refrigerada e o headspace aquecido, o que aumenta significativamente o coeficiente de partição dos analitos.

Chen and Pawliszyn [5], em uma publicação recente, utilizaram a refrigeração (com dióxido de carbono) para resfriar a parte interna de uma fibra. Este sistema mostra que com o aumento da temperatura da amostra e simultâneo resfriamento do recobrimento da fibra ocorre um aumento no coeficiente de distribuição, resultando em extração praticamente exaustiva (com recuperação próxima de 100\%).

O processo de refrigeração em SPME tem sido estudado por Pawliszyn e colaboradores [4-10] e outros grupos de pesquisa [11-16].

Uma desvantagem da SPME é o seu volume de fase, muito inferior do que o presente na técnica de SBSE, o que gera nesta técnica melhores recuperações e capacidade de amostragem.

Baseado nestas observações avaliou-se a possibilidade, pela primeira vez, de seguir a tendência da SPME na técnica de extração sortiva em barras de agitação (SBSE). Para aplicar a refrigeração nesta última é necessário trabalhar no modo headspace. A SBSE foi anteriormente aplicada no modo de amostragem headspace por Tienpont et al. [17] e Bicchi et al. [18], sob o nome de Extração Sortiva Headspace (HSSE).

Considerando as vantagens da SBSE, devido ao volume de PDMS ser superior ao da SPME a qual promove melhores recuperações e limites de detecção, e também as novas tendências de refrigeração em SPME, foi desenvolvido um novo sistema 
denominado de Extração Sortiva Refrigerada (RSE). Este sistema foi construído com equilíbrio similar ao equilíbrio da HSSE e da HS-SPME.

\subsection{EXTRAÇÃO SORTIVA REFRIGERADA}

Assim como no headspace SPME [2], em SBSE existem dois processos envolvidos na remoção dos analitos de sua matriz e a sorção dos analitos por um recobrimento de PDMS. A quantidade de analito extraída é determinada pela mesma equação da teoria da SPME.

$$
n=\frac{K_{0} V_{f} C_{0} V_{s}}{K_{0} V_{f}+V_{s}}
$$

onde n é a massa adsorvida pelo recobrimento da fibra; $V_{f}$ e $V_{s}$ são os volumes do recobrimento da fibra e do headspace, respectivamente; $K_{0}$ é o coeficiente de partição de um analito entre a fibra e o headspace; $C_{0}$ é a concentração inicial do analito no headspace.

Para uma análise quantitativa ter sucesso, a maior parte das moléculas de analito deve estar livre no headspace. É crítico escolher condições de extração os quais sejam aptas a facilitar a liberação da maior parte das moléculas de analitos.

Para atingir melhores extrações devemos utilizar um volume de amostra menor $\left(V_{s}\right)$ ou aumentar o volume do recobrimento $\left(V_{f}\right)$, ou mudar a fase para uma que tenha mais afinidade com os analitos ou um método fácil e mais prontamente aplicável é aumentar o coeficiente de partição entre o recobrimento e a amostra de headspace. A vantagem para esta abordagem é que além de aumentar os coeficientes 
de partição podemos facilitar a liberação dos analitos da matriz para o headspace devido à dessorção térmica [1].

Um tratamento teórico similar ao já utilizado para a headspace SPME foi utilizado neste trabalho, já que ambas as técnicas seguem a mesma abordagem de extração sortiva.

O coeficiente de partição do analito entre o PDMS refrigerado e o headspace "quente" pode ser obtido de acordo com a seguinte equação

$$
K_{T}=K_{0} \frac{T_{s}}{T_{f}} \exp \left[\frac{C_{p}}{R}\left(\frac{\Delta T}{T_{f}}+\ln \frac{T_{f}}{T_{s}}\right)\right]
$$

onde $C_{p}$ é a capacidade de calor à pressão constante do analito; $\Delta T=T_{s}-T_{f}, K_{0}$ é o coeficiente de partição recobrimento/headspace do analito quando o recobrimento e o headspace estão ambos à temperatura $T_{f}$ e $R$ é a constante do gás e tem um valor de $8.31 \mathrm{~J} . \mathrm{K}^{-1} \cdot \mathrm{mol}^{-1}$.

A equação 2 indica que existem três elementos principais que afetam o coeficiente de partição de um analito particular: o coeficiente de partição de um analito à temperatura $T_{f}, K_{0}$ (que é determinado pela temperatura do recobrimento $\left(T_{f}\right)$ e a interação entre o analito e o recobrimento); a temperatura do recobrimento, $T_{f}$ e a temperatura do headspace, $T_{s}$.

Desde que os valores de $T_{f}$ sejam baixos, $K_{0}$ (absorção exotérmica) será maior, mantendo-se uma temperatura baixa do recobrimento e gerando uma diferença de temperatura que aumentará o coeficiente de partição. 


\subsection{NOVOS RECOBRIMENTOS}

Uma limitação da SBSE, em oposição à SPME, na qual existem diversos tipos de fases poliméricas disponíveis para cobrir uma ampla faixa de polaridade, é que até o presente existem somente barras comerciais com recobrimento de PDMS. Fases não polares não podem recuperar todos os tipos de analitos por SBSE, particularmente os mais polares $\left(\log \mathrm{K}_{\mathrm{o} / \mathrm{w}}<3\right)$, desde que eles apresentem baixa afinidade ao PDMS.

Recentemente, alguns procedimentos "in-house" para recobrir barras de SBSE foram desenvolvidos. Bicchi et al. [19] desenvolveram barras com fase dupla utilizando diferentes tipos de carvão como uma fase adicional. A combinação de duas fases aumentou a recuperação de compostos voláteis e/ou polares comparado à barras convencionais. Liu et al. [20] descreveram a utilização de uma fase compacta e termicamente estável com uma terminação hidróxi para a extração de hidrocarbonetos poliaromáticos (PAHs), n-alcanos e pesticidas fosforados em amostras de água.

Lambert e colaboradores [21] prepararam uma barra biocompatível utilizando uma sílica alquil-diol (ADS) de colunas de acesso restrito (RAM) como recobrimento. A RAM-SBSE é apta a fracionar o componente proteico de uma amostra biológica enquanto extrai cafeína e seus metabólitos, superando a desvantagem atual de amostragem direta em matrizes biológicas, como a adsorção de proteínas no recobrimento.

Neng et al [22] propuseram filmes de poliuretana (PU) como novas fases poliméricas para SBSE. Foi demonstrado que estes polímeros apresentam 
estabilidade e excelente resistência mecânica para enriquecimento de compostos orgânicos em amostras aquosas. Os filmes de PU parecem ser alternativa conveniente para substituir o PDMS convencional para análises de metabólitos mais polares por SBSE em nível de traços [23], assim como aumentar a extração de herbicidas triazínicos em amostras de água [24].

Nogueira et al. [25] desenvolveram e aplicaram a PU dopada com carvão ativado como fase polimérica de SBSE seguido de cromatografia líquida. Neste trabalho, antidepressivos, anticonvulsivantes, ivermectina e benzoimidazol presentes em níveis terapêuticos foram analisados em amostras de plasma. A comparação dos dados obtidos é apresentada na Figura 3.1. A adição de materiais aumenta o número de sítios ativos que participam do processo de extração, aumentando a difusão de moléculas dentro dos poros. Os mecanismos de extração dentro da PU dopada com carvão ativado são baseados em processo de adsorção em ambos, carvão ativado e PU. 

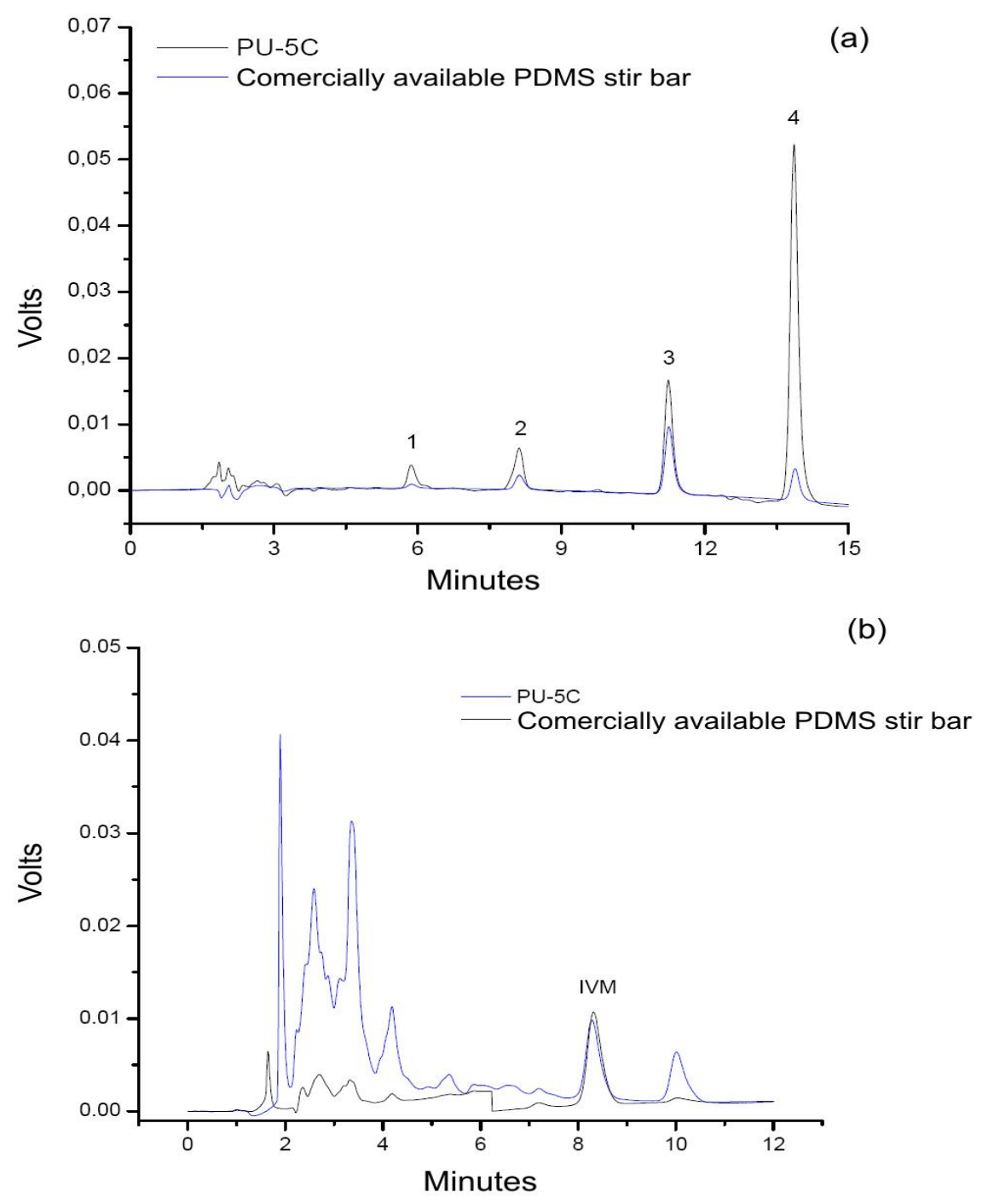

Figura 3.1. Comparação entre a barra de PU dopada com 5\% de carvão ativado (---), PDMS convencional (---). Analitos: (a) anticonvulsivantes. 1. fenobarbitol, 2. epóxido, 3. carbamazepina, 4. metil-fenil-etil hidantoína. (b) ivermectina. Extraído de [26].

Para aumentar a eficiência das barras de PU, o polímero foi dopado com diferentes porcentagens de carvão ativado, que é conhecido por apresentar capacidade de adsorção, Figura 3.2. 


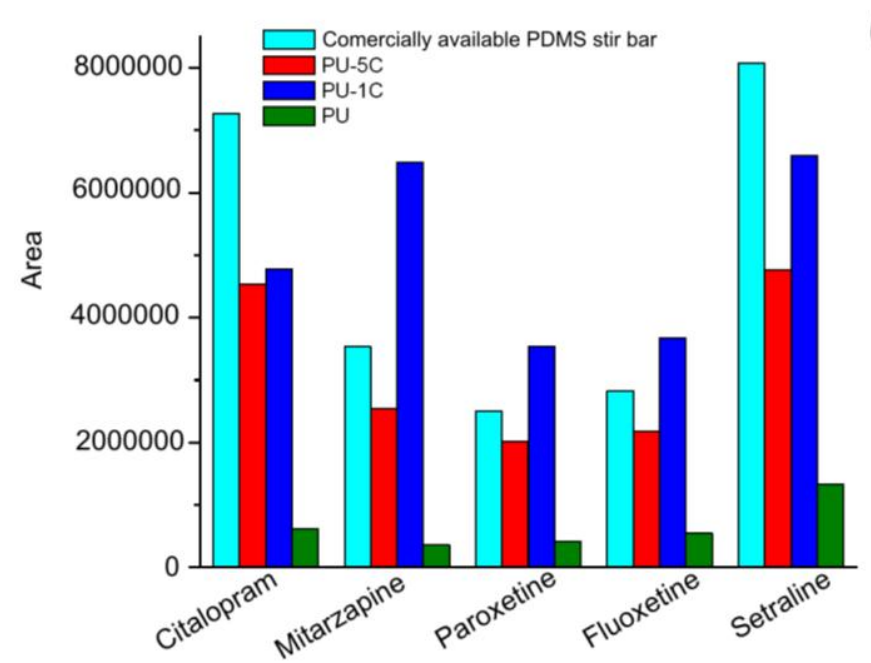

(a)

(b)
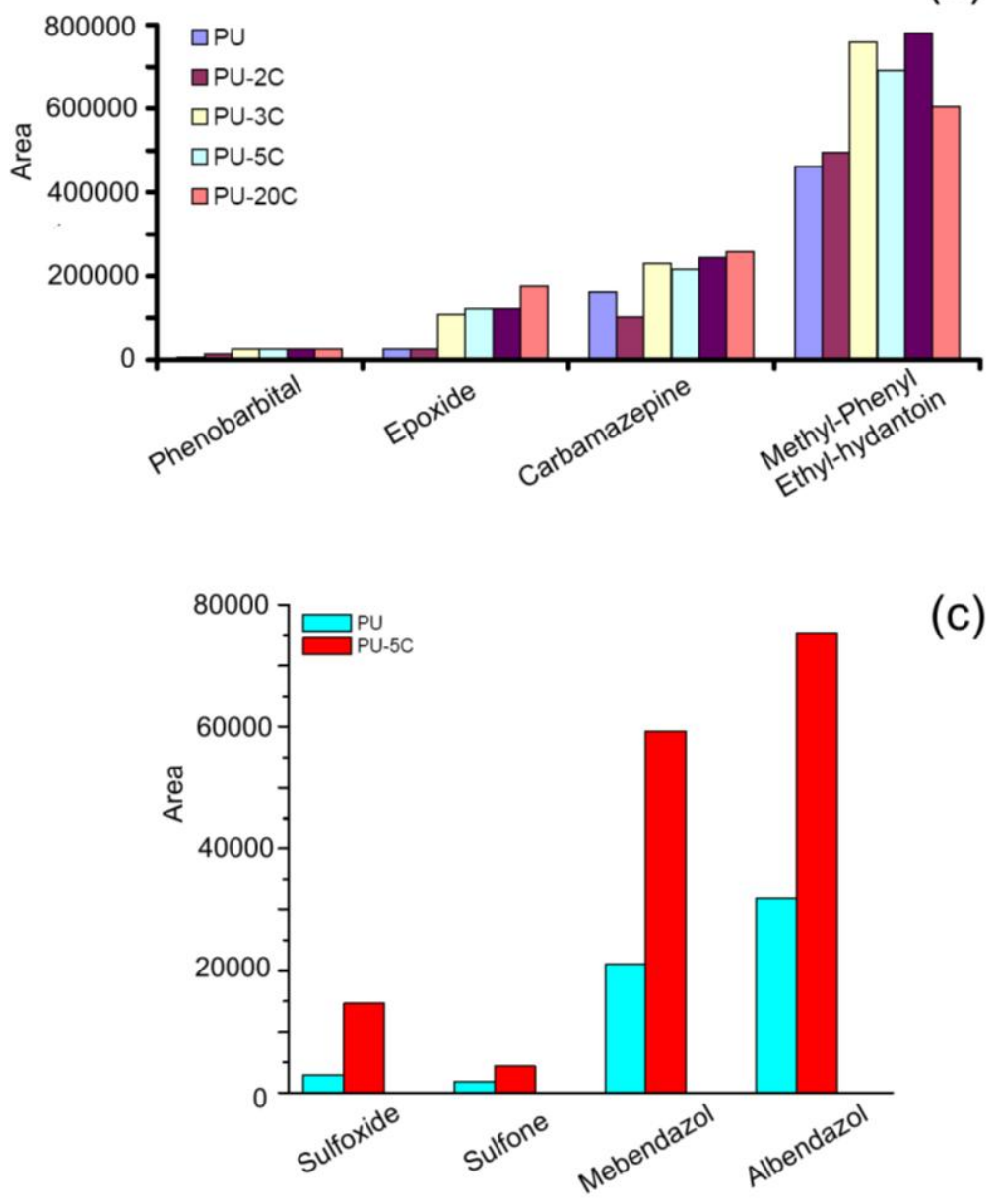

(c)

Figura 3.2. Comparação entre áreas dos picos obtidos por LC extraídos por uma fase pura de poliuretana e poliuretana dopada com material adsorvente. Analitos: (a) antidepressivos, (b) anticonvulsivantes, (c) benzoimidazóis. Extraído de [25]. 
Huang et al. [26] desenvolveram uma nova fase contendo poli (ester-etileno dimetilacrilato ácido estearil metacrílico) para determinação simultânea de 6 hormônios sexuais em urina.

A SBME (Micro-extração em Barra Solvente), uma nova técnica desenvolvida por Chia e Huang [27] para pré-concentração de amostras, que envolve o uso de uma membrana de polipropileno em uma fibra oca de comprimento selecionada para ser aplicada em análises de traço de OCPs em amostra de vinho.

Fases com PDMS modificado foram também utilizadas por Lanças e colaboradores [28]. As novas fases foram avaliadas em diferentes analitos. Para extração de ivermectina foi realizada uma comparação com extração em barras comerciais e barras desenvolvidas in-house com PDMS modificado e testadas em amostras de plasma bovino. A barra contendo PDMS e 5\% de OV-17-OH extraiu o composto 4,5 vezes mais eficiente do que a barra comercial. A barra contendo PDMS e 10\% de DEGS mostrou também o dobro de extração comparada à comercial. (Figura 3.3)

A partir do desempenho das barras de SBSE desenvolvidas "in-house", apresentadas no Capítulo 2, o estudo de novos recobrimentos despertou a atenção. Além do PDMS puro, focou-se na modificação das características de polaridade deste polímero visando recobrimentos mais indicados para a recuperação de compostos orgânicos por SBSE em matrizes aquosas. 


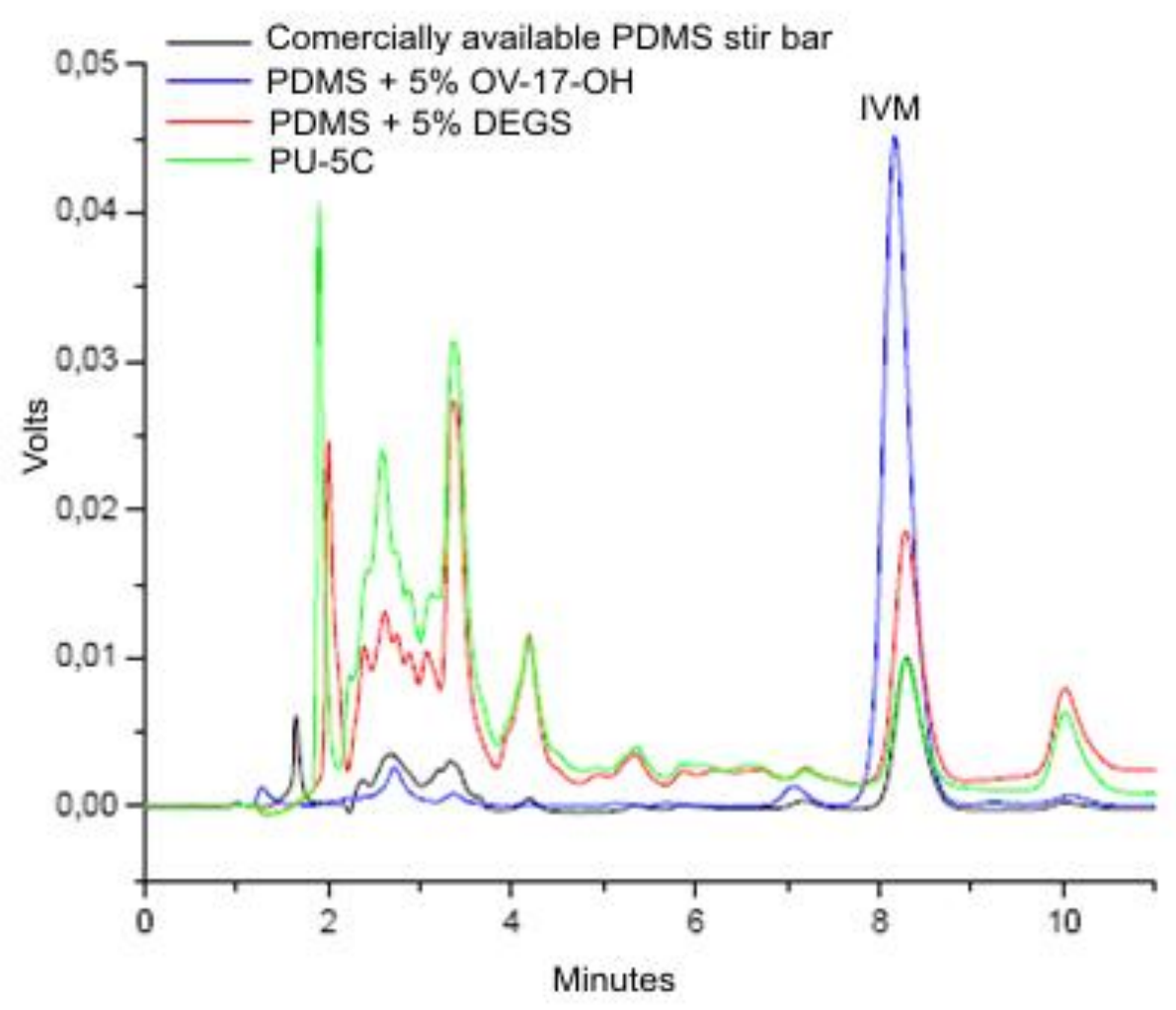

Figura 3.3. Comparação obtida através dos cromatogramas da ivermectina: utilizando barra commercial e barras de PDMS modificadas com 5\% OV-17-OH e 10\% DEGS (-).

Extraído de [28].

Fases como OV-17, OV-17-Vinil e RTX foram adicionadas ao PDMS, em diferentes proporções, e estas novas fases obtidas foram testadas em extrações de BTEX e pesticidas organoclorados em água. 


\section{OBJETIVOS}

Desenvolver um novo molde de Teflon para preparo de barras de RSE.

Desenvolver barras de RSE utilizando o polímero polidimetilsiloxano (PDMS) como recobrimento.

Aplicar a barra desenvolvida e otimizá-la para extração de pesticidas organoclorados em água.

Validar a barra desenvolvida avaliando os parâmetros: Linearidade; Precisão; Exatidão (Recuperação); Limite de Detecção e Limite de Quantificação.

Aplicar a barra de RSE em amostra real.

* Desenvolver novos recobrimentos para a técnica de SBSE, a partir da adição de outros polímeros ao PDMS. 


\section{PARTE EXPERIMENTAL}

\subsection{PADRÕES E REAGENTES}

Os padrões de pesticidas organoclorados (pureza > 98\%) e padrões de BTEX foram obtidos da Supelco, (Bellefonte, PA, EUA). Os solventes acetonitrila e tolueno (grau analítico) foram obtidos da Mallinckrodt (Phillipsbourg, NJ, USA). Cloreto de sódio foi obtido da Merck (Darmstadt, Alemanha). O polímero PDMS Sylgard 184 e seu agente de cura foram obtidos da Dow Corning Corporation (Midland, USA). Os polímeros silicone OV-17 e OV-17-Vinil foram obtidos da Alltech (Kentucky, USA). O polímero RTX ${ }^{\circledR}-50$ da Restek (Philadelphia, USA).

\subsection{EQUIPAMENTOS E MATERIAIS UTILIZADOS}

Lavadora Ultra-sônica, Ultra Cleaner Unique.

Balança analítica modelo BL 210S, Sartorius, EUA.

* Sistema de purificação de água modelo Milli-Q, Millipore, EUA.

Balões volumétricos de 5, 10, 50 mL, Pyrex, EUA.

Agitador magnético, Scientific, EUA.

Banho de água, Quimis.

* Bomba de aquário, Sarlo.

Moldes de Teflon.

Barras e tubos de aço inoxidável. 


\subsection{MÉTODO}

\subsubsection{Preparo dos padrões analíticos}

Inicialmente foi preparada uma solução estoque de OCPs com uma concentração de $100 \mathrm{mg} . \mathrm{L}^{-1}$. Esta solução foi diluída para $10 \mathrm{mg}$. $\mathrm{L}^{-1}$ e, a partir desta, foram preparadas as soluções para fortificação das amostras e desenvolvimento do método cromatográfico.

Para os BTEX foi preparada uma solução estoque $\left(10 \mu \mathrm{g} \cdot \mathrm{mL}^{-1}\right)$ em metanol. As amostras foram preparadas colocando-se $1 \mu \mathrm{g} \cdot \mathrm{mL}^{-1}$ de BTEX em um frasco do tipo headspace adicionando-se $9 \mathrm{~mL}$ água (Mili-Q), 3,6g da $\mathrm{NaCl}$ e 1 gota da $\mathrm{H}_{3} \mathrm{PO}_{4} / \mathrm{H}_{2} \mathrm{O}$ $5 \%$ para atingir $\mathrm{pH}=2,00$.

\subsubsection{Otimização das condições cromatográficas}

Para as condições cromatográficas (utilizando o equipamento GC-MS Shimadzu QP 5000), buscando uma maior sensibilidade para identificação dos pesticidas organoclorados, foi utilizada uma mistura de solução padrão com os pesticidas de interesse, a qual foi injetada no cromatógrafo. Os compostos foram analisados nas seguintes condições:

\section{Detector Volts: $1,85 \mathrm{kV}$}

Sampling Rate: 0,2

Forma de aquisição de íons: Modo SIM programando a aquisição de três íons, recomendados pelo método 8270D da EPA (EPA Method 8270d, 1998) em uma janela de tempo referente ao tempo de eluição de cada composto. 
Quanto aos demais parâmetros de análise, os melhores resultados foram obtidos nas seguintes condições:

Coluna: NST $5(30 \mathrm{~m} \times 0,15 \mathrm{~mm} \times 0,25 \mu \mathrm{m})$ - 5\% fenildimetilpolisiloxano

Modo injeção: splitless (5 minutos)

Volume injetado: $2,0 \mu \mathrm{L}$.

Programação de temperatura da coluna:

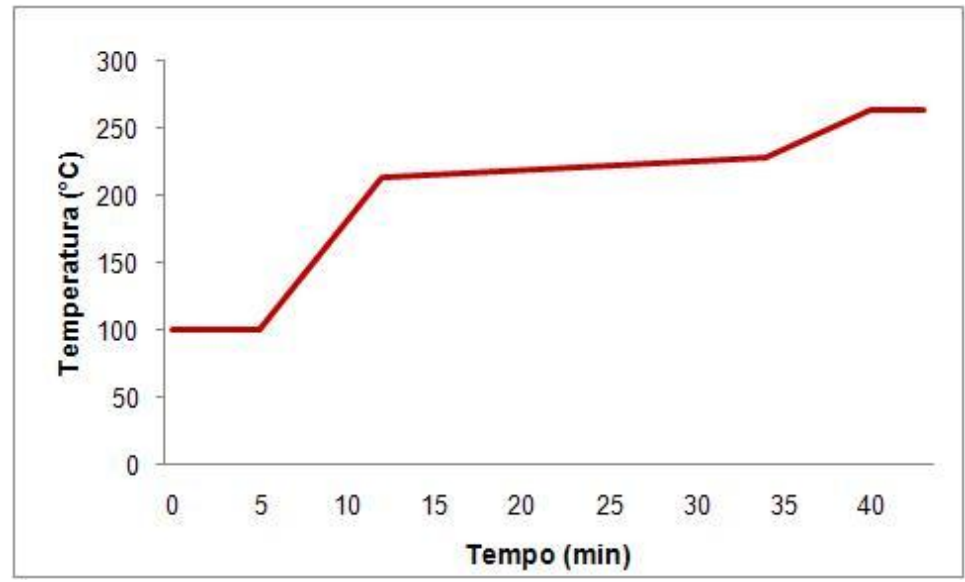

Gás de arraste: He (1,1 mL.min-1)

Velocidade Linear: 38,6 mL.min ${ }^{-1}$

Temperatura do injetor: $270^{\circ} \mathrm{C}$

* Temperatura da interface: $280^{\circ} \mathrm{C}$

Modo ionização: impacto eletrônico (70eV)

Início do tempo de aquisição: 9,1 min

Solvent cut time: 9,0 min

Os íons monitorados, tempos de retenção e log de $\mathrm{K}_{\mathrm{o} / \mathrm{w}}$ de cada composto são apresentados na Tabela 2.5 do Capítulo 1. 
A análise dos BTEXs (utilizando o equipamento GC-FID, Shimadzu) foi realizada em uma coluna contendo $5 \%$ fenil, $95 \% 30 \mathrm{~m} \times 0.15 \mathrm{~mm} \times 0.25 \mu \mathrm{m}$ da marca NST (São Carlos, Brazil). A temperatura do forno do GC para a análise de BTEX foi mantida durante 2 min à temperatura de $40^{\circ} \mathrm{C}$, então aquecida à $5^{\circ} \mathrm{C} /$ min até $70^{\circ} \mathrm{C}$ e então aquecida à taxa de $10^{\circ} \mathrm{C} / \mathrm{min}$ até $150^{\circ} \mathrm{C}$.

\subsubsection{Barras RSE}

\subsubsection{Preparo das barras de RSE}

Para o preparo das barras de RSE um novo molde de Teflon foi desenvolvido e construído em uma oficina de ferramentaria. O PDMS obtido comercialmente consiste de uma fase viscosa e seu agente de cura. Para formar o polímero na consistência e espessura desejada aproximadamente $0,4 \mathrm{~g}$ da fase viscosa foi vigorosamente misturada com $0,04 \mathrm{~g}$ do agente de cura em um frasco de vidro. A mistura foi levada ao vácuo durante 15 minutos para eliminar as bolhas formadas na homogeneização. O polímero foi então adicionado nas cavidades do molde de Teflon desenvolvido e em seguida adicionou-se a barra magnética. O molde foi fechado, pressionado com um suporte de aço, com ajuste manual, para evitar vazamento. $\mathrm{O}$ conjunto foi levado ao forno durante 1 hora a temperatura de $60^{\circ} \mathrm{C}$.

O molde foi então resfriado a temperatura ambiente e a barra foi retirada e voltou novamente ao forno, sem o molde, nas seguintes condições: $40^{\circ} \mathrm{C}$ durante 30 minutos, $10^{\circ} \mathrm{C} \cdot \mathrm{min}^{-1}$ até $250^{\circ} \mathrm{C}$ durante 2 horas.

A camada de PDMS da RSE um volume de aproximadamente $80 \mu \mathrm{L}$. As extrações foram realizadas através da suspensão da barra no headspace de um frasco 
de $20 \mathrm{~mL}$ contendo água fortificada com pesticidas organoclorados e lacrado com um septo de PTFE e lacre de alumínio.

\subsubsection{Sistema de miniaturização da RSE}

O sistema consiste de uma bomba de aquário, um frasco contendo água refrigerada, um agitador magnético, um banho de água com temperatura controlada e um frasco de headspace modificado desenvolvido no laboratório.

Para iniciar o funcionamento, a barra de RSE foi conectada ao sistema, dentro do frasco. O sistema foi fechado com anilhas de Teflon e roscas metálicas conectadas às mangueiras de circulação de água refrigerada. Em seguida inicia-se a agitação da amostra e o aquecimento da amostra simultaneamente ao resfriamento da barra. Após o período de equilíbrio de extração era removida e os analitos extraídos em um frasco contendo solvente em banho de ultra-som.

Durante o desenvolvimento do sistema de RSE, diferentes partes foram desenvolvidas, adaptadas e otimizadas. Primeiramente um molde foi desenhado e construído (Figura 3.4.a) para recobrir 1,5cm de um tubo de aço inoxidável de 1,0mm de diâmetro, formando assim a barra de RSE. Para conectar a barra no frasco foi necessário adaptar o frasco de headspace utilizado normalmente em extrações. O frasco adaptado foi construído e pode ser observado na Figura 3.4.b. A barra foi inserida no frasco de extração e o sistema foi vedado com septos de cromatografia gasosa e tampas de Teflon, considerando sua resistência e inércia, promovendo um fechamento adequado (Figura 3.4.c). A refrigeração foi realizada utilizando-se circulação de água refrigerada através do uso de uma bomba de aquário conectada à 
barra com mangueiras, anilhas de Teflon e roscas de aço inoxidável (Figura 3.4.d,e). O sistema montado pode ser observado na Figura 3.4.f.

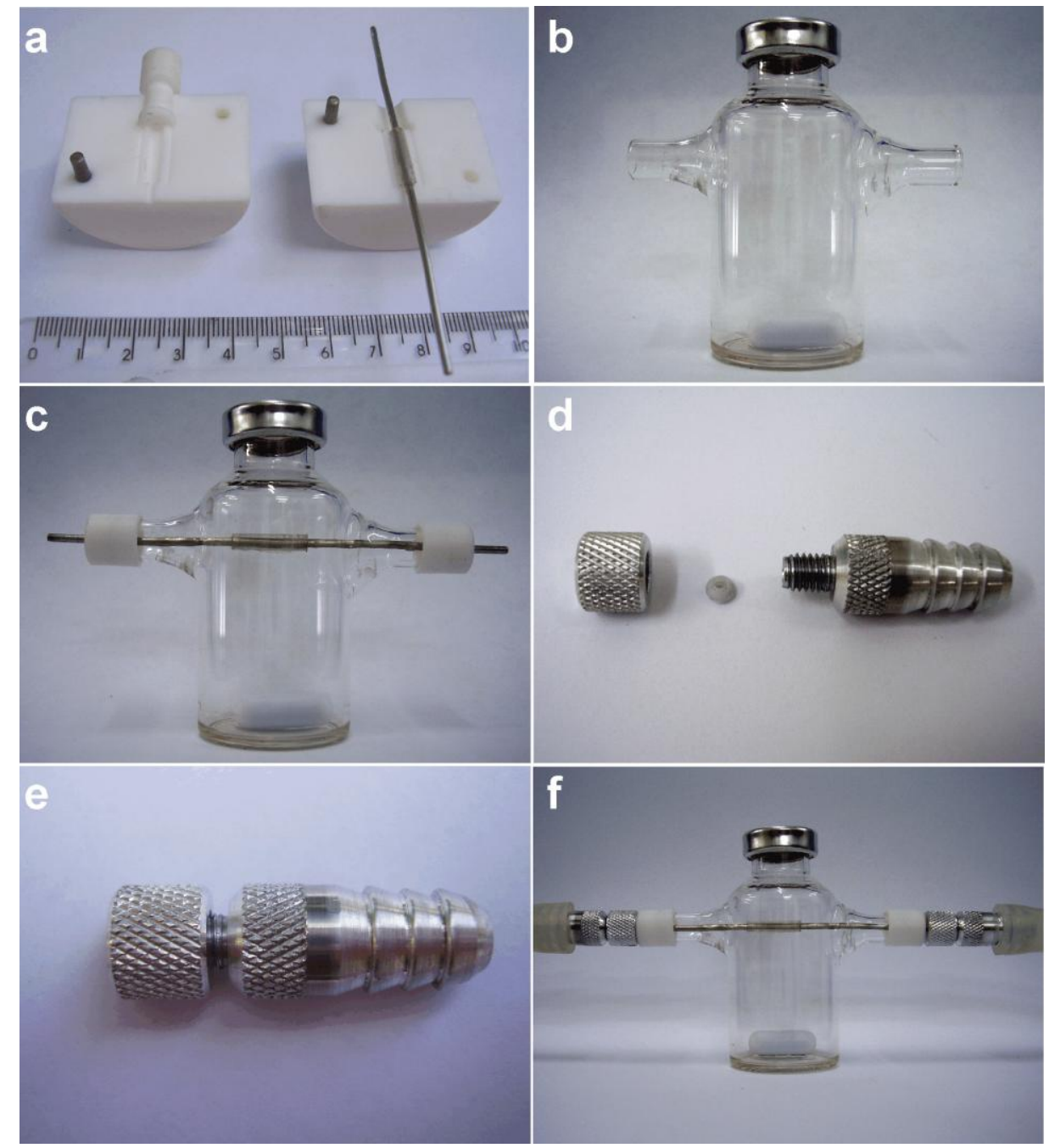

Figura 3.4. Sistema RSE (a. Molde; b. Frasco headspace modificado; c. Sistema fechado; d. Conexão com anilhas de Teflon - aberto; e. Conexão com anilhas de Teflon - fechado; $f$. Sistema RSE montado).

O sistema completo, utilizando o frasco, a barra de RSE e a bomba de aquário, é mostrado na Figura 3.5. O aquecimento e agitação foram realizados utilizando-se um agitador magnético. 


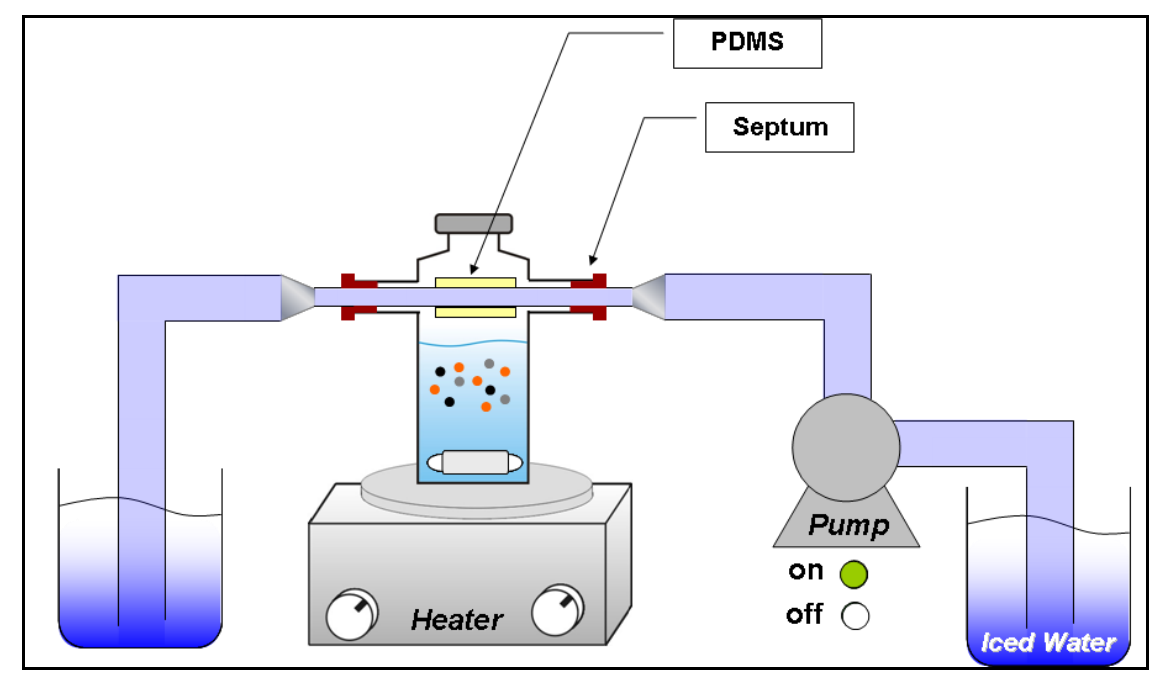

Figura 3.5. Esquema do sistema de RSE.

\subsubsection{Extrações - RSE}

As extrações foram realizadas em frasco de headspace modificado, contendo $10 \mathrm{~mL}$ de amostra de água, lacrados com septo de Teflon e lacre de alumínio. A amostra de água milli-Q foi fortificada com soluções de padrão de pesticidas. A temperatura do banho foi de $85{ }^{\circ} \mathrm{C}$ e a temperatura de refrigeração foi testada em duas condições: sem e com circulação de água à $0^{\circ} \mathrm{C}$. $\mathrm{O}$ equilíbrio da extração foi conduzido por agitação da amostra a $600 \mathrm{rpm}$ em diferentes períodos de tempo. A dessorção foi realizada em solvente com $2 \mathrm{~mL}$ em um insert dentro de um frasco de vidro levado em banho de ultra-som. A mistura de acetonitrila e tolueno (80:20) foi utilizada como solvente de dessorção, previamente testada e otimizada, conforme descrito no Capítulo 2. 


\subsubsection{Barras SBSE}

\subsubsection{Preparo das barras de SBSE}

O molde de Teflon desenvolvido (Figuras 2.4 e 2.5) para recobrir os tubos de aço inoxidável com as novas fases. Aproximadamente 0,4g da fase viscosa do PDMS foram adicionadas e misturadas vigorosamente a $0,04 \mathrm{~g}$ do agente de cura em um frasco de vidro. Em seguida adicionou-se cada uma das fases, em diferentes proporções, para obtenção de consistência adequada para formação do recobrimento.

O mesmo frasco foi colocado sob vácuo de aproximadamente 20 minutos para eliminar as bolhas formadas na homogeneização.

O polímero e a barra foram adicionados no molde. $\mathrm{O}$ molde foi pressionado com o suporte de aço, com ajuste manual, para evitar vazamento da mistura polimérica. Diferentes temperaturas e tempos foram testados para obter uma fase consistente e homogênea. Após a otimização o molde foi levado ao forno durante 70 minutos à temperatura de $80^{\circ} \mathrm{C}$. Posteriormente o molde foi resfriado a temperatura ambiente e a barra foi retirada do molde e levada novamente ao forno seguindo a seguinte programação de temperatura: $40^{\circ} \mathrm{C}$ (durante $30 \mathrm{~min}$ ), $10^{\circ} \mathrm{C} / \mathrm{min}$ até $150^{\circ} \mathrm{C}$ (durante $120 \mathrm{~min})$.

Para a imobilização do filme polimérico, foi utilizado o reagente azo-t-butano como gerador de radicais livres para as reações de entrecruzamento da cadeia de polisiloxanos. Ao final deste procedimento foi realizada uma etapa de entrecruzamento com azo-t-butano.

Este procedimento foi realizado da seguinte forma: em um frasco de vidro, colocou-se a barra presa em um suporte e adicionou-se $1 \mu \mathrm{L}$ de azo-t-butano. $\mathrm{O}$ 
frasco foi levado ao forno à $200^{\circ} \mathrm{C}$ por uma hora e este mesmo procedimento foi repetido três vezes. A Figura 3.6 ilustra o sistema descrito.

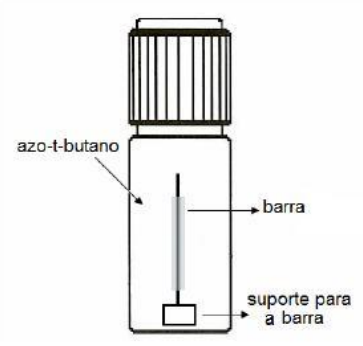

Figura 3.6. Frasco usado para o entrecruzamento do PDMS com as fases empregadas na sua modificação, utilizando azo-t-butano. Extraído de [29].

\subsubsection{Extrações SBSE}

Foram desenvolvidas conforme descrito na seção 4.2 do Capítulo 2. 


\section{RESULTADOS}

\subsection{EXTRAÇÃO SORTIVA REFRIGERADA (RSE)}

\subsubsection{Sistema RSE}

O sistema montado foi ilustrado e descrito anteriormente nas Figuras 3.4 e 3.5.

\subsubsection{Extração}

A extração via SBSE convencional foi inicialmente avaliada para pesticidas organoclorados, mas os resultados não foram tão satisfatórios. Visando uma melhora no desempenho de extração a RSE foi desenvolvida. Neste sistema a amostra pode ser aquecida enquanto a fase de PDMS pode ser refrigerada. Termodinamicamente o coeficiente de partição dos analitos aumentará drasticamente neste ambiente de aquecimento-refrigeração.

As amostras foram preparadas por adição de pesticidas organoclorados em frasco de 20mL. O solvente (tolueno) foi evaporado em fluxo de nitrogênio até secura e então 10mL de água foi adicionada ao frasco. A temperatura de extração utilizada foi de $85^{\circ} \mathrm{C}$. O volume de PDMS utilizado na RSE foi de $81 \mu \mathrm{L}$.

Uma comparação entre a extração de OCPs com e sem a refrigeração interna da RSE é mostrada nas Figuras 3.7 e 3.8. 


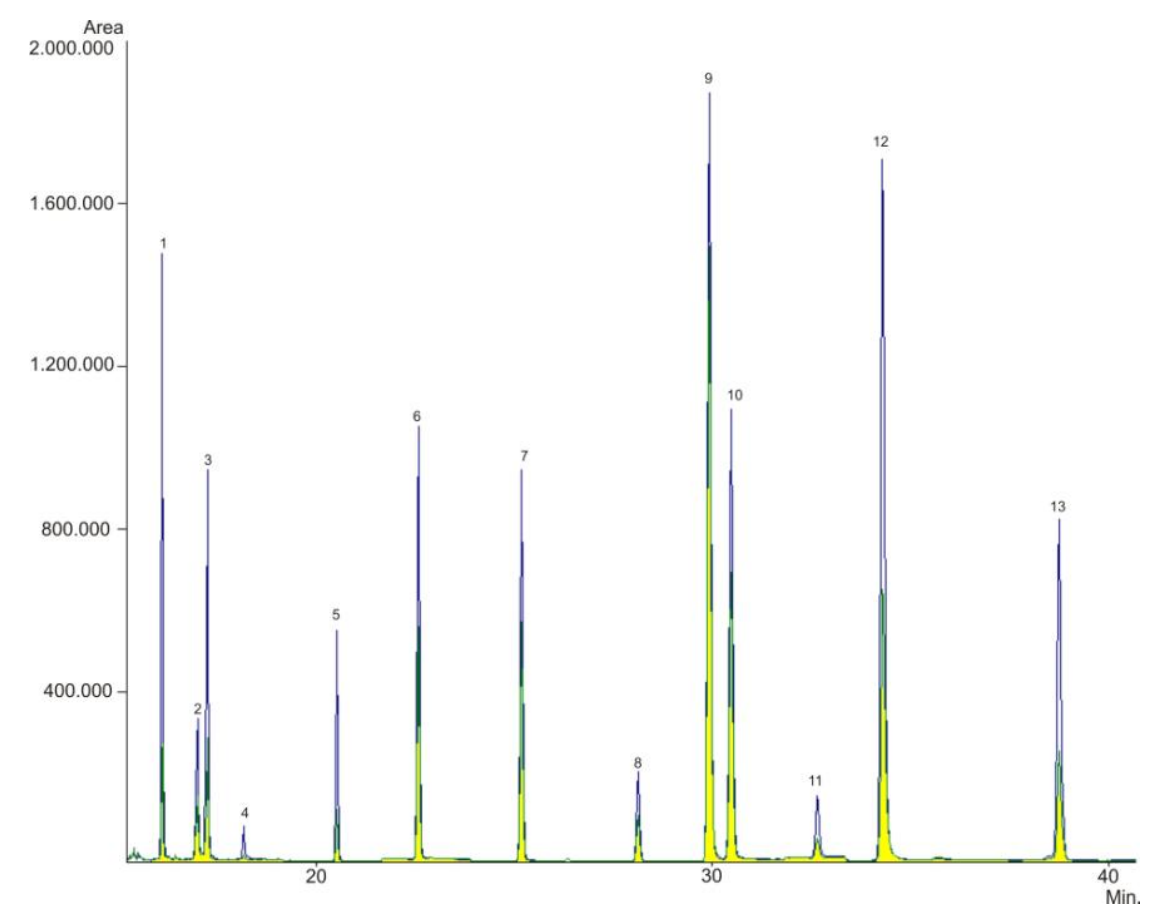

Figura 3.7. Cromatograma de extração de $\mathrm{OCP} 100 \mathrm{ppb}$ a $85^{\circ} \mathrm{C}$ em água, 120 minutos, através de RSE sem e com refrigeração a $0^{\circ} \mathrm{C}$. (1. a HCH, 2. $\beta \mathrm{HCH}, 3$. y HCH, 4. $\Delta \mathrm{HCH}, 5$. Heptacloro, 6. Aldrin, 7. Heptacloro epóxido, 8. a Endosulfan, 9. DDE, 10. Dieldrin, 11. Endrin, 12. DDD, 13. DDT).

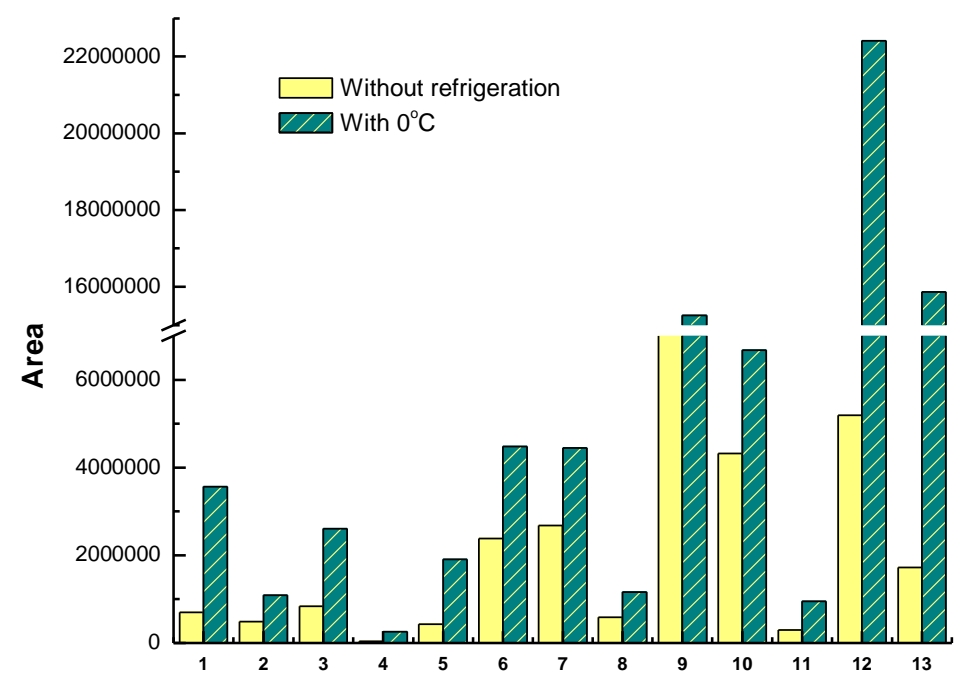

Figura 3.8. Gráfico de barras da comparação da extração $\mathrm{OCP} 100 \mathrm{ppb}$ a $85^{\circ} \mathrm{C}$ em água, 120 minutos, através de RSE sem e com refrigeração a $0^{\circ} \mathrm{C}$. (1. a HCH, 2. $\beta \mathrm{HCH}, 3$. $\gamma \mathrm{HCH}, 4$. $\Delta$ $\mathrm{HCH}$, 5. Heptacloro, 6. Aldrin, 7. Heptacloro epóxido, 8. a Endosulfan, 9. DDE, 10. Dieldrin, 11. Endrin, 12. DDD, 13. DDT). 
O resultado de extração de OCPs em água, na concentração de 100ppb, com temperatura de extração de $85^{\circ} \mathrm{C}$, tempo de extração de 120 minutos, através de RSE sem e com refrigeração à $0^{\circ} \mathrm{C}$ mostra que a quantidade de analitos extraída é superior quando aplicada a refrigeração. Os resultados demonstram que a temperatura da fase de PDMS promove influência significativa na extração.

Para um estudo detalhado selecionou-se alguns dos compostos organoclorados previamente extraídos, usualmente denominados DDXs (DDE, DDD e DDT).

A Tabela 3.1 mostra os coeficientes de partição octanol-água $\left(\log \mathrm{K}_{\mathrm{o} / \mathrm{w}}\right)$, os íons selecionados $(\mathrm{m} / \mathrm{z})$ e os tempos de retenção $\left(t_{R}\right)$ para os analitos selecionados. De acordo com a teoria de SBSE os coeficientes de distribuição dos analitos entre o PDMS e a matriz água (K $\mathrm{K}_{\mathrm{PDS} / \mathrm{w}}$ ) são fortemente correlacionados com o $\mathrm{K}_{\mathrm{o} / \mathrm{w}}$ correspondente. É esperado que pesticidas apolares $\left(\log K_{\mathrm{o} / \mathrm{w}}>5\right)$ devem ter afinidade significativa com fases do polímero PDMS. Assumindo um volume de 10 mL de amostra de água $\left(\mathrm{V}_{\mathrm{w}}\right)$ e uma barra de RSE com volume de $81 \mu \mathrm{L}$ ( $\left.\mathrm{V}_{\mathrm{SBSE}}\right)$ a razão de fase $\beta$ pôde ser calculada $\left(\beta=V_{\mathrm{w}} / \mathrm{V}_{\mathrm{SBSE}}\right)$ e foi estabelecida com 123,5 .

Tabela 3.1. Coeficiente de partição octanol-água $(\log \mathrm{ko} / \mathrm{w})$, ions selecionados $(\mathrm{m} / \mathrm{z})$ e tempo de retenção $\left(t_{R}\right)$ para os analitos analisados sob as condições experimentais do estudo.

\begin{tabular}{cccc}
\hline Pesticida & $\log \mathbf{k}_{\mathrm{o} / \mathbf{w}^{\mathbf{a}}}$ & $\mathbf{m} / \mathbf{z}$ & $\mathbf{t}_{\mathrm{R}}(\mathbf{m i n})$ \\
DDE & 6.00 & $246 ; 248 ; 176$ & 9.08 \\
DDD & 5.87 & $235 ; 237 ; 165$ & 10.32 \\
DDT & 6.79 & $235 ; 237 ; 165$ & 11.67 \\
\hline
\end{tabular}

a Baseado em cinco replicatas 
Utilizando a razão de fase foi possível calcular a recuperação teórica, para os compostos DDXs, e esta foi de 100\%. É descrito na literatura [30] que existe um bom acordo da recuperação teórica calculada com a recuperação real para a SBSE e através dos experimentos realizados também foi possível confirmar este acordo para a técnica de RSE, conforme Tabela 3.2.

A Tabela 3.2 resume a média das recuperações de extração de DDX’s em amostras de água por RSE. Através da Tabela 3.2 podemos concluir que ocorreu uma extração exaustiva destes compostos da água, com melhores resultados para o tempo de extração de 120 minutos, selecionando este como melhor tempo de extração, conforme pode ser observado na Figura 3.9.

Tabela 3.2. Recuperação dos DDXs em água fortificada a 90, 120 e $180 \mathrm{~min}$ de extração( $\left(85^{\circ} \mathrm{C}\right)$.

\begin{tabular}{|c|c|c|c|}
\hline Pesticida & $\begin{array}{l}\text { Recuperação a } \\
\text { (\%) } 90 \text { min }\end{array}$ & $\begin{array}{l}\text { Recuperação a } \\
\text { (\%) } 120 \text { min }\end{array}$ & $\begin{array}{l}\text { Recuperação a } \\
\text { (\%) } 180 \text { min }\end{array}$ \\
\hline DDE & 84,5 & 106,0 & 101,4 \\
\hline DDD & 63,1 & 99,7 & 83,3 \\
\hline DDT & 55,5 & 77,3 & 73,4 \\
\hline
\end{tabular}

a Baseado em cinco replicatas 


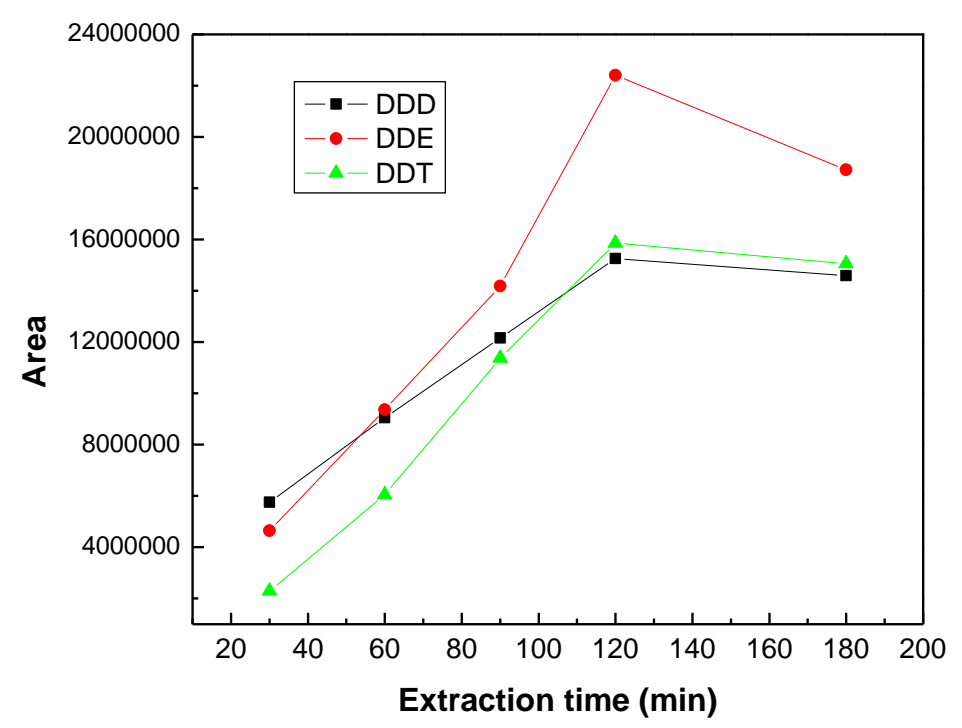

Figura 3.9. Curva cinética de extração para os DDXs utilizando RSE (PDMS), $85^{\circ} \mathrm{C}$.

\subsubsection{Validação}

Alguns dos parâmetros de validação como precisão, limites de detecção e limites de quantificação foram avaliados conforme descrito no item 3.3.4 do Capítulo 1.

Para determinação da precisão, foi utilizado o cálculo através do coeficiente de variação nos resultados de cinco amostras fortificadas, na concentração de $100 \mu \mathrm{g} . \mathrm{L}^{-1}$, analisadas nas mesmas condições e no mesmo dia, por um tempo de extração de 120 minutos.

Os valores obtidos foram comparados com os valores especificados pela Agência de Proteção Ambiental dos EUA (EPA), a Agência Nacional de Vigilância Sanitária (ANVISA) e o Ministério da Agricultura, Pecuária e Abastecimento (MAPA). (Tabela 3.3) 
Tabela 3.3. Resultados da precisão para os DDXs por RSE.

\begin{tabular}{ccccc}
\hline Pesticidas & Precisão & $\begin{array}{c}\text { Requisitos } \\
\text { EPA }\end{array}$ & Requisitos ANVISA & $\begin{array}{c}\text { Requisitos } \\
\text { MAPA }\end{array}$ \\
DDE & 9,1 & $<15 \%$ & $<15 \%$ & \\
DDD & 12,7 & & $($ ou $<20 \%$ no LOQ $)$ & $<35 \%$ \\
DDT & 6,5 & & & \\
\hline
\end{tabular}

O limite de deteç̧ão (LOD), baseado na razão sinal ruído (S/N) de 3 [31], foi entre 0,055 e 0,069 $\mu \mathrm{g} \cdot \mathrm{L}^{-1}$, e o limite de quantificação (LOQ), baseado na razão sinal ruído (S/N) de 10, foi entre 0,170 e 0,206 $\mu \mathrm{g} . \mathrm{L}^{-1}$ (Tabela 3.4). Assim como na técnica de SBSE os limites de detecção e quantificação encontrados foram limitados pelo modo de injeção, mas com o uso de um injetor de grande volume (LVI) valores ainda menores poderiam ter sido obtidos. Mesmo que limitados pela técnica de injeção os valores encontrados estão abaixo dos limites de tolerância para pesticidas organoclorados em água potável segundo as diretrizes de qualidade de água da União Européia [32] confirmando assim a eficiência e sensibilidade da técnica RSE.

Tabela 3.4. Limites de detecção e quantificação encontrados.

\begin{tabular}{lcc} 
Analito & LOD $\left(\mu \mathrm{g} \cdot \mathrm{L}^{-1}\right)$ & LOQ $\left(\mu \mathrm{g} \cdot \mathrm{L}^{-1}\right)$ \\
DDE & 0,069 & 0,206 \\
DDD & 0,055 & 0,170 \\
DDT & 0,066 & 0,190 \\
\hline
\end{tabular}




\subsection{APLICAÇÃO DA TÉCNICA RSE}

\subsubsection{Aplicação em amostra real}

Para aplicação da técnica de RSE em amostra real realizou-se uma coleta de água no rio Atibaia, na cidade de Paulínia-SP, em uma região com sérios problemas de contaminação por pesticidas organoclorados devidos acidentes ocorridos nas mediações da Empresa Shell Brasil S/A.

\subsubsection{Rio Atibaia, Paulínia (SP)}

O Rio Atibaia, pertencente à unidade de gerenciamento UGRHI 05 que compreende as bacias do rio Capivari, Piracicaba e Jundiaí. Segundo relatório da situação dos recursos hídricos da UGRHI 5 (Comitê das Bacias Hidrográficas dos Rios Piracicaba, Capivari e Jundiaí, 2000), esta área é caracterizada como uma região industrial, com sérios problemas ambientais decorrentes da poluição dos rios, principalmente pela falta de tratamento de esgotos e elevado índice de indústrias poluidoras [33]. (Figura 3.10)

O Rio Atibaia recebe efluentes domésticos, de indústrias dos ramos de papel e celulose, alimentício, têxtil, couros, metalúrgico, químico e petroquímico uma descarga com cerca de 40 tDBO5/dia, além da contribuição de 72 kgDBO5/dia oriunda do tratamento de efluentes das indústrias do ramo sucro-alcooleiro. 


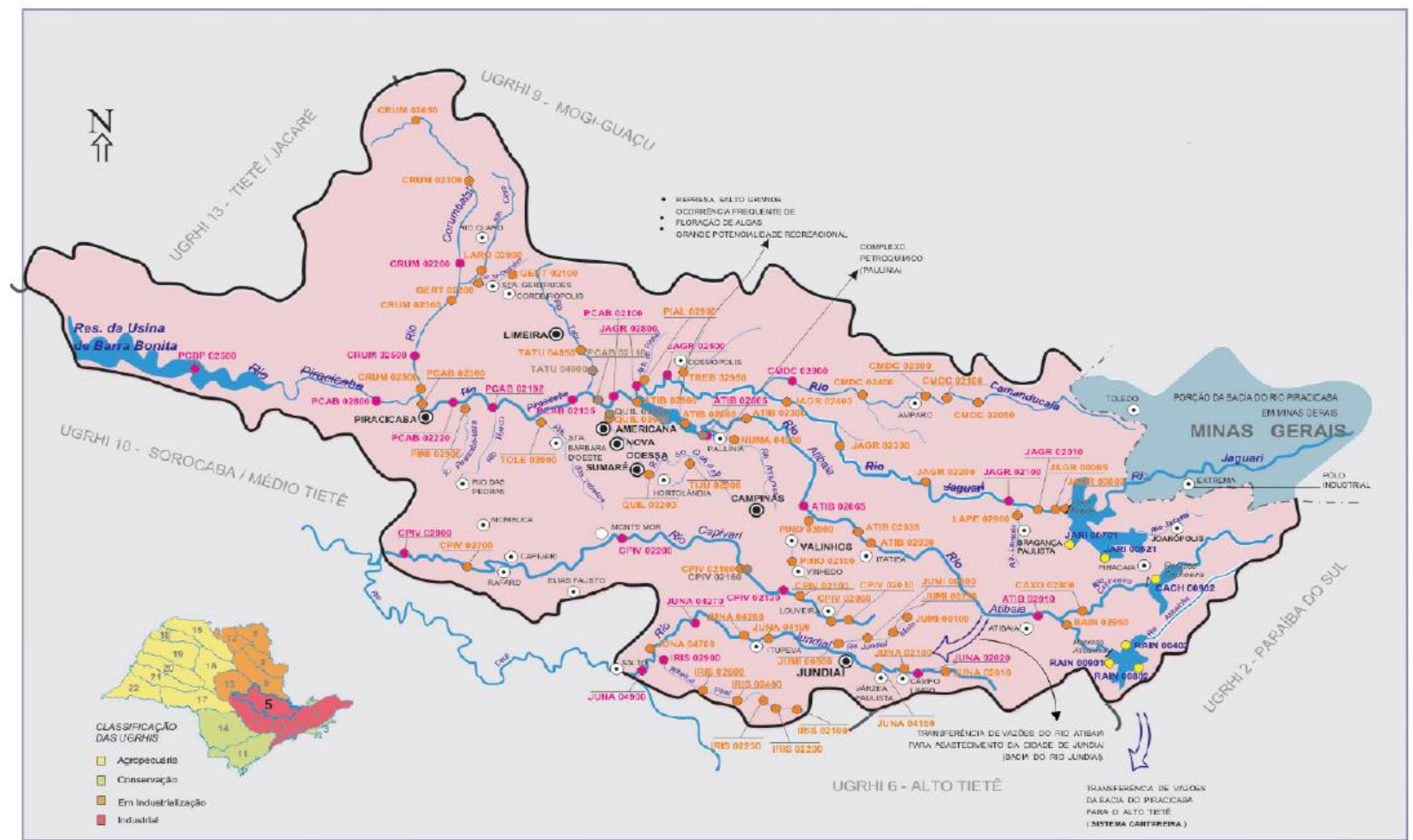

LEGENDA:

PRINCIPAIS CIDADES

TIPOS DE MONITORAMENTO:

UGRHI 5 - PIRACICABA / CAPIVARI / JUNDIAÍ

- SEDE MUNICIPAL

-.- LIMITE INTERESTADUAL

G CURSO DAGUA

Rede monitoramento - Agua.

MONITORAMENTO REgIONAL - água

- REDE MONITORAMENTO - AGUA + SEDIMENTO

PEDE MONITORAIEE

MONITORAMENTO AUTOMATICO - KFW

BARRAGENS

Figura 3.10. UGRHI 05 - Piracicaba, Capivari e Jundiaí . Extraído de [33]. 
Em conseqüência dessas descargas, o Rio Atibaia apresenta-se continuamente em desconformidade com seu enquadramento na classe 2, definido segundo CONAMA 20 (1986), para os parâmetros coli-fecal e fosfato-total, além dos metais cádmio, chumbo, cobre, níquel e zinco, apresentando ao longo de seu curso um IQA (Índice de Qualidade de Água) que indica uma água de qualidade boa e aceitável, com tendência a piorar e, na sua foz, em Americana, a qualidade é ruim com tendência indefinida .

O Rio Atibaia ainda sofre a influência do cultivo de 52 ha de tomates, 6.327 ha de cana de açúcar e 1.309 ha de laranja, o qual estima-se a quantidade de agrotóxicos utilizados para estas culturas de respectivamente: $5.143 \mathrm{~kg}, 50.616 \mathrm{~kg}$ e $47.517 \mathrm{~kg}$ [33].

A partir do histórico, do rio Atibaia, foram selecionados 2 pontos para realização da coleta. Estes pontos localizam-se próximos à antiga área da empresa Shell Brasil S/A.

A empresa Shell instalou-se em Paulínia (SP), na década de 70, no Bairro Recanto dos Pássaros, em uma área de aproximadamente 80 hectares. Os limites destas instalações seguem o formato do Rio Atibaia ao norte, oeste e sul. A leste a divisa da propriedade é uma linha reta. O terreno da fábrica ainda é contornado por uma estrada, não pavimentada, que separa algumas residências particulares e, em seguida, o Rio Atibaia $[33,34]$.

Entre os produtos fabricados e manipulados por esta unidade destacam-se pesticidas da classe dos organoclorados, organofosforados, piretróides, triazinas, carbamatos, entre outros. Dentre estes produtos, os organoclorados merecem destaque devido a sua alta toxicidade, o que levou à expulsão das fábricas 
produtoras de "Drins" nos Estados Unidos pelo menos três anos antes da Shell se instalar no Brasil (em 1973). A fabricação de “Drins" no site de Paulínia ocorreu no período de 1975 a 1990, sendo que a partir de 1986, quando a comercialização destes foi proibida no Brasil (segundo portaria 329 de 02 de Setembro de 1985 do Ministério da Agricultura), passaram a ser produzidos apenas para exportação [33, 34].

Em 1994, a negociação e venda da Shell para a Cyanamid incluiu uma ampla auditoria ambiental, a qual constatou a contaminação das águas subterrâneas e solo. A Shell reconheceu que a contaminação aconteceu devido a três acidentes ecológicos ocorridos em 1978, 1982 e 1985. Devido a este fato, a Shell apresentou uma autodenúncia à Curadoria do Meio Ambiente de Paulínia. A curadoria autorizou a venda da fábrica, ficando para a Shell a responsabilidade de descontaminar o solo e as águas subterrâneas. Um ano depois, a empresa se comprometeu a realizar trabalhos de remediação, por meio de barreiras hidráulicas, e o monitoramento da água [33, 34].

\subsubsection{Amostragem}

O plano de amostragem também pode considerar a obtenção de amostras simples (obtida em um único ponto), ou amostras compostas (obtida pela mistura de amostras de diferentes pontos). Segundo Suguio [36, 33] não existem regras fixas em relação aos méritos destes dois tipos de amostragem. Assim, neste trabalho optou-se a utilização de amostras simples.

Durante o processo de amostragem, é muito importante considerar a descontaminação dos equipamentos empregados, para que não ocorra arraste dos 
contaminantes de um ponto a outro amostrado. Segundo a CETESB, esta descontaminação deve ser realizada pela remoção física, neutralização/remoção química dos contaminantes ou ainda desinfecção/esterilização dos equipamentos, sendo realizada, na prática, uma combinação de duas ou mais dessas ações $[33,34]$.

A amostragem foi realizada no dia 15 de Dezembro de 2008. A amostragem foi realizada em dois pontos os quais era possível o acesso sem a utilização de embarcação e foram coletados 1L de amostra de cada ponto. Fotos individuais dos pontos de amostragem são indicadas nas Figuras 3.11 e 3.13.

Durante a amostragem, as amostras foram preservadas em isopor com gelo, as quais em seguida foram transportadas para o Laboratório de Cromatografia da USP e acondicionadas em freezer à temperatura estipulada pelo plano de amostragem até serem analisadas.

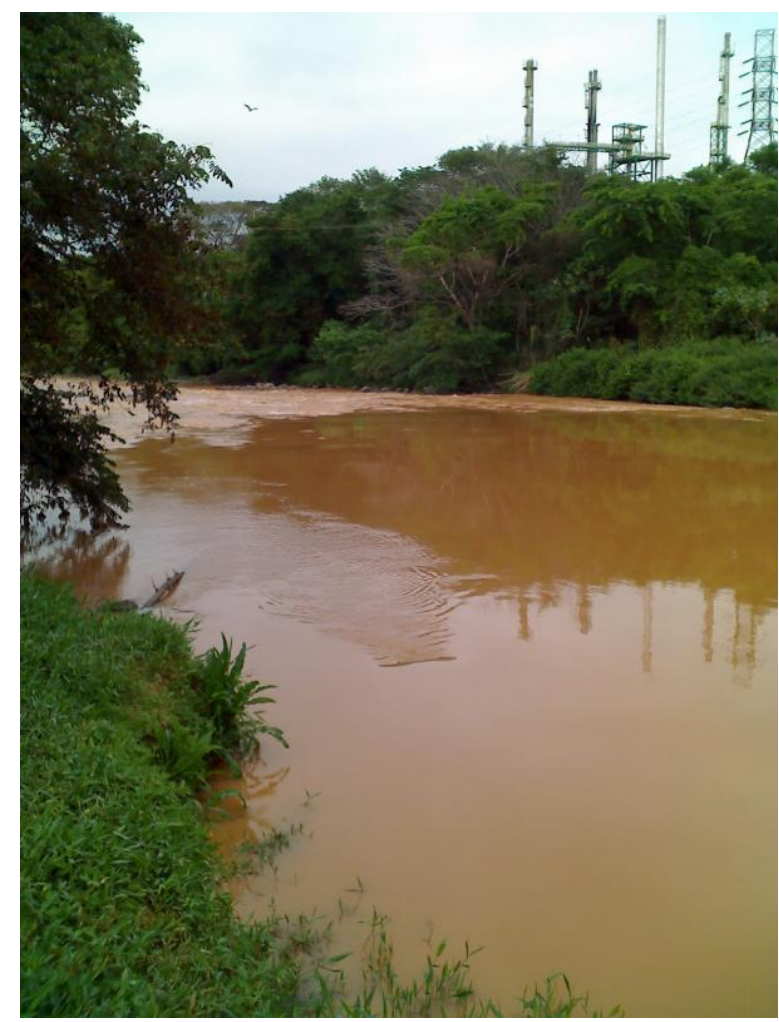

Figura 3.11. Ponto de amostragem 1: Final do contorno do Rio Atibaia na empresa Shell (região de curva). 


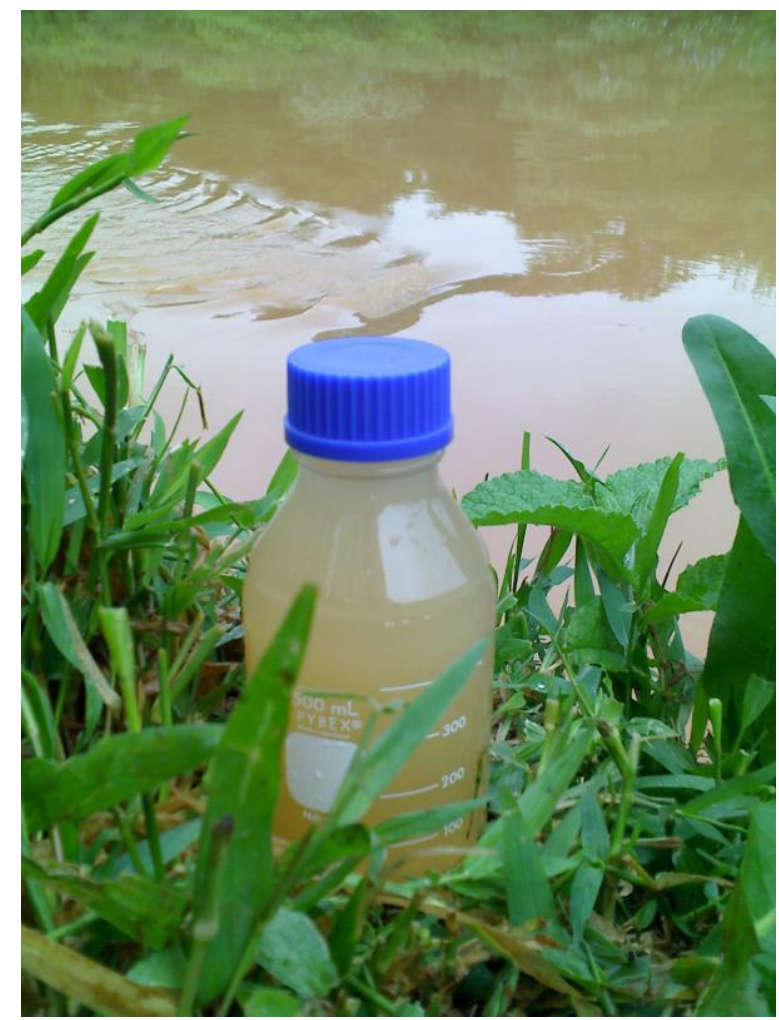

Figura 3.12. Frasco de amostragem à margem do rio Atibaia.

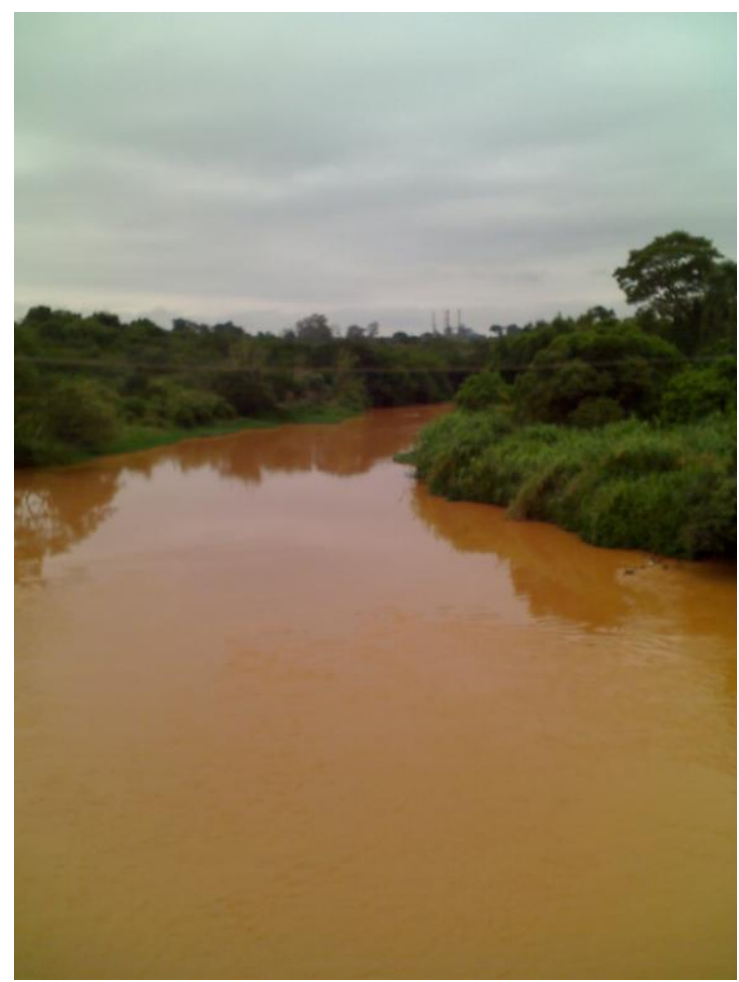

Figura 3.13. Ponto de amostragem 2: Ponte sobre o Rio Atibaia na cidade de Paulínia, próximo à empresa Syngenta. 


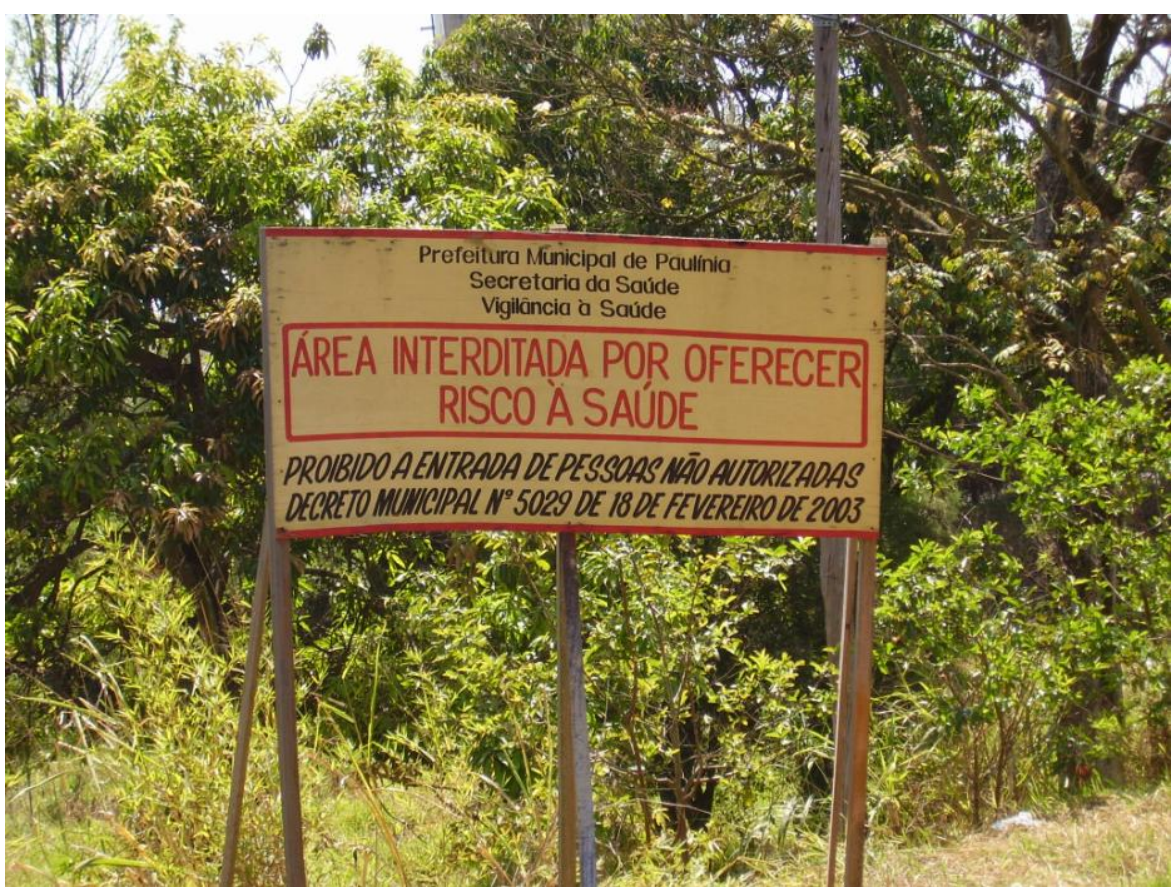

Figura 3.14. Placa indicando a interdição do bairro Recanto dos Pássaros, próximo ao local de coleta. Extraído de [33].

\subsubsection{Análise das amostras e tratamento de dados}

As amostras foram analisadas de acordo com a metodologia desenvolvida no item 3.2 deste Capítulo. A partir das análises foi possível encontrar a presença de alguns OCPs na amostra do Ponto 1. Na Tabela 3.5 estão apresentados os analitos que obtiveram sinal acima do LOD, sendo estes: $\gamma-\mathrm{HCH}$, heptacloro epóxido, DDD, DDE e DDT.

Devido à limitação da técnica de injeção os valores de LOD e LOQ para os analitos $\gamma-\mathrm{HCH}$ e heptacloro epóxido obtidos não foram tão baixos. Os valores de LOD encontrados foram de $0,54 \mu \mathrm{g} . \mathrm{L}^{-1}$ para o $\mathrm{\gamma}-\mathrm{HCH}$ e $0,12 \mu \mathrm{g} . \mathrm{L}^{-1}$ para o heptacloro epóxido, já os valores de LOQ encontrados foram de 1,61 $\mu \mathrm{g} . \mathrm{L}^{-1}$ para o $\gamma-\mathrm{HCH}$ (ou Lindano) e de $0,36 \mu g . \mathrm{L}^{-1}$ para o heptacloro epóxido. 
Tabela 3.5. Resultados encontrados comparados com a legislação.

\begin{tabular}{|c|c|c|}
\hline $\begin{array}{c}\text { Ponto de } \\
\text { Amostragem }\end{array}$ & $\begin{array}{l}\text { Resultados encontrados } \\
\left(\mu \mathrm{g} . \mathrm{L}^{-1}\right)\end{array}$ & $\begin{array}{l}\text { Valores Máximos } \\
\text { CETESB }{ }^{[35]}\left(\mu g . L^{-1}\right)\end{array}$ \\
\hline Ponto 1 & $\begin{array}{l}\text { ץ-HCH < LOQ } \\
\text { Heptacloro epóxido: } 0,371 \\
\text { DDE: } 0,665 \\
\text { DDD: } 0,496 \\
\text { DDT: } 0,568 \\
(\text { DDE+DDD+DDT) }=1,729\end{array}$ & $\begin{array}{c}0,02 \\
0,01 \\
(\mathrm{DDE}+\mathrm{DDD}+\mathrm{DDT}) \\
=0,002\end{array}$ \\
\hline Ponto 2 & Nada encontrado & - \\
\hline
\end{tabular}

Os resultados das análises foram comparados com os limites de tolerância de compostos organoclorados apresentados pela CETESB. A partir da comparação observou-se que Ponto 1 possui valores de heptacloro epóxido, DDE, DDD e DDT acima dos limites permitidos, o que indica que provavelmente a presença destes compostos poderá provocar efeitos nas diversas formas de vida aquática durante um período de exposição associado a este ambiente. Já o $\gamma-\mathrm{HCH}$, embora abaixo do LOQ, também foi encontrado no Ponto 1. Este composto apresenta peculiaridade por ser o mais solúvel entre seus isômeros e gera uma grande mobilidade no meio aquático. No Ponto 2 de amostragem não foi detectada a presença de OCPs.

A técnica RSE permitiu diagnosticar a contaminação por pesticidas organoclorados no Rio Atibaia, na região próxima ao caso de contaminação citado anteriormente, e mostra acordo com diagnóstico da contaminação realizado em amostras de sedimento da mesma região [33]. 


\subsection{NOVOS RECOBRIMENTOS TESTADOS}

As barras preparadas possuíam uma mistura de OV-17/PDMS, OV-17 Vinil/PDMS e RTX-50/PDMS. Para a fase OV-17/PDMS as proporções foram de 30:70 e 50:50. A barra de OV-17 Vinil/PDMS foi desenvolvida na proporção 5:95 Já para o desenvolvimento da barra com a mistura RTX-50/PDMS foi utilizada a proporção de 14:86. As quantidades utilizadas foram diferenciadas devido a viscosidade de cada uma das fases e da consistência necessária para a formação do recobrimento da barra de SBSE.

As novas fases poliméricas para SBSE desenvolvidas foram testadas e comparadas na análise de benzeno, tolueno, etilbenzeno e xileno (BTEX) em água. A comparação pode ser observada nas Figuras.

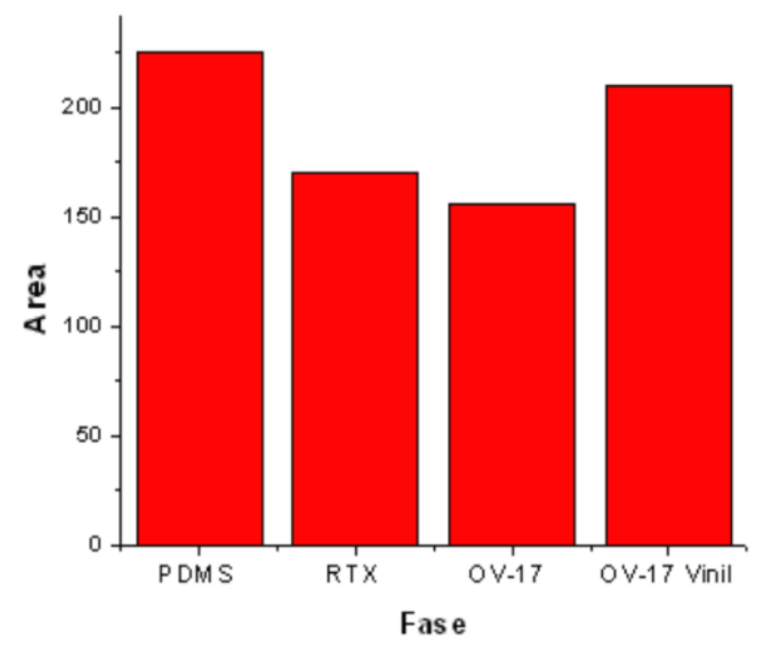

Figura 3.15. Extração de Benzeno utilizando barras desenvolvidas in-house com diferentes fases poliméricas. (PDMS= 100\% PDMS; RTX=14:86\% de RTX/PDMS; OV17= 50\% de OV-17/PDMS; OV-17Vinil= 5:95\% de OV-17/PDMS). 


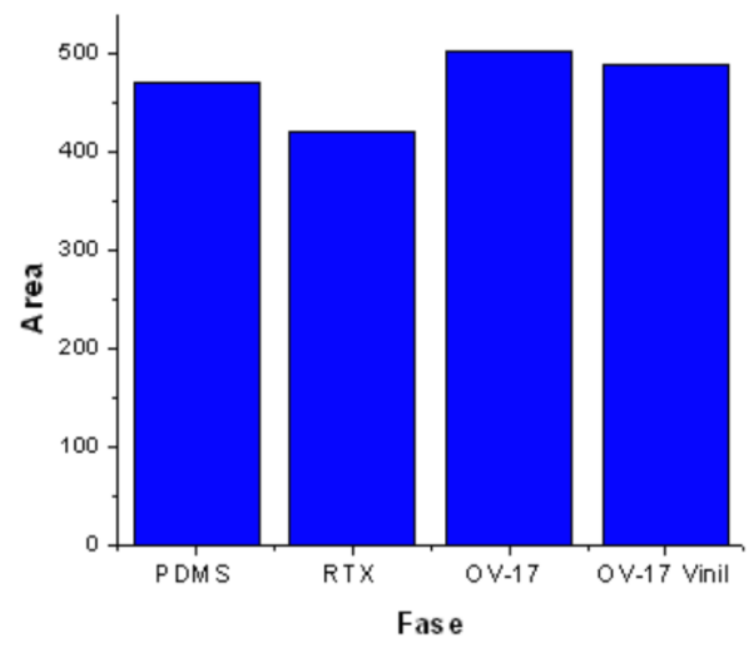

Figura 3.16. Extração de Etilbenzeno utilizando barras desenvolvidas in-house com diferentes fases poliméricas. (PDMS $=100 \%$ PDMS; RTX $=14: 86 \%$ de RTX/PDMS; OV-17= 50\% de OV-17/PDMS; OV-17Vinil= 5:95\% de OV-17/PDMS).

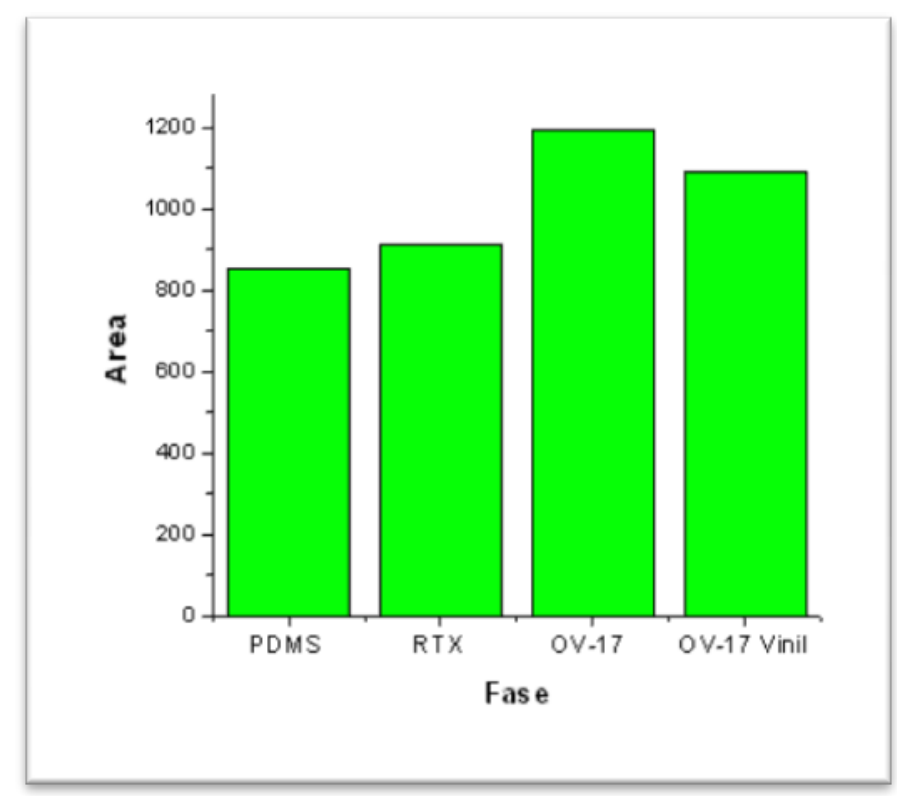

Figura 3.17. Extração de Xilenos (soma o, m, p-xileno) utilizando barras desenvolvidas inhouse com diferentes fases poliméricas. (PDMS=100\% PDMS; RTX=14:86\% de RTX/PDMS; OV-17= 50\% de OV-17/PDMS; OV-17Vinil= 5:95\% de OV-17/PDMS). 
Para a análise de BTEX a mistura OV-17/PDMS (50\%) mostrou-se mais eficiente para a maioria dos compostos, exceto para o tolueno em que a melhor fase foi a de PDMS 100\% (Figura 3.18).

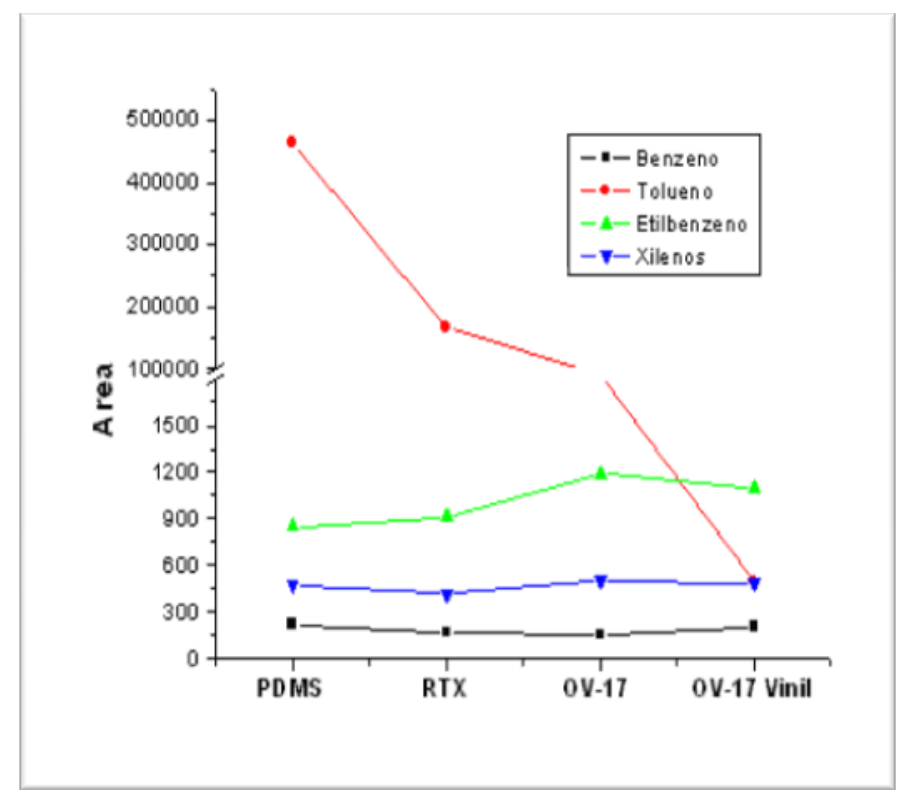

Figura 3.18. Comparação da extração de BTEX utilizando barras desenvolvidas in-house com diferentes fases poliméricas. (PDMS $=100 \%$ PDMS; RTX= 14:86\% de RTX/PDMS; OV$17=50 \%$ de OV-17/PDMS; OV-17Vinil= 5:95\% de OV-17/PDMS).

Além disso, as novas fases foram testadas para pesticidas organoclorados (OCPs) e para a maioria dos compostos a fase com RTX ${ }^{\circledR}-50 /$ PDMS mostrou-se mais eficiente, exceto para os compostos 1, 3 e 4 onde a fase contendo 100\% PDMS apresentou melhor resultado (Figura 3.19).

Através das áreas obtidas podemos observar que o aumento da polaridade da fase pode ser positivo ou não para a extração, dependendo da polaridade de cada analito. Com a adição da fase $\mathrm{RTX}^{\circledR}{ }^{\circledR} 50$ ao PDMS há um aumento na polaridade e conseqüentemente um melhor resultado de extração para os OCPs mais polares. A fase $\mathrm{RTX}^{\circledR}-50$, com média polaridade, é freqüentemente utilizada como fase 
estacionária de colunas capilares para aplicações ambientais, incluindo os métodos EPA-604 (Fenol) e 8060 (Éster ftálico).

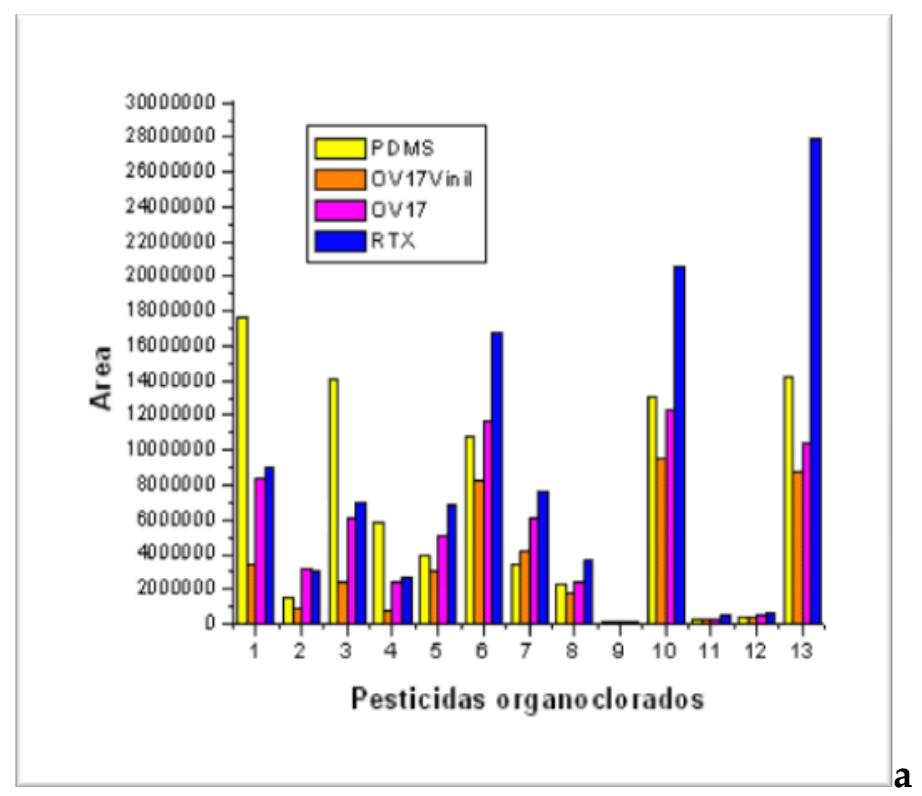

Figura 3.19. a) Extração de OCPs em amostras de água utilizando diferentes fases poliméricas.

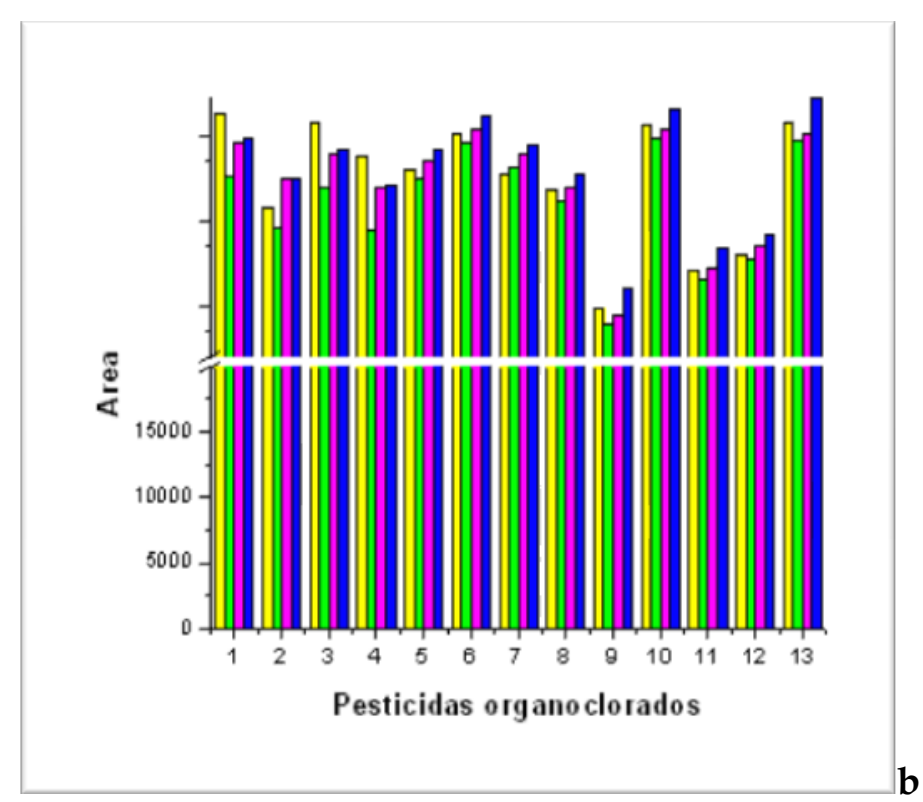

Figura 3.19. b) Redução da escala do gráfico da figura a. Os algarismos nos gráficos representam: 1) Alfa-BHC, 2) Beta-BHC, 3) Gama-BHC, 4) Delta-BHC, 5) Heptacloro, 6) Aldrin, 7) Heptacloro epóxido, 8) Alfa Endosulfan, 9) DDE, 10) Dieldrin, 11) Endrin, 12) DDD, 13) DDT. 


\section{CONCLUSÕES}

A partir dos resultados obtidos foi possível verificar que a temperatura exerce influência significativa e deve ser otimizada para melhorar a extração e alcançam extração exaustiva dos analitos de interesse. $\mathrm{O}$ aumento das áreas dos cromatogramas pode promover melhores limites de detecção. A técnica RSE desenvolvida foi aplicada na análise de pesticidas organoclorados em água com sucesso, mostrando ser uma técnica eficiente e econômica. Além disso, a RSE pode ser aplicada na extração de outros compostos voláteis em diferentes matrizes como alimentos, plantas e fármacos.

As barras de SBSE, desenvolvidas no laboratório, com novas fases poliméricas podem ser aplicadas em diferentes matrizes. Através do estudo realizado verificou-se ótimos resultados da fase contendo a mistura de RTX ${ }^{\circledR}-50 /$ PDMS quando comparada com demais fases na extração de pesticidas organoclorados. Estas barras poderão ainda ser testadas no futuro em diversas matrizes e também novas misturas poderão ser desenvolvidas focando o analito de interesse. 


\section{REFERÊNCIAS BIBLIOGRÁFICAS}

[1] BALTUSSEN, E.; SANDRA, P.; DAVID, F.; CRAMERS, C. Stir Bar sorptive extraction (SBSE), a novel extraction technique or aqueous samples: theory and principles. J. Microcol. Sep., v.11, p.737-747, 1999.

[2] PAWLISZYN, J.; ARTHUR, C. L. Solid Phase Microextraction with Thermal Desorption Using Fused Silica Optical Fibers. Anal. Chem., v. 62, p. 2145-2148, 1990.

[3] GHIASVAND, A.R., HOSSEINZADEH, S. PAWLISZYN, J. New cold-fiber headspace solid-phase microextraction device for quantitative extraction of polycyclic aromatic hydrocarbons in sediment. J. Chromatogr. A, v. 1124, p. 35-42, 2006.

[4] ZHANG, Z., PAWLISZYN, J. Quantitative Extraction Using an Internally Cooled Solid Phase Microextraction Device. Anal. Chem., v. 67, p. 34-43, 1995.

[5] CHEN, Y., PAWLISZYN, J. Miniaturization and Automation of an Internally Cooled Coated Fiber Device, Anal. Chem., v. 78, p. 5222-5226, 2006.

[6] J. O'REILLY, O., WANG, L., SETKOVA, L., HUTCHINSON, J. P., CHEN, Y., LORD, H. L., LINTON, C. M., PAWLISZYN, J. Automation of solid-phase microextraction. J. Sep. Sci., v. 28 p. 2010-2022, 2005.

[7] CARASEK, E., PAWLISZYN, J. Screening of tropical fruit volatile compounds using solid-phase microextraction (SPME) fibers and internally cooled SPME fiber. J. Agric. Food Chem., v. 54, p. 8688-8696, 2006.

[8] CARASEK, E., CUDJOE, E., PAWLISZYN, J. Fast and sensitive method to determine chloroanisoles in cork using an internally cooled solid-phase microextraction fiber. J. Chromatogr.A, v. 1138, p. 10-17, 2007.

[9] CHEN, Y., BEGNAUD, F., CHAINTREAU, A., PAWLISZYN, J. Analysis of flavor and perfume using an internally cooled coated fiber device. J. Sep. Sci., v. 30, p. 10371043, 2007.

[10] GHIASVAND, A. R., SETKOVA, L., PAWLISZYN, J. Determination of flavour profile in Iranian fragrant rice samples using cold-fibre SPME-GC-TOF-MS. Flavour Fragr. J., v.22 , p. 377-391, 2007. 
[11] ACHTEN, C., PÜTTMANN, W. Determination of Methyl tert-Butyl Ether in Surface Water by Use of Solid-Phase Microextraction. Environ. Sci. Technol., v. 34, p. 1359-1364, 2000.

[12] CHIA, J-K., LEE, T-Y., HUANG, S-D. Simple device for the solid-phase microextraction screening of polychlorodibenzo-p-dioxins and polychlorodibenzofurans in heavily contaminated soil samples. Anal. Chim. Acta., v.527, p. 157-162, 2004.

[13] LIAO, L., YANG, J., WANG, Y., SUN, T., JIA, J. Study on a novel circulating cooling solid-phase microextraction method. J. Chromatogr. A v. 1135, p. 1-5, 2006.

[14] CHAI, X., JIA, J., SUN, T., WANG, Y., LIAO, L. Application of a novel cold activated carbon fiber-solid phase microextraction for analysis of organochlorine pesticides in soil. J. Environ. Sci. Health B, v. 42, p. 629-634, 2007.

[15] HUANG, S. P., HUANG, S. D. Determination of organochlorine pesticides in water using solvent cooling assisted dynamic hollow-fiber-supported headspace liquid-phase microextraction. J. Chromatogr. A., v. 1176, p. 19-25, 2007.

[16] FRIES, E. PÜTTMANN, W. Improvement of HS-SPME for analysis of volatile organic compounds (VOC) in water samples by simultaneous direct fiber cooling and freezing of analyte solution. Anal. Bioanal. Chem. v. 386, p. 1497-1503, 2006.

[17] TIENPONT, B., DAVID, F., BICCHI, C., SANDRA, P. High capacity headspace sorptive extraction. J. Microcol. Sep., v. 12, p. 577-584, 2000.

[18] BICCHI, C; CORDERO, C; IORI, C; RUBIOLO, P. Headspace sorptive extraction (HSSE) in the headspace analysis of aromatic and medicinal plants. J. High Resolut. Chrom., v.23, n.9, p. 539-546, 2000.

[19] BICCHI, C., CORDERO, C., LIBERTO, E., RUBIOLO, P., SGORBINI, B., DAVID, F., SANDRA. P. Dual-phase twisters: A new approach to headspace sorptive extraction and stir bar sorptive extraction. J. Chromatogr. A, v. 1094, p.9-16, 2005.

[20] LIU, W., WANG, H., GUAN., Y. Preparation of stir bars for sorptive extraction using sol-gel technology. J. Chromatogr. A, v. 1045, p. 15-22, 2004.

[21] LAMBERT, J. P., MULLETT, W. M., KWONG, E., LUBDA, D. Stir bar sorptive extraction based on restricted access material for the direct extraction of caffeine and metabolites in biological fluids. J. Chromatogr. A, v. 1075, p. 43-49, 2005. 
[22] NENG, N. R., PINTO, M. L., PIRES, J., MARCOS, P. M., NOGUEIRA, J. M. F. Development, optimisation and application of polyurethane foams as new polymeric phases for stir bar sorptive extraction. J. Chromatogr. A, v. 1171, p. 8-14, 2007.

[23] SILVA, A. R., PORTUGAL, F. C. M., NOGUEIRA, J. M. Advances in stir bar sorptive extraction for the determination of acidic pharmaceuticals in environmental water matrices: Comparison between polyurethane and polydimethylsiloxane polymeric phases. J. Chromatogr A, v. 1209, p.10-16, 2008.

[24] PORTUGAL, F. C. M., PINTO, M. L., NOGUEIRA, J. M. F. Optimization of Polyurethane Foams for Enhanced Stir Bar Sorptive Extraction of Triazinic Herbicides in Water Matrices. Talanta, v. 77, p. 765-773, 2008.

[25] NOGUEIRA, A. M., GROSSI, P., OLIVARES, I. R. B., QUEIROZ, M. E., LANCAS, F. M., Poliurethane in SBSE. J. Sep. Sci. - (Submetido Mar/2009)

[26] HUANG, X., YUAN, D., HUANG, B. Determination of steroid sex hormones in urine matrix by stir bar sorptive extraction based on monolithic material and liquid chromatography with diode array detection. Talanta, v.75, p. 172-177, 2008.

[27] CHIA, K. J., HUANG, S. D., Analysis of organochlorine pesticides in wine by solvent bar microextraction coupled with gas chromatography with tandem mass spectrometry detection. Rapid Commun. Mass Spectrom., v. 20, p. 118-124, 2006.

[28] NOGUEIRA, A. M., GROSSI, P., OLIVARES, I. R. B., QUEIROZ, M. E., LANCAS, F. M., Modified PDMS in SBSE. J. Sep. Sci. - (Submetido Mar/2009)

[29] NOGUEIRA, A. M. Desenvolvimento, avaliação e aplicações de novas fases para extração por sorção em barra de agitação (SBSE). 2007. 118f. Dissertação (Mestrado em Química Analítica) - Instituto de Química de São Carlos, USP, São Carlos, 2007.

[30] SERÔDIO, P., NOGUEIRA, J. M. F. Multi-residue screening of endocrine disrupters chemicals in water samples by stir bar sorptive extraction-liquid desorption-capillary gas chromatography-mass spectrometry detection. Anal. Chim. Acta, v. 517, p. 21 - 32, 2004.

[31] CLESCERI, L. S., GREENBERG, A. E., EATON, A. D. Standard Methods for the Examination of Water and Wastewater, American Public Health Association, (1995) Washington, DC, USA. 
[32] European Commission: Council Directive 98/83/EC, Official Journal of the European Commission L330 (1998) 32.

[33] OLIVARES, I. R. B. Desenvolvimento, otimização e validação da técnica HSSPME-GC/MS para análise de amostras obtidas do Rio Atibaia através da aplicação de uma sistemática "ISO" para diagnóstico ambiental de áreas contaminadas. 2006. 191f. Tese (Doutorado em Química Analítica) - Instituto de Química de São Carlos, USP, São Carlos, 2006.

[34] CAMPOS, F. C.; SOUZA, A. J. Contaminação do Site Shell. Paulínia: Secretaria da Saúde, 2001. 96p.

[35] COMPANHIA DE TECNOLOGIA DE SANEAMENTO AMBIENTAL (CETESB). Manual de gerenciamento de áreas contaminadas. 2. ed. 2001. Disponível em: <http://www.cetesb.sp.gov.br/Solo/areas_contaminadas/manual.asp >. Acesso em: 20/11/2008.

[36] SUGUIO, K. Introdução à sedimentologia. São Paulo: Editora da Universidade de São Paulo, 1973.317 p.

[37] COMPANHIA DE TECNOLOGIA DE SANEAMENTO AMBIENTAL (CETESB). Relatório de Qualidade das Águas Interiores do Estado de São Paulo. 2007. Disponível em: <http://www.cetesb.sp.gov.br/Agua/rios/publicacoes.asp> Acesso em: 17/12/2008. 
4

Conclusão Geral 


\section{CONCLUSÃO GERAL}

O presente trabalho foi dividido em diferentes capítulos, onde foram desenvolvidas e aplicadas técnicas miniaturizadas de preparo de amostras para análises ambientais via GC-MS.

No Capítulo 1 foi desenvolvido um método para analisar Paclobutrazol em solo utilizando a técnica de Extração em Fase Sólida (SPE). O método apresentou linearidade, precisão, exatidão/recuperação e limites de quantificação e detecção adequados para análise de paclobutrazol em solo. Foi possível apresentar uma alternativa viável na determinação de PBZ em solo já que utiliza quantidade de solvente reduzida e menor número de etapas de preparo de amostras quando comparado com trabalho anterior apresentado na literatura. Além disso, permitiu o uso da cromatografia gasosa acoplada à espectrometria de massas, o que auxilia na confirmação de identidade do extrato.

No Capítulo 2 foram desenvolvidas barras "in-house" para SBSE e estas foram otimizadas, validadas e aplicadas no modo headspace, seguidas de dessorção líquida e cromatografia gasosa acoplada à espectrometria de massas. É uma técnica que apresentou uma boa relação custo/benefício sendo que o valor da extração é reduzido quando comparado ao da barra comercial. Além disso, o desenvolvimento de barras apresentou uma vantagem adicional com a possibilidade da utilização de diferentes materiais e espessuras de recobrimento com características específicas adequadas para diferentes tipos de extrações e analitos de interesse. 
No Capítulo 3 após o desenvolvimento de metodologias e aplicação de técnicas já bem difundidas na literatura foi desenvolvida uma nova técnica baseada na extração sortiva, a denominada RSE. A partir dos resultados obtidos foi possível verificar que a temperatura exerce influência significativa e que se otimizada pode melhorar a extração e alcançar extração praticamente exaustiva. A técnica RSE desenvolvida foi aplicada na análise de pesticidas organoclorados em água com sucesso, mostrando ser uma técnica eficiente e econômica. Além disso, esta pode ser aplicada na extração de outros compostos voláteis em diferentes matrizes como alimentos, plantas e fármacos.

Foram desenvolvidos também novos recobrimentos para "in-house" SBSE, com novas fases poliméricas, que podem ser aplicadas em diferentes matrizes. Através dos estudos realizados verificou-se que a modificação do PDMS pode melhorar a capacidade sortiva da fase dependendo do analito de interesse.

Com base nos resultados apresentados nas conclusões de cada capítulo e resumidos neste último Capítulo, é possível então afirmar que foram atingidos plenamente todos os objetivos estabelecidos para este trabalho. Além disso, este trabalho poderá ser continuado com novos desenvolvimentos de fases sortivas, miniaturização e aplicação em diversas matrizes. 


\section{PRODUÇÃO CIENTÍFICA DURANTE O DOUTORADO}

\section{Artigos completos publicados em periódicos}

GROSSI, P., OLIVARES, I. R. B., DE FREITAS, D. R., LANCAS, F. M. A novel HS-SBSE system coupled with gas chromatography and mass spectrometry for the analysis of organochlorine pesticides in water samples. J. Sep. Sci., v. 31, p. 3630-3637, 2008.

POCRIFKA, L., GONCALVES, C., GROSSI, P., COLPA, P., PEREIRA, E. Development of $\mathrm{RuO} 2 \mathrm{TiO} 2$ (70 30) mol\% for $\mathrm{pH}$ measurements. Sensors and Actuators. B, Chemical, v. 113, p. 1012-1016, 2006.

\section{Artigos submetidos}

LANCAS, F., QUEIROZ, M. E., GROSSI, P., OLIVARES, I. R. B., Recent Developments and applications of Stir Bar Sorptive Extraction J. Sep. Sci. (Aceito Jan/2009).

CARMI, J., OLIVARES, I., GROSSI, P., LANCAS, F. M. Refrigerated Sorptive Extraction (RSE) for determination of BTEX in water samples. J. Chrom. Sci. (Aceito Jan/2009).

\section{Comunicações e resumos publicados em anais de congressos}

GROSSI, P., OLIVARES, I., LANCAS, F. M. Refrigerated Sorptive Extraction (RSE). In: COLACRO XII, 2008, Florianópolis. CD-ROM Colacro XII, 2008.

CARMI, J., OLIVARES, I., GROSSI, P., LANCAS, F. M. Refrigerated Sorptive Extraction (RSE) for determination of BTEX in water samples. In: COLACRO XII, 2008, Florianópolis. CD-ROM Colacro XII, 2008.

GRAUPNER, G., GROSSI, P., OLIVARES, I., LANCAS, F. M., Shawn, R. Desenvolvimento de novas fases poliméricas de SBSE para análise de BTEX em água. In: COLACRO XII, 2008, Florianópolis. CD-ROM Colacro XII, 2008.

GROSSI, P., OLIVARES, I., de FREITAS, D., LANCAS, F. M. Development and optimization of a home-made headspace sorptive extraction methodology (HSSE) for the analysis of organochlorine pesticides in water samples. In: Tenth 
International Symposium on Advances in Extraction Techniques 2008, 2008, Bruges. Tenth International Symposium on Advances in Extraction Techniques 2008, 2008.

GROSSI, P. ; OLIVARES, I. ; LANCAS, F. M. . Otimização da técnica HSSE ( home-made ) para análise de pesticidas organoclorados em amostra de água. In: 16 Encontro Regional da Sociedade Brasileira de Química, 2007, Franca. LIVRO DE RESUMOS 16 ENCONTRO DA SBQ REGIONAL, 2007.

GROSSI, P. ; OLIVARES, I. ; GOUVEIA, E. ; LANCAS, F. M. . Development, validation and application of a method to analyze paclobutrazol in soil samples by SPE - GC/MS. In: 2 CONGRESSO DA SOCIEDADE BRASILEIRA DE ESPECTROMETRIA DE MASSAS, 2007, CAMPINAS. LIVRO DE RESUMOS DO 2 CONGRESSO DA SOCIEDADE BRASILEIRA DE ESPECTROMETRIA DE MASSAS, 2007.

CLIQUET, E. ; GROSSI, P. ; REZENDE, M. O. O. Determinação de compostos organoclorados em amostras de sedimento e espécies de mangues dos complexos estuarinos da baixada Santista e de Cananéia - São Paulo. In: 16 Encontro Regional da Sociedade Brasileira de Química, 2007, Franca. LIVRO DE RESUMOS 16 ENCONTRO DA SBQ REGIONAL, 2007.

GROSSI, P. ; COTTA, J. A. O. ; VALENTIN, L. A. ; REZENDE, M.O.O. . Otimização de método para determinação de HPAs em HPLC. In: $15^{\circ}$ Encontro Regional de Química - SBQ, 2005, RIBEIRÃO PRETO. LIVRO DE RESUMOS 15 ENCONTRO DA SBQ REGIONAL, 2005.

\section{Formação complementar}

Extensão universitária em Estágio de Doutorando (Sanduíche) Universität Tübingen, TÜBINGEN, Alemanha Bolsista do (a): Coordenação de Aperfeiçoamento de Pessoal de Nível Superior (CAPES) e Deustcher Akademischer Austausch Dienst (DAAD).

\section{Ministração de cursos}

LANCAS, F. M., OLIVARES, I., GROSSI, P., CLIQUET-SIMOES, E. Cromatografia Gasosa/Espectrometria de Massas. Promovido pelo Instituto Internacional de Cromatografia (IIC), São Carlos - SP, Brasil, 2008.

LANCAS, F. M., OLIVARES, I., GROSSI, P., CLIQUET-SIMOES, E. Técnicas Modernas de Preparo de Amostras. Promovido pelo Instituto Internacional de Cromatografia (IIC), São Carlos - SP, Brasil, 2008. 
LANCAS, F. M., OLIVARES, I., GROSSI, P. Técnicas Modernas de Preparo de Amostras. Promovido pelo Instituto Internacional de Cromatografia (IIC), São Carlos - SP, Brasil, 2007.

\section{Participação em eventos}

1. Curso NBR ISO 17025 / IEC. Promovido pelo Instituto Internacional de Cromatografia (IIC), São Carlos - SP, Brasil, 2008.

2. Curso de Caracterização e Remediação de Áreas Contaminadas. Promovido pelo Conselho Regional de Química IV - Região (CRQ - IV - Região), São Paulo - SP, Brasil, 2008.

3. Curso de LC/MS e LC/MS/MS. Promovido pelo COLACRO XII, Florianópolis - SC, Brasil, 2008.

Feira Analytica. Promovida pelo Messe München International, Munique Alemanha, 2006.

4. $4^{\mathrm{o}}$ Encontro Nacional de Segurança em Química. Promovido pela Universidade de São Paulo, São Carlos - SP, Brasil, 2006.

5. $3^{\circ}$ International Symposium on Residue Management in Universities. Promovido pela Universidade de São Paulo, São Carlos - SP, Brasil, 2006.

6. II Encontro regional dos Usuários de Técnicas Termoanalíticas. Promovido pela Universidade de São Paulo, São Carlos - SP, Brasil, 2006.

7. $2^{\mathrm{a}}$ Conferência Anual ICTR. Promovido pela Universidade Federal de São Carlos, São Carlos - SP, Brasil, 2004. 